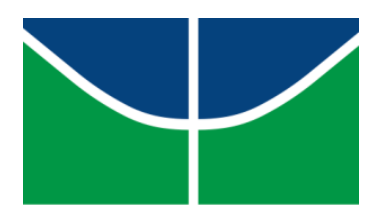

Universidade de Brasília - UnB

Faculdade de Economia, Administração, Contabilidade e Gestão de Políticas

Públicas - FACE

Programa de Pós-Graduação em Economia - PPGECO

Mestrado em Economia

EFICIÊNCIA E PARTICIPAÇÃO SOCIAL NO SUS: UM ESTUDO DA REDE CEGONHA UTILIZANDO O MÉTODO DEA NETWORK

Loyane Mota Fernandes

BRASÍLIA

2016 
LOYANE MOTA FERNANDES

\section{EFICIÊNCIA E PARTICIPAÇÃO SOCIAL NO SUS: UM ESTUDO DA REDE CEGONHA UTILIZANDO O MÉTODO DEA NETWORK}

Dissertação apresentada ao
Departamento de Economia da Faculdade
de Economia, Administração,
Contabilidade (FACE) da Universidade de
Brasília como requisito parcial para
obtenção do título de Mestre em
Economia.
Área de concentração: Economia do Setor
Público.
Orientador: Prof. Dr. Alexandre Maduro-
Abreu




\title{
EFICIÊNCIA E PARTICIPAÇÃO SOCIAL NO SUS: UM ESTUDO DA REDE CEGONHA UTILIZANDO O MÉTODO DEA NETWORK
}

\author{
LOYANE MOTA FERNANDES \\ Dissertação apresentada como exigência do curso de Mestrado em \\ Economia da Universidade de Brasília.
}

\section{Avaliação}

BANCA EXAMINADORA

Professor Dr. Alexandre Maduro-Abreu, UnB Orientador

Professor Dr. Roberto de Goes Ellery Junior, UnB Membro interno

Professor Dr. Carlos Rosano Peña, UnB Membro externo 


\section{RESUMO}

Este trabalho tem como objetivo compreender a contribuição do modelo de gestão da Rede Cegonha para a eficiência da atenção à saúde maternoinfantil. Para tanto foi estimada a fronteira da eficiência de 918 municípios brasileiros a partir da técnica não-paramétrica de Análise por Envoltória de Dados (DEA) em duas análises. Na análise estática aplicou-se o modelo Network-DEA. Na análise dinâmica utilizou-se o DEA-Malmquist para analisar a evolução da eficiência ao longo de dois triênios 2007-2009 e 2013-2015. O resultado encontrado sugere que a Rede Cegonha não foi estatisticamente determinante para o incremento da eficiência do SUS.

Palavras-chave: SUS. Eficiência. Redes de Atenção à Saúde. Rede Cegonha. Network DEA. 


\title{
EFICIÊNCIA E PARTICIPAÇÃO SOCIAL NO SUS: UM ESTUDO DA REDE CEGONHA UTILIZANDO O MÉTODO DEA NETWORK
}

\begin{abstract}
This study aims to understand the contribution of Stork Network management model on the maternal and child health efficiency. The study estimated the efficiency of 918 municipalities of Brazil from Data Envelopment Analysis model - DEA in two phases. In the first phase it was applied the Network DEA model for analysis cross-section. In the second phase it was adopted the Malmquist DEA model for painel data analysis of evolution of the efficiency by two trienniums 2007-2009 and 2013-2015. The results showed that Stork Network was not statistically significant to the maternal and child health efficiency.
\end{abstract}

Keywords: Unified National Health System. Efficiency. Stork Network. DEA Network 


\section{LISTA DE SIGLAS E ABREVIAÇÕES}

\begin{tabular}{|c|c|c|}
\hline APS & - & Atenção Primária à Saúde \\
\hline $\mathrm{ClB}$ & - & Comissão Intergestores Bipartite \\
\hline CIR & - & Comissão Intergestores Regional \\
\hline CIT & - & Comissão Intergestores Tripartite \\
\hline COAP & - & Contrato Organizativo de Ação Pública \\
\hline CNES & - & Cadastro Nacional de Estabelecimentos de Saúde \\
\hline CONASS & - & Conselho Nacional de Secretários de Saúde \\
\hline CONASEMS & - & Conselho Nacional dos Secretários Municipais de Saúde \\
\hline CS & - & Conselho de Saúde \\
\hline ESF & - & Estratégia Saúde da Família \\
\hline FIOCRUZ & - & Fundação Oswaldo Cruz \\
\hline IBGE & - & Instituto Brasileiro de Geografia e Estatística \\
\hline IDSUS & - & Índice de Desempenho do Sistema Único de Saúde \\
\hline MAC & - & Média e Alta Complexidade \\
\hline MS & - & Ministério da Saúde \\
\hline NOAS & - & Norma Operacional de Assistência à Saúde \\
\hline NOB & - & Norma Operacional Básica \\
\hline OCDE & - & Organização para a Cooperação e Desenvolvimento Econômico \\
\hline OMS & - & Organização Mundial da Saúde \\
\hline OPAS & - & Organização Pan-Americana da Saúde \\
\hline PAB & - & Piso da Atenção Básica \\
\hline PIB & - & Produto Interno Bruto \\
\hline PNAD & - & Pesquisa Nacional de Domicílios \\
\hline RAS & - & Redes de Atenção à Saúde \\
\hline SAS & - & Secretaria de Atenção à Saúde \\
\hline SINASC & - & Sistema de Informações sobre Nascidos Vivos \\
\hline
\end{tabular}


- Sistema de Captação do Atendimento

SUS

- Sistema Único de Saúde 


\section{SUMÁRIO}

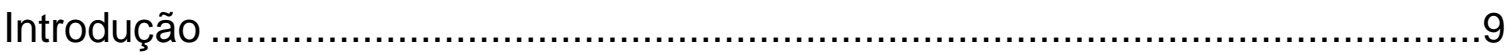

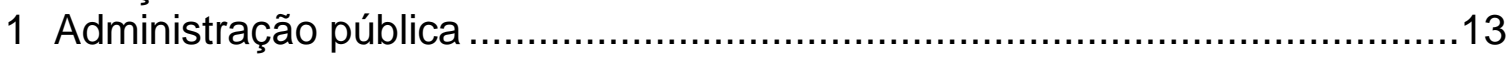

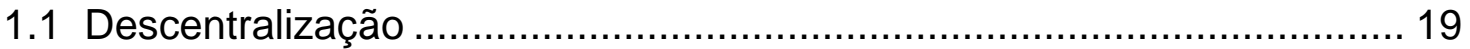

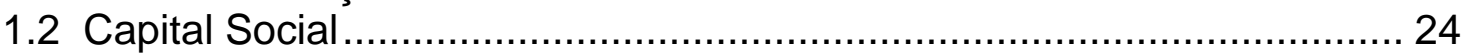

2 Novas configurações da Administração Pública: Possibilidades para melhoria da gestão da saúde pública ..........................................................................27

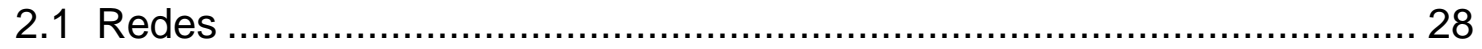

3 Marcos conceituais de Eficiência ............................................................

3.1 Métodos de Mensuração da Eficiência ......................................... 38

4 Saúde pública no brasil ...................................................................40

4.1 Processo de descentralização do SUS ............................................ 44

4.2 Esferas de Participação social no SUS ............................................ 46

4.3 Aplicações da Eficiência em Saúde Pública ....................................... 51

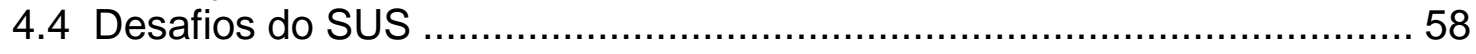

4.5 As Redes de Atenção à Saúde .................................................... 59

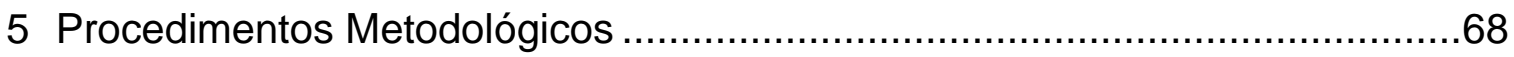

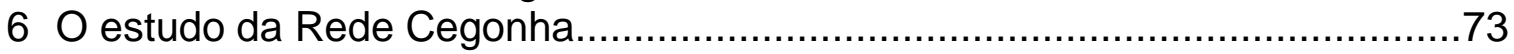

6.1 Dados e Análises ............................................................................. 78

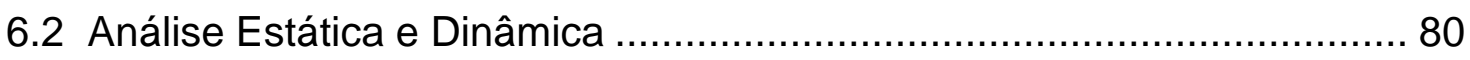

6.3 Análise de correlação ............................................................ 90

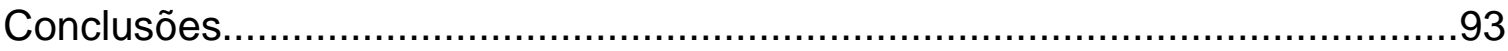

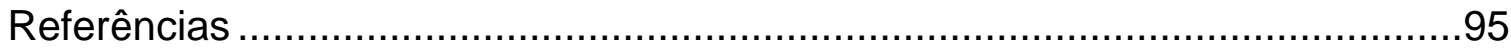




\section{INTRODUÇÃO}

Segundo a teoria econômica tradicional, a alocação de recursos Pareto eficiente, ou seja, situação em que não é possível melhorar o bem-estar de nenhuma pessoa sem piorar o bem-estar de outra, é dada pela competição dos mercados.

Este ideal de mercado competitivo caracterizado pela livre concorrência e pela busca da maximização dos lucros somente seria alcançado com o pleno funcionamento do modelo de concorrência perfeita (GRUBER, 20079).

Porém, em situações reais de mercado, existem distúrbios como externalidades, assimetria de informação, falhas de competição e mercados incompletos que tornam os mercados não competitivos e impedem a alocação de recursos ótima (STIGLITZ, 2000). Desta forma, caberia ao Estado o ajuste dessas falhas de mercado por meio de suas funções de alocação de recursos na sociedade, distribuição da renda e manutenção da estabilidade econômica (MUSGRAVE, 1980).

Dentre as formas de atuação do Estado, os gastos públicos são empregados para priorizar a prestação de serviços públicos básicos, realizar investimentos que visam assegurar o bem-estar social e crescimento econômico (RAM, 1986; ASCHAUER, 1989).

No Brasil, os gastos públicos cresceram sobremaneira após a promulgação da Constituição Federal de 1988 que expandiu as funções do Estado e consequentemente o tamanho da máquina pública. Porém, diante da conjuntura econômica dos anos 90 decorrente do alto endividamento, crise fiscal, inflação e desemprego (GIAMBIAGI, 2011), foram adotadas políticas de estabilização econômica, reajuste fiscal e reformas administrativas que acarretaram na redução do tamanho do Estado e em cortes dos gastos públicos. Essas medidas visavam a racionalização do uso dos recursos e a eficiência dos serviços públicos (AFONSO, 2005).

No caso dos gastos em saúde pública, dada a escassez de recursos públicos destinados à saúde no Brasil, torna-se ainda mais imperativa a necessidade de utilizálos de maneira eficiente para que o SUS alcance seus objetivos por meio de ações e serviços de saúde mais sustentáveis (PIOLA et al, 2010).

Ademais, de acordo com dados do IBGE, nos últimos anos houve um aumento da expectativa de vida da população brasileira e consequentemente no número de pessoas pertencentes à faixa de 60 anos ou mais, passando de 19,6 milhões em 2010 
para 26,1 milhões em 2013. Ainda segundo dados do IBGE, as projeções indicam uma tendência de crescimento desse quantitativo para 41,5 milhões, em 2030, e 73,5 milhões, em 2060. Segundo Acuña e Cruz (2004) pessoas faixa de idade acima de 60 anos demandam maiores cuidados em saúde, principalmente aqueles relacionados à doenças crônicas.

Em 2013, a Pesquisa Nacional em Saúde (PNS), demonstrou que as doenças crônicas não transmissíveis (DCNT) representam mais de $70 \%$ das causas de mortes e que estas tendem a crescer nos próximos anos devido à fatores de risco como tabagismo, consumo de álcool em excesso, obesidade, alto nível de colesterol, sedentarismo e alimentação inadequada.

Diante desse cenário, Lavras (2011) alerta que o modelo de atenção à saúde atualmente adotado pelo Sistema Único de Saúde não está orientado para o tratamento de doenças crônicas, o que provoca um desequilíbrio entre o aumento da demanda por serviços de saúde voltado para o tratamento de doenças crônicas e a oferta reduzida desses serviços, suscitando uma crise no sistema de saúde atual (MENDES, 2010). Esse desequilíbrio é refletido na baixa satisfação do usuário com o serviço de saúde, dificuldade de acesso e ineficiência da utilização de recursos disponíveis (CAMARANO, 2014).

No âmbito dos serviços específicos à saúde materno-infantil, os indicadores relacionados apontam que apesar dos esforços realizados nos últimos anos para a redução da morbimortalidade materno-infantil, o sistema de saúde ainda apresenta taxas elevadas de óbitos maternos e infantis evitáveis. Além disso, nos últimos anos nota-se um crescimento nas taxas de cesáreas. Segundo dados da Organização Mundial de Saúde, enquanto em países da Europa essa taxa é de $20 \%$ a $22 \%$, no Brasil em 2011, cerca de 53\% dos partos realizados no brasil foram cesáreas.

Essas taxas são reflexo da fragmentação das ações e serviços de saúde, subfinanciamento e modelo de atenção que tende a "medicalizar" e "intervir" desnecessariamente nos processos de gestação, parto e nascimento (BRASIL, 2011) e que geram dificuldade de acesso das gestantes ao pré-natal de qualidade, situação de peregrinação de gestantes no momento do parto e práticas inadequadas de parto e nascimento (CAVALCANTI et al, 2013).

Diante deste cenário foram estabelecidas, em 2010, diretrizes para a organização do SUS em Redes de Atenção à saúde como medida de superação do financiamento público insuficiente, fragmentação do sistema e baixa eficiência no 
emprego dos recursos. Para Rhodes (1996) as redes são estruturas horizontalizadas que permitem maior interação entre os seus atores. Segundo Putnam (2002) quanto maior a interação entre os participantes, maior a confiança mútua e facilidade de cooperação, reforçando os laços comunitários e a participação social. Desta forma, questiona-se qual a relação entre a eficiência da Rede de atenção à saúde maternoinfantil e a participação social no SUS ?

Nesta pesquisa foram assumidas as hipóteses:

H1: A implantação das Redes de Atenção à Saúde aumentou a eficiência da saúde materno-infantil do SUS;

H2: Quanto maior a participação social e por sua vez o capital social, maior a eficiência Redes de Atenção à Saúde na saúde materno-infantil do SUS.

Em consonância com o problema de pesquisa e as hipóteses acima elencadas, têm-se como objetivo geral compreender a contribuição do modelo de gestão da Rede Cegonha para a eficiência do Sistema Único de Saúde. Para tanto, têm-se como objetivos específicos investigar o funcionamento da Rede Cegonha; entender a dinâmica da participação social no âmbito do SUS; desenvolver um modelo de eficiência para a Rede Cegonha; e analisar a aplicação de recursos públicos em serviços de saúde através da Rede Cegonha.

A motivação para a realização desta pesquisa é a necessidade de se avaliar a reconfiguração do SUS em redes integradas de saúde. Muito embora, haja evidências na literatura internacional sobre os efeitos positivos das Redes de Atenção em Saúde nos indicadores de saúde (MENDES, 2010; KUSCHNIR \& CHORNY, 2010), no âmbito nacional, grande parte dos estudos realizam uma avaliação ex-ant da Rede de Atenção à Saúde se concentrando em análises normativas sobre como essa deveria ser implementada no SUS, bem como analisando a percepção dos gestores do SUS com relação aos desafios da formação das Redes de Atenção à Saúde e os principais desafios a serem superados por elas (SHIMIZU, 2013; SANTOS, 2013, SILVA, 2011; MENDES, 2010).

Tendo em vista a escassez de estudos que avaliem quantitativamente os efeitos da implementação da Rede de Atenção à Saúde na eficiência do SUS, este estudo visa preencher essa lacuna, fornecendo subsídios ao processo de tomada de decisão aos gestores na adoção da configuração em redes do SUS, bem como no apoio à formulação de políticas públicas. Porém, dada a complexidade do SUS e abrangência, 
optou-se por restringir esta pesquisa à eficiência do SUS no âmbito da saúde maternoinfantil nos municípios brasileiros.

Esta pesquisa se delimita a avaliar a medida de eficiência da implantação da Redes de Atenção à Saúde ex-post apenas para a saúde materno-infantil no âmbito do SUS. Não é escopo desta pesquisa avaliar todas as ações e serviços relacionados às Redes de Atenção à Saúde, tampouco a realização de análise de redes, metaavaliação, de processos, impacto ou qualquer outro tipo de avaliação relacionada ao funcionamento interno da Redes de Atenção à Saúde.

Além desta introdução, o presente trabalho está estruturado nos seguintes capítulos: (1) Fundamentação teórica abordando a evolução da Administração Pública e o contexto do Estado em rede; os marcos conceituais relacionados à eficiência; a trajetória do SUS e a implementação das Redes de Atenção à Saúde (2) Procedimentos metodológicos da pesquisa. (3) Dados e análises de resultados encontrados (4) Conclusões. 


\section{ADMINISTRAÇÃO PÚBLICA}

Em meio ao contexto de revolução industrial, os princípios científicos de organização da produção da Escola de Administração Científica se apresentavam sob uma aplicação de métodos capazes de tornar a organização mais produtiva e eficiente por meio da organização do trabalho.

Segundo Kettl (2005), a administração pública americana foi influenciada pelo movimento de busca pela eficiência na gestão, baseado no "one best way" Taylorista. Em seu estudo de tempos e movimentos, Taylor apresentou métodos alternativos de tornar a mesma tarefa mais rápida, fácil e barata de ser executada, reduzindo a fadiga física e aumentando tanto o tempo de vida dos trabalhadores quanto a produção. No âmbito da administração pública, a adoção da administração científica foi justificada pela necessidade de eliminar a corrupção e incompetência presentes no setor público (GULICK, 1937; URWICK, 1937; GRAICUNAS, 1937).

Segundo Gulick (1937), para a Administração Científica a eficiência é considerada como um "bem" basilar, seja no setor público ou privado, tendo como objetivo fundamental o monitoramento do trabalho para lidar com o menor gasto de energia, homem e materiais. Segundo Osborne e Gaebler (1992, p.12), durante a era industrial, os governos foram capazes de grandes realizações em estruturas configuradas em cadeias de comando hierárquicas com ênfase nas tarefas.

Entretanto, críticos da administração pública científica questionaram os métodos ditos científicos e a redução dos trabalhadores a meras engrenagens de maquinários industriais (SIMON, 1976). Em resposta às críticas à administração científica, surge no século XIX a teoria da administração burocrática, um modelo racional-legal legitimado por um sistema de normas racionalmente instituídas, em contraposição ao poder tradicional e carismático respectivamente típicos da sociedade tradicional e carismática (WEBER, 2004).

Esse modelo burocrático de organização caracterizava-se pela racionalidade constituída pelos atributos de divisão do trabalho, hierarquia, profissionalização e impessoalidade (PFIFFNER e PRESTHUS, 1960). Essa racionalidade visa assegurar o alcance da eficiência máxima no alcance dos objetivos organizacionais com base na sua superioridade técnica. Segundo Simon et al. (1991), a busca pela eficiência é um valor inerente à burocracia, muitas vezes intercambiável por Weber como sinônimo de racionalidade (SIMON et al., 1991). 
[A burocracia] designava um método de organização racional e eficiente, para substituir o exercício arbitrário do poder pelos regimes autoritários. A burocracia trouxe ao trabalho do governo a mesma lógica que a linha de montagem deu ao processo industrial. Com a sua autoridade hierárquica e especialização funcional, a organização burocrática tornou possível a realização eficiente de tarefas amplas e complexas (OSBORNE \& GAEBLER,1992, p.14)

Com o advento da globalização e da nova sociedade da informação, o ambiente anteriormente previsível e estável se torna imprevisível e complexo, impondo às organizações novos padrões de gestão.

\begin{abstract}
Neste ambiente, as instituições burocráticas, públicas e privadas que se desenvolveram durante a era industrial, parecem-nos cada vez mais deficientes. $O$ ambiente contemporâneo, exige instituições extremamente flexíveis e adaptáveis, instituições que produzam bens e serviços de alta qualidade, assegurando alta produtividade aos investimentos feitos. Requer instituições que respondam as necessidades dos clientes, oferencendo-lhes opções de serviços personalizados, que influenciem pela persuasão e com incentivos, sem usar comandos, que tenham para seus empregados uma significação e um sentido de controle, que eles as sintam como se fossem deles. Instituições que confiram poder aos cidadãos ao invés de simplesmente servi-los (OSBORNE \& GAEBLER,1992, p.16).
\end{abstract}

Diante desse novo contexto, as organizações burocráticas estruturadas para funcionarem em ambiente extremamente previsível, não conseguem se adaptar ao novo contexto dinâmico e incerto, tornando-se "dinossauros da era pós-tradicional" (GIDDENS, 1996)

$\mathrm{Na}$ sua época [burocrática], esses governos foram capazes de grandes realizações, mas ao longo do tempo se afastaram das nossas necessidades. Tornaram-se inchados, ineficientes, funcionando com desperdício. E quando o mundo começou a mudar, não acompanharam essas mudanças. As burocracias hierárquicas, centralizadas e concebidas nas décadas de 30 e 40 simplesmente não funcionam bem no quadro altamente mutável da sociedade e da economia dos anos 90 , rico de informações e conhecimento. São como transatlânticos de luxo numa era de jatos supersônicos: grandes, caros e pouco ágeis (OSBORNE \& GAEBLER, 1992, p.13).

Seja como dinossauros ou transatlânticos de luxo na era de jatos supersônicos, o fato é que essa inadequação do modelo burocrático na Era da Informação se converteu em disfunções burocráticas e ineficiência (CROZIER, 1996). Dentre as disfunções, Merton (1978) destaca o excesso de normatização ou o que o autor chama de "devoção às regras", que seria dada pela situação em que há ênfase demasiada às normas que deveriam ser um meio de controle mas que acabam sendo distorcidas para terem um fim em si mesmas. 
Ao tornar impossível demitir funcionários de baixa produtividade, proporcionou estabilidade aos medíocres. Ao tentar controlar virtualmente tudo na administração pública, tornamo-nos tão obsessivos em ditar o modo como as coisas deviam ser feitas- regulando os procedimentos e controlando os insumos - que passamos a ignorar os resultados. O resultado foi o governo com um ethos especial: governo lento, ineficiente, impessoal (OSBORNE \& GAEBLER,1992, p.15).

Como alternativa de superação das disfunções existentes no modelo burocrático, bem como das críticas às falhas do mercado e às falhas do Estado identificadas pela Teoria da Escolha Pública, surge a New Public Management - NPM (GRUENING, 2001). Esse novo modelo de gestão foi adotado pela Inglaterra, Estados Unidos, Austrália e Nova Zelândia entre 1970 e 1980 com variações de intensidade.

$\mathrm{Na}$ Inglaterra durante o governo de Margareth Thatcher, os valores liberais foram representados em diversas políticas de seu governo por meio da eliminação dos controles exercidos pelo comércio, corte de gastos do governo e restrição da atuação estatal em atividades exclusivamente próprias, delegando as demais para o mercado ou para organizações filantrópicas quando as atividades não fossem atrativas para o mercado (PAULA, 2005).

Segundo Rhodes (1996) a NPM pode ser dividida em duas abordagens: gerencialismo e nova economia institucional. $\mathrm{Na}$ abordagem gerencialista, a administração pública era pautada pela introdução de métodos de gestão do setor privado, resultantes das tendências de consultorias empresariais. Essa transferência de práticas do setor privado para o setor público provocou mudanças como a profissionalização da gestão pública, valorização dos recursos e principalmente da perspectiva do cidadão que antes era visto como usuário de serviços e nessa abordagem passa a ser visto como cliente.

Hood (1991) complementa essa abordagem caracterizando-a pela busca da eficiência e da minimização de custos, com ênfase no controle e nos resultados, utilizando-se para tal ferramentas como padrões de desempenho e medidas de avaliação oriundas das empresas privadas.

Por sua vez, a abordagem da nova economia institucional se refere à introdução de uma estrutura de incentivos de competição de mercado na prestação de serviços públicos.

\footnotetext{
1 O termo New Public Management apresenta diversos sinônimos na literatura: gerencialismo, novo gerencialismo, nova gerência pública, administração gerencial, Nova Administração Pública e gerência baseada no desempenho
} 
Há uma fragmentação das burocracias, melhor competição por contratualização, semi-mercados e escolha do cliente. Sob o argumento de que o novo modelo de gestão foi capaz de romper com os padrões ultrapassados da administração pública burocrática e implementar novas técnicas de gestão, Ferlie et al. (1999) criaram uma tipologia dividida em quatro modelos básicos de gestão pública: modelo 1 - impulso para a eficiência; modelo 2 - downsizing e descentralização; modelo 3 - em busca da excelência e modelo 4 - orientação para o serviço público. Segundo Ferlie et al (1999, p.26), o modelo 1 "representou uma tentativa de tornar o setor público mais parecido com a iniciativa privada, guiado por noções rudimentares de eficiência". Nesse modelo, houve a transferência das tendências favoráveis que foram "testadas" pelo mercado para a administração pública, criando incentivos para a eficiência e meios de avaliação baseada em medidas de avaliação de desempenho (KETTL,1991). Por meio dessa avaliação, é possível mensurar a eficiência dos serviços públicos em termos de resultados alcançados e recursos utilizados.

Segundo Hood (1991), a tendência do modelo 1 retoma a filosofia de administração baseada nos valores da eficiência e alocação racional de recursos com foco na limitação do desperdício, na simplicidade e transparência. Essa lógica é decorrente da visão de cidadão-contribuinte, que como tal, cobra pela eficiência da sua contribuição (insumo) representada pela melhor prestação de serviços públicos possível (resultado). O governo parte do pressuposto de que é preciso modificar a estrutura burocrática do modelo weberiano e apresentar resultados por meio dos cortes de gastos com o objetivo de alcance de maior eficiência governamental enfatizando a economia e eficiência como seus principais objetivos. Essa ênfase na estratégia da eficiência na NPM relega a segundo plano outros valores como a efetividade dos serviços públicos e a flexibilidade para a tomada de decisão e inovação (ABRUCIO, 1991).

Autores críticos a esta tendência afirmam que o modelo se refere ao resgate do modelo mecânico e racional de alcance dos objetivos (DENHARDT, 2012). Segundo Pollitt (1993), esse modelo é visto como "neotaylorista" por apresentar características de ênfase excessiva na produtividade e eficiência, presente nos estudos de Taylor. Mayordomo (1990) também critica esse modelo por simplificar a transferência de diversos métodos organizacionais próprios de organizações privadas para organizações públicas desconsiderando as características intrínsecas ao setor público. Waldo(1948) reforça esse entendimento argumentando que a natureza das 
tarefas executadas por organizações públicas são fundamentalmente diferente das privadas.

O governo é uma instituição fundamentalmente diferente da empresa.

Os empresários são motivados pela busca do lucro, as autoridades governamentais se orientam pelo desejo de serem reeleitas. As empresas recebem dos clientes a maior parte dos seus recursos, os governos são custeados pelos contribuintes. As empresas normalmente trabalham em regime de competição, os governos usam habitualmente o sistema de monopólio. Essas diferenças fazem com que o setor público os incentivos sejam fundamentalmente diferentes dos que existem no mundo empresarial. Os governos tem receita fundada primariamente na arrecadação tributária, enquanto as empresas auferem rendimentos dos clientes que adquirem livremente seu produto ou serviço [...] o governo é democrático e aberto, por isso seus movimentos são mais lentos comparados aos das empresas, cujos administradores podem tomar decisões rapidamente a portas fechadas. A missão fundamental do governo é fazer bem não é fazer dinheiro (OSBORNE \& GAEBLER,1992, p.21).

Dentre as características identificadas por Ferlie et al (1990) e apresentadas no modelo 2 - downsizing e descentralização - é a tendência de fortalecimento da competição e da descentralização da prestação de serviços para o alcance da eficiência. A maior flexibilidade organizacional por meio da horizontalização da estrutura organizacional e pela terceirização de serviços promovendo o "enxugamento" da máquina pública vão de encontro à ideologia do liberalismo clássico de 'estado mínimo' caracterizado pela execução terceirizada de serviços públicos indiretos e pela privatização (OSBORNE \& GAEBLER, 1992).

A ênfase no desenvolvimento e aprendizagem organizacional é apresentada no modelo 3 - em busca da excelência. Nesse modelo há uma substituição dos pressupostos do modelo 1, representando uma aplicação da escola das relações humanas ao serviço público enfatizando o modo como as organizações públicas gerenciam a mudança e a inovação (FERLIE et al., 1999). Dentre os pontos característicos desse modelo está o desenvolvimento organizacional e aprendizagem, avaliação de desempenho por resultados, modelos carismáticos de liderança oriundas do setor privado para o setor público e programas de treinamento.

O modelo 4 - orientação para o serviço público - enfatiza a qualidade e excelência na prestação do serviço público, com foco nos valores do usuário dos serviços. Nesse modelo, observa-se uma fusão das ideias presentes no setor público e privado, adaptando-as às características próprias do setor público, dado que diferentemente do modelo 2, onde o Estado é visto com desconfiança quanto à sua capacidade de responder às demandas da sociedade e o mercado é visto como uma 
solução para o alcance da eficiência na prestação de serviços; no modelo 4 ocorre o oposto, a desconfiança é com relação ao mercado (FERLIE et al. 1999). Apesar das críticas à NPM, Ferlie et al. (1999) ressaltam que há consenso na literatura a respeito da contribuição dessa teoria para a ruptura dos padrões de gestão do setor público.

Em contraste com o gerencialismo constituído a partir da busca pela maximização do auto interesse, a corrente de administração pública Novo Serviço Público (NSP) retoma a ideia da busca do interesse comum. Sob essa nova perspectiva, o cidadão exerce uma tarefa mais ampla dentro da sociedade, indo além da garantia dos seus direitos individuais, seguindo em direção à responsividade, atuando de maneira pró ativa frente aos problemas públicos, sustentado pelo sentimento de pertencimento comunitário (DENHARDT, 2012). Sandel (1996) ressalta que essa mudança de postura dos cidadãos na sociedade seria alcançada mediante a adoção de virtudes cívicas. Esse conceito tem origem no pensamento de Aristóteles, relacionada com a dedicação dos cidadãos aos assuntos públicos e ao bem comum, o que asseguraria a coesão e solidariedade à polis (FERNANDES, 2000).

A corrente do NSP tem origem no "movimento comunitariano" de Etzioni que se baseia em três fundamentos: relações afetivas ou emocionais que se cruzam e são reforçadas pelos elos relacionais; comprometimento com o compartilhamento dos valores sociais, normas e sentidos e certo grau de responsividade (DENHARDT, 2012). 


\subsection{DESCENTRALIZAÇÃO}

O debate sobre descentralização tem origem no século XVII e XVIII na discussão de filósofos como Mill, Montesquieu, Rousseau e Tocqueville sobre a formação do Estado (FAGUET, 2004). A princípio, discutia-se a relação entre o tamanho ótimo e a estrutura das unidades políticas para atender à demanda da população, limitando a descentralização a uma distribuição de autoridade entre o governo central e governos locais. Após a Segunda Guerra Mundial, descentralização era vista como forma de expandir a cobertura dos serviços prestados pelo governo de maneira centralizada, de modo a tornar a prestação de serviços mais eficiente. Para tanto, realizava-se a descentralização administrativa do tipo desconcentração, para que os governos locais fossem responsáveis apenas pela execução dos serviços para os governos locais.

Essa visão se estendeu até os anos 80 , quando, devido ao advento da globalização, os governos centrais tiveram que quebrar com os gargalos burocráticos e adotar formas de descentralização: devolução e delegação (CHEEMA; RONDINELLI, 2007). Neste período a devolução teve como objetivo o fortalecimento dos governos locais, concedendo autoridade, responsabilidade e recursos para prestação de serviços e infraestrutura necessária para oferta de serviços de saúde pública, segurança, além da formulação e implementação de políticas locais.

Por meio da delegação, os governos centrais deslocaram a autoridade da execução de funções específicas do Estado para as organizações semiautônomas ou paraestatais e empresas estatais para o ordenamento do território e desenvolvimento. Atualmente, a retomada da discussão sobre o tema tem como origem o questionamento a respeito do papel do Estado, sociedade e mercado na estrutura de descentralização. Nesta nova perspectiva, esta seria um estímulo à emergência da governança como forma de ampliação da participação social (CHEEMA \& RONDINELLI, 2007).

Há na literatura vários estudos que apresentam a complexidade de se definir o conceito de descentralização, decorrente da amplitude de definições disponíveis e da ausência de consenso. Apesar disto, grande parte dos trabalhos compreendem a descentralização como um processo onde há a transferência da autoridade, responsabilidade, poder, recursos e prestação de contas a partir dos níveis centrais de governo a níveis subnacionais (RONDINELLI \& NELLIS, 1986). Conceitualmente, 
pode-se relacionar a descentralização com as relações existentes entre as instituições centrais e subnacionais, sejam elas públicas, privadas ou até mesmo civis (GRÄVINGHOLT et al., 2006). Larson e Ribot (2005) afirmam que desde meados dos anos 80, houve uma onda em prol da descentralização em diversos países. Esta foi adotada como instrumento por meio do qual busca-se o alcance de maior equidade e eficiência das decisões públicas, devido à proximidade, transparência e accountability da população local.

A descentralização pode ser dividida em quatro categorias distintas: descentralização política, administrativa, fiscal, e para o mercado. A descentralização política é caracterizada por situações onde há a transferência de autoridade e de poder político para os níveis subnacionais. Essa categoria é equivalente à tipologia de descentralização por devolução de Rondinelli (1983), que refere-se a uma transferência total de determinadas responsabilidades, poder de decisão, gestão de recursos e autonomia para a geração de receitas como impostos pelo governo local. Este tipo de descentralização fortalece os governos locais com autonomia e independência do governo central e insere a população local no processo de tomada de decisão (LARSON \& RIBOT, 2005). Há, neste caso, uma transferência de responsabilidades pelos serviços aos munícipios que elegem seus próprios prefeitos e conselhos, aumentam suas receitas próprias e têm autoridade para tomar decisões de investimentos (LITVACK et al, 1998).

A descentralização administrativa é caracterizada pela delegação da execução de serviços públicos a um nível local. Neste caso, há apenas uma transferência da tomada de decisão, recursos e responsabilidades pela prestação de serviços a partir do governo central para níveis inferiores de governo, porém sem que haja a transferência de autoridade (LITVACK et al, 1998). Larson e Ribot (2005) afirmam que esse tipo de descentralização visa ajudar o governo a melhor identificar as preferências da população local e assim mobilizar recursos locais para a execução das atividades. A descentralização administrativa é dividida em dois tipos: desconcentração e delegação.

A desconcentração é dada pela transferência de poder de decisão e responsabilidade do governo central para níveis mais baixos. Este tipo de descentralização administrativa é considerada uma forma mais fraca de descentralização. Por outro lado, na delegação, há a transferência de responsabilidade pela tomada de decisão e administração de funções públicas para 
governos locais ou organizações semiautônomas que não são totalmente controladas pelo governo central, mas estão na última instância de responsabilidade (JACOBI, 2000).

No tocante à descentralização fiscal, esta pode assumir muitas formas, dentre elas, a transferência intergovernamental do governo central para os governos locais e a possibilidade de expansão das receitas locais, por meio de taxas ou impostos indiretos locais (GRÄVINGHOLT, et al., 2006).

Por fim, a descentralização para o mercado, é definida como a transferência das funções públicas de governo para instituições voluntárias, privadas ou não governamentais. Nesta categoria de descentralização estão relacionadas as práticas de contratação de prestação parcial de serviços ou as funções administrativas, a desregulamentação ou privatização. A privatização pode variar de fornecimento de bens e serviços pelas forças de mercado para Parcerias Público-Privadas (PPPs).

Em análise sobre os tipos de descentralização, Schneider (2003) considera que as tipologias: desconcentração, delegação e devolução se distinguem pela posição assumida por cada uma no continuum de autonomia administrativa. Neste sentido, a desconcentração ocorre quando o governo central descentraliza o mínimo de autonomia possível, mantendo a autoridade sobre a unidade local, e exercendo sua autoridade através dos canais hierárquicos (FADEL et al., 2009; SCHNEIDER, 2003). $\mathrm{Na}$ delegação, o governo central exerce seu controle por meio de uma relação contratual que impõe a responsabilidade do governo local, representando um nível ligeiramente superior de autonomia administrativa para entidades locais. Já a devolução proporciona o maior grau de autonomia para a unidade local que se torna responsável perante o governo central. Em comparação com os outros dois tipos de descentralização, a devolução proporciona o maior grau de autonomia para a unidade local. Larson e Ribot (2005) ressaltam que os mecanismos de desconcentração são limitados à responsividade e accountability. Por outro lado, a devolução permite que os benefícios da eficiência e equidade surjam do processo de descentralização que encoraja as autoridades locais a entregarem bens e serviços que estejam alinhados com os desejos e necessidades da população local. Desta forma, a desconcentração seria uma forma mais frágil de descentralização.

A literatura elenca uma ampla variedade de argumentos que justificam a descentralização. A corrente econômica (BAHL, 2001; MUSGRAVE, 1997; OATES, 1999; TANZI, 1995) aponta a descentralização como mecanismo para aumentar a 
eficiência para a demanda por bens e serviços localmente expressas dada a capacidade de resposta dos governos locais às necessidades da população determinada pelas preferências dos grupos menores mais homogêneos (WALLIS E OATES 1991). Klugman (1994), complementa essa argumentação afirmando que devido à proximidade dos governos locais com a população estes estão susceptíveis a terem mais informações sobre as necessidades dos cidadãos, o que os tornaria mais capazes de prover serviços de forma mais eficiente e eficaz do que o governo central.

Além disso, há uma maior influência da comunidade local na tomada de decisão o que gera maior accountability e controle social. Santos (2002) complementa afirmando que os governos locais possuem benefícios localizados geograficamente e maior flexibilidade para investir em bens e serviços consonantes com a vontade da população local.

A partir da ciência política, a descentralização é preferível dada à sua tendência de aumentar a transparência, controle e participação social, fatores estes que tem um efeito positivo indireto na eficiência (PUTNAM, 2002; RODRíGUEZ-POSE \& BWIRE, 2004). A descentralização seria uma oportunidade de "empoderamento" do cidadão, alcançada por meio da participação e controle social (KULIPOSSA, 2004).

Segundo Larson e Ribot (2005), a descentralização produz no nível local o conhecimento do processo de decisão que poderá resultar em políticas mais adequadas à realidade local e consequentemente em redução de custos de transação e informação. A participação social no processo de decisão pode vir a gerar um senso de "pertencimento" dessas decisões que acarretará no engajamento da população na implementação, monitoramento e reforço de normas. A proximidade dos governos locais com a população da região permite que haja maior responsividade para a prestação de serviços que estejam consonantes com as necessidades locais e que haja uma combinação mais eficiente entre os gastos públicos e necessidades individuais (SEDDON, 1999).

Desta forma, o sucesso do processo de descentralização só seria alcançado mediante a participação ativa da população nos governos locais. Apesar disto, Bergh (2004) afirma que o processo de descentralização pode ser, por si só, uma forma de participação dado que a própria transferência de poder e recursos no nível governamental para um nível mais próximo das população permite que o processo de tomada de decisões seja mais facilmente influenciado pelos habitantes daquela região. Assim, para governos locais que não tenham tradição de participação ou esta 
é muito baixa, a descentralização pode ser um mecanismo importante para a criação de uma interação entre Estado e Cidadão. Além disso, a descentralização e o governo local não é apenas um conjunto de serviços públicos locais, mas também está relacionado à participação democrática e diálogo civil (BHUYAN, 2010).

Em resumo, pode-se afirmar que o argumento da descentralização parte da premissa de que ao transferir a responsabilidade pelo planejamento, gestão e alocação de recursos do governo central para os governos locais, a representação do Estado passa a estar mais próximo do cidadão em forma de governo local. Considerando que as unidades locais de governo têm sob sua alçada um universo reduzido de cidadãos estes estão mais sensíveis às demandas da população local.

A autonomia e concentração de poder de decisão nos governos locais incentivaria os cidadãos a participarem mais ativamente do processo decisório local e do controle social sobre o uso dos recursos públicos (GAMA, SANTOS, 2004). A partir dessa maior participação social haveria maior democratização das estruturas de poder, desenvolvimento socioeconômico e legitimidade ao poder público (JONES \& STEWART, 1985).

Entretanto, os resultados esperados da descentralização podem ser afetados por entraves presentes tanto no governo local como no governo como um todo. Dentre os principais entraves presentes no governo local à descentralização está a presença de estruturas clientelistas, elites locais e corrupção. Esses entraves além de dificultar a igualdade de participação de todas as partes interessadas no processo de participação social, geram ineficiência da prestação de serviços.

Segundo Sousa (2002), esta situação pode ser agravada ainda mais em países caracterizados por grandes disparidades regionais como no caso do Brasil, onde grande parte dos níveis locais possui incapacidade técnica para a prestação de serviços básicos e dificuldades financeiras para executar atividades que não estejam relacionadas ao pagamento dos servidores públicos municipais. As desigualdades regionais existentes no Brasil acabam anulando o objetivo da descentralização, limitando os recursos federais e constrangendo a política de transferência de recursos.

Conforme Bergh (2004), dentre as principais consequências da descentralização que desconsidera o contexto local é a possível captura dos benefícios e serviços públicos por pequenas elites locais e ineficiência na prestação de serviços públicos. 


\subsection{CAPITAL SOCIAL}

O termo capital social apresenta diferentes aplicações, dependendo do campo considerado para estudo. Na literatura de ciência política, sociologia e antropologia, o capital social em geral está relacionado a um conjunto de normas, redes e organizações por onde as pessoas ganham acesso ao poder e recursos que thes são fundamentais para o planejamento e tomada de decisões (SERAGELDIN \& GROOTAERT, 2000). Desta forma, o conceito de capital social está relacionado à dimensões intangíveis como participação, associativismo, confiança e ajuda mútua. Apesar das inúmeras definições de capital social, as suas origens do conceito remontam o trabalho de Alex Tocqueville em "Democracia na américa" em 1835. Posteriormente o termo foi desenvolvido por diversos autores, dentre eles Lya Hanifran, Jane Jacobs, Pierre Bourdieau, James Coleman, Robert Putnam, Amartya Sen e Bernard Kliksberg que contribuíram para a popularização do termo na literatura (SANTOS, 2003).

Em seu estudo sobre o funcionamento do regime político e análise da vida sócio-política dos norte-americanos, Tocqueville identificou uma forte tendência dos americanos à associação. $O$ espírito associativo americano está fortemente presente atuando como um estímulo ao comércio, incremento à indústria, desenvolvimento moral e fortalecendo a democracia participativa (FERNANDES, 2000).

Apesar de não ter feito referência ao termo exato de capital social, Hanifran (1916), retoma os valores de solidariedade, redes sociais, vizinhança e cooperativismo como determinantes para a democracia e desenvolvimento local. Segundo Hanifran (1916), à medida em que um indivíduo se relaciona com os demais, há um acúmulo de capital social que pode satisfazer imediatamente suas necessidades sociais o que permitirá desenvolver o seu potencial social para a melhoria substancial das condições de vida em toda a comunidade.

Após a elaboração inicial de Hanifan (1916), o conceito de capital social desapareceu da literatura durante várias décadas, retornando ao debate apenas nos anos 1970, em várias áreas do conhecimento. Na sociologia, Bourdieu (1986) retoma o conceito de capital social como redes permanentes que pertencem a um grupo e asseguram a seus membros um conjunto de recursos atuais e potenciais. Para Bourdieu (1986), o capital social está associado ao número de relações do indivíduo. 
Assim, quanto maior o número de relações sociais, econômicas e culturais de uma pessoa maior será o seu capital social.

Coleman (1998) introduziu o conceito de capital social no campo da sociologia. Segundo Coleman (1998), o capital social é definido pela sua função, uma variedade de diferentes entidades, com dois elementos em comum: todas consistem em algum aspecto da estrutura social, e facilitam certas ações dos atores - atores tanto individuais como corporativos - dentro da estrutura. Conforme o autor, todas as relações sociais e estruturas sociais facilitam o surgimento de alguma forma de capital social. Apesar de se distinguir das demais formas de capital por aumentar à medida em que é utilizado, o capital social é produtivo, possibilitando a realização de determinados fins que, na sua ausência não seria possível.

Para Putnam (2002, p.177), o capital social está relacionado à "características da organização social, como confiança, normas e sistemas que contribuam para aumentar a eficiência da sociedade, facilitando ações coordenadas". Neste contexto, a confiança é um componente básico do capital social e estaria relacionada às interações entre os participantes dessa organização social.

Segundo Putnam (2002) a confiança social pode se originar de duas fontes: regras de reciprocidade e sistemas de participação cívica. As regras de reciprocidade podem ser de dois tipos: a balanceada ou específica que é dada pela troca simultânea de itens de igual valor ; e generalizada ou difusa, que se baseia na relação de troca contínua, que pressupõe uma expectativa de recompensa relacionada à um favor realizado hoje com relação ao futuro. Assim, "a regra da reciprocidade generalizada é um componente altamente produtivo do capital social. As comunidades em que essa regra é obedecida têm melhores condições de coibir o oportunismo e solucionar os problemas da ação coletiva" (PUTNAM, 2002, p.180).

Não obstante, Putnam (2002) ressalta que os sistemas de intercâmbio e de comunicação interpessoal podem ser horizontais e verticais. Os sistemas verticais, são caracterizados pela predominância de relações desiguais, assimétricas e baseadas na hierarquia e dependência, tipicamente presente em relações clientelistas que envolvem trocas interpessoais verticais e obrigações recíprocas assimétricas. Além disso, sistemas verticalizados são incapazes de sustentar a confiança e cooperação social. Por sua vez, os sistemas horizontais auxiliam seus participantes a solucionar os dilemas da ação coletiva. Uma forma de sistema horizontal são os sistemas de participação cívica que são consideradas uma parte crucial para a 
formação de capital social, "quanto mais desenvolvidos forem esses sistemas numa comunidade, maior será a probabilidade de seus cidadãos sejam capazes de cooperar em benefício mútuo" (PUTNAM, 2002, p. 182)

Com base na teoria de Tocqueville, Putnam (2002) comparou duas regiões da Itália, a região sul e norte, verificando quais instituições tiveram bom desempenho e quais não tiveram, com o objetivo de explicar as diferenças de desempenho institucional. Como resultado, Putnam (2002) identificou o norte da Itália como a região mais desenvolvida que segundo ele é justificada por suas origens culturais, herdadas da idade média, ao passo que na região sul é caracterizada por uma política verticalmente estruturada, vida social fragmentada, isolamento e cultura dominada pela desconfiança. $O$ engajamento da população do norte da Itália representaria, então, a comunidade cívica caracterizada por cidadãos atuantes e imbuídos de espírito público, por relações políticas igualitárias e estrutura social baseada na confiança e colaboração. Essa comunidade cívica seria consequência de um processo cultural de longo prazo, uma evolução histórica do sistema político e existência de prérequisitos desenvolvimentistas que facilitam a implementação de políticas públicas.

Percebe-se que existem regiões mais cívicas comparadas as outras, dependendo da maior ou menor cultura cívica. Em regiões com menor grau de civismo a política caracteriza-se por relações verticais de autoridade e dependência típico de sistemas clientelistas. Da mesma forma, as relações políticas são mais autoritárias e a participação política se restringe a elite (PUTNAM, 2002).

Assim, regiões menos cívicas estão mais sujeitas à corrupção e desconfiança entre os cidadãos. Quanto maior o acúmulo de capital social e maior a cultura cívica, maior será o desenvolvimento. Segundo Putnam (2002), é preciso conhecer as diferenças básicas da vida cívica de uma comunidade para posteriormente perceber o êxito ou fracasso das instituições, a relação entre o bom desempenho institucional e a comunidade cívica leva ao desenvolvimento de determinada região. 


\title{
2 NOVAS CONFIGURAÇÕES DA ADMINISTRAÇÃO PÚBLICA:
}

\section{POSSIBILIDADES PARA MELHORIA DA GESTÃO DA SAÚDE PÚBLICA}

A transição da sociedade agrícola para a sociedade industrial e posteriormente para a sociedade da informação provocou mudanças significativas para a estrutura de administração pública. Diante da complexidade do mundo contemporâneo, o Estado enfrentou o desafio de lidar com as incertezas típicas da globalização, optando pela superação da era da burocracia governamental hierárquica adaptando-se às novas exigências. Essa transição de Estado-nação para Estado-rede é apresentada por Castells (1999, p. 164)

\begin{abstract}
Assim, surge um novo tipo de Estado, que não é o Estado-nação, mas que não o elimina e sim o redefine. O Estado que denomino Estado-rede se caracteriza por compartilhar a autoridade (ou seja, a capacidade institucional de impor uma decisão) através de uma série de instituições [...]Esse tipo de Estado parece ser o mais adequado para processar a complexidade crescente de relações entre o global, o nacional e o local, a economia, a sociedade e a política, na era da informação [...] O Estado-nação herdado da era industrial não é esse instrumento. Sua utilização forçada para tarefas novas aprofunda sua crise de operacionalidade e, por último, solapa sua capacidade representativa [...] O Estado-rede é a forma de sobrevivência do Estado na era da informação e da globalização.
\end{abstract}

Em meio a um cenário caracterizado por turbulências, incertezas, alto nível de competitividade, crises de reestruturação e de problemas tanto mais globais quanto locais (GOLDSMITH E EGGERS, 2004), surge a necessidade de uma estratégia de atuação tanto na esfera da ação pública quanto na esfera dos negócios de configuração em rede (LOIOLA E MOURA, 1996). Métodos tradicionais de gestão pública caracterizados por estruturas hierárquicas e fronteiras rígidas tem sido comprovadamente menos efetivas para lidar com o contexto atual (KAPUCU, ARSLAN, \& DEMIROZ, 2010; KETTL, 1997). Goldsmith \& Eggers (2004) complementam que apesar persistir, o modelo hierárquico tradicional caracterizado pela rigidez burocrática operacionalizadas por comando e controle, restrições de trabalho e culturas é inapto para atender as demandas desse contexto complexo e de rápida transformação. O novo contexto exige uma mudança da autoridade hierárquica convencional para processos e mecanismos operacionais mais fluidos, com estrutura horizontal, igualitária, baseada na confiança, reciprocidade e ganhos mútuos (RHODES, 1996). 
Em comparação com as estruturas hierárquicas típicas de organizações burocráticas que operam de modo a produzir bens e serviços públicos paronizados para uma demanda heterogênea, a estrutura de redes possui maior compatibilidade para atender à complexidade e diversidade da Era da Informação (KOOIMAN, 1993). Provan \& Lemaire (2012) afirmam que as redes são mais efetivas do que o mercado ou hierarquias quando o problema requer uma abordagem adaptada e flexível, ambiente incerto ou conhecimento e recursos necessários atravessam as fronteiras. Bennington (2011) argumenta que as redes possuem potencial maior do que qualquer estrutura hierárquica, dada a sua capacidade de adaptação à sistemas complexos, resposta a mudanças contínuas e coordenação de diversos atores e organizações. A estrutura de redes é, então, vista como a melhor alternativa a ser adotada para lidar com os problemas mais complexos que exigem uma ação conjunta de múltiplos atores, múltiplas esferas de governo e múltiplas organizações (AGRANOFF, 2014).

\subsection{REDES}

A teoria de redes surgiu nas ciências sociais em 1930 com o trabalho do sociólogo Jacob Moreno. Nele, o autor introduziu o sociograma para descrever os indivíduos como um conjunto de nós conectados por linhas, isolando esquematicamente as relações entre pessoas e intervenções. A partir deste estudo, Cartwright e Harary (1956) desenvolveu um novo conceito de redes, unindo o conceito de redes sociais à teoria de grafos e à álgebra linear. Desde então, a teoria de redes foi adotada pelas mais diversas áreas de estudo: psicologia, tecnologia da informação, ciência política, administração, biologia, etc.

Essa diversidade de abordagens e aplicações suscitou uma infinidade de estudos sobre o tema na literatura. Todavia, Oliver \& Ebers (1998) ressaltam que esse crescimento considerável no número de estudos, não tornou o campo de estudo de redes mais claro e consolidado conceitualmente, pelo contrário, houve o que os autores chamam de "cacofonia conceitual" dada a heterogeneidade dos conceitos e teorias. Dada a diversidade de disciplinas, as redes têm sido definidas em termos de metáforas, arranjos governamentais e dispositivos estruturais ou institucionais. O termo redes tem sido utilizado em referência às estruturas que envolvem múltiplos nós com múltiplas ligações. Assim, o desenvolvimento da teoria de redes ocorreu de duas formas: a primeira decorreu da concentração de diversas disciplinas que produziram 
teorias próprias ao seu contexto (MANDELL, 2014). A segunda ocorreu pela sobreposição de diversas tradições relacionadas. Em análise sobre a literatura sobre redes Kenis \& Provan (2009) observaram que houve um período de euforia em que grande parte dos estudos sobre os efeitos das redes consideravam a sua simples existência em arranjo institucional como um efeito positivo. Posteriormente foram surgindo questões sobre se e sob quais condições as redes realmente executariam um desempenho tal que justificasse os seus custos de colaboração (KENIS; PROVAN, 2009).

Kenis \& Provan (2009) apontam que o estudo de se e sob que circunstâncias específicas as redes são realmente eficazes recebeu pouca atenção nos últimos anos. A literatura apresenta poucos estudos que consideram o desempenho da rede como variável dependente, sendo a avaliação do desempenho global da rede pouco explorado. A grande maioria dos estudos se concentram em explicar as características das redes ou apresentam o desempenho como ferramenta para explicar os resultados das políticas e eficácia do serviço ao nível da organização. Provan \& Milward (1995) chamam essa situação de "problema de produção conjunta", onde várias agências são responsáveis por um ou mais componentes de um único serviço (PROVAN; MILWARD, 1995). Nessa situação, embora as organizações pertencentes a uma rede possam prestar excelentes serviços individualmente, os resultados globais da rede pode ser aquém do esperado (KENIS \& PROVAN, 2009).

Apesar da diversidade de conceitos existentes para o termo redes, sob a perspectiva da administração pública as redes são entendidas como estruturas e interdependência que envolve várias organizações ou parte dela, onde não há uma relação de subordinação e hierarquia (O'TOOLE; MEIER, 1999). Esse novo fenômeno é dado pela articulação entre agências governamentais, organizações privadas, organizações sem fins lucrativos e sociedade com a finalidade de aliar interesses em comum, enfrentar problemas sociais e implementar políticas públicas.

Segundo Loiola e Moura (1996) a origem dessa nova configuração no setor público é resultante de questionamentos quanto ao desempenho das estruturas burocráticas e hierárquicas, associadas às novas configurações de organização e gestão do trabalho. Segundo Kenis \& Provan (2009), especialmente no setor público, as redes estão cada vez mais reconhecidas como um mecanismo viável para a prestação de serviços e implementação de política bem como uma alternativa à governança hierárquica tradicional. Visando compreender essa variedade de termos 
e conceitos de redes, Börzel (1998) compara duas escolas de análise para definir redes públicas. Uma escola de predomínio britânico é composta de estudos sobre relações e intermediações de interesses. A outra composta de estudos alemães é chamada de governança, onde as redes são vistas como mecanismos de redução da fragmentação por meio de uma ação conjunta e coordenada de atores públicos e privados que cooperam entre si para o alcance de objetivos comuns.

A literatura sobre redes no setor público apresentam diversos estudos (WILKS e WRIGHT, 1987; RHODES, 1988; MARIN e MAYENTZ, 1991; MARSH e RHODES, 1992; GLASBERGEN, 1995; KICKERT et al., 1997 MILWARD e WAMSLEY, 1985; PROVAN e MILWARD, 1995; O'TOOLE, 1997), dentre eles, o de Agranoff \& McGuire (2007) que estudaram as redes no setor público e a definiram como um método alternativo de orientação com foco na intermediação e coordenação interorganizacional de políticas públicas.

Segundo Rovere (1999), as redes são constituídas de relações horizontais, que facilitam a tomada de decisão coletiva e a resolução de interesses comuns. A alteração da configuração em rede versus hierárquica afeta diretamente a estrutura de dominação da administração clássica onde a hierarquia é um instrumento de poder e controle. Dentre os tipos de redes mais comuns na literatura estão as redes interorganizacionais, redes de políticas públicas e governança em redes. $O$ conceito de redes como redes interorganizacionais está relacionado com alianças, parcerias e joint venture (NOHRIA \& ECCLES, 1992). No contexto de redes de políticas públicas, esta é similar a redes interoganizacionais porém o foco é em juntar os diferentes atores envolvidos. Comparativamente, existem redes baseadas na relação interpessoal, confiança, mutualidade, reciprocidade e são levados além de arranjos interorganizacionais para redes transformacionais em que novos sistemas são criados. (MANDELL \& STEELMAN, 2003; KEAST et al. 2004). 


\section{MARCOS CONCEITUAIS DE EFICIÊNCIA}

A eficiência econômica teve origem no conceito de eficiência elaborado por Vilfredo Pareto em 1906. Segundo esse conceito, em uma situação Pareto-eficiente ou ótimo de Pareto as preferências individuais são tomadas para indicar mudanças no bem estar individual, não sendo possível que haja melhoria da satisfação de um indivíduo sem que haja piora da satisfação de outro (BUCHANAN, 1959).

Dado certo arranjo econômico, esse é eficiente se não puder existir um rearranjo que deixe alguém em melhor situação sem piorar a posição dos outros. Nessa situação é impossível uma alteração do método de produção, ou do conjunto de bens produzidos, ou do tamanho do setor público, que ajude A sem prejudicar B e C. Se por outro lado a alteração for possível, então o arranjo em voga é ineficiente e um ganho de eficiência pode ser obtido (MUSGRAVE E MUSGRAVE, 1980, p. 55).

Sob o ponto de vista da teoria da produção, a eficiência baseia-se na relação entre a quantidade de recursos disponíveis e produtos (AHLEIM, 1988). Com base nesta perspectiva Koopmans (1951) desenvolveu o conceito formal de eficiência técnica. Segundo o autor, a eficiência técnica ou situação de eficiência ParetoKoopmans é dada pela situação em que dados os recursos disponíveis é tecnologicamente impossível aumentar qualquer saída sem reduzir simultaneamente outra saída reciprocamente. Isto posto, uma firma é tecnicamente ineficiente no sentido Pareto-Koopmans quando essa pode obter a mesma produção com pelos menos um insumo ou pode utilizar os mesmos insumos para produzir pelo menos mais de um produto (FRIED et. al, 2008).

Com base no conceito de eficiência técnica de Koopmans, Debreu (1951) desenvolveu um método para mensuração da eficiência técnica capaz de quantificar a ineficiência de recursos chamado de coeficiente de utilização de recursos. A partir deste coeficiente, Farrell (1957) propôs uma metodologia de avaliação de eficiência produtiva capaz de abranger múltiplos inputs. Nessa nova metodologia, Farrell (1957) desmembrou a eficiência em dois tipos: eficiência técnica e eficiência alocativa. A eficiência técnica é dada pela comparação entre a produção realizada e a produção máxima possível de se produzir dados os recursos disponíveis. Assim, segundo este conceito, a mensuração da eficiência técnica refletiria a capacidade de produção máxima de uma firma dada uma quantidade de insumos disponíveis (FARRELL, 1957). 
Por sua vez, o conceito de eficiência alocativa ou eficiência de preço ${ }^{2}$ refere-se à habilidade de combinar insumos e produtos em proporções ótimas em função dos preços vigentes. Desta forma, a mensuração da eficiência alocativa é dada em termos de comportamentos e objetivos da unidade de produção, ou seja, em custo observado versus custo ótimo (FRIED et al., 2008). Como forma de representação dos conceitos de eficiência técnica e alocativa, Farrell (1957) considerou uma economia que utiliza apenas um insumo $(x)$ para produção de apenas um output $(y)$, a fronteira da eficiência é determinada pela reta $\boldsymbol{f}(\boldsymbol{x})$ que possui declividade igual à produtividade da Unidade de Tomada de Decisão (DMU) mais produtiva, representada na figura 1 pela coordenada $x_{e f}$ e $y_{e f}$ (MELLO et al., 2005). Desta forma, as DMUs consideradas tecnicamente eficientes estão sob a fronteira de eficiência $f(x)$, enquanto as ineficientes se encontram abaixo da fronteira, como no caso da DMU "O" na Figura 1.

Figura 1 - Gráfico da Eficiência Técnica

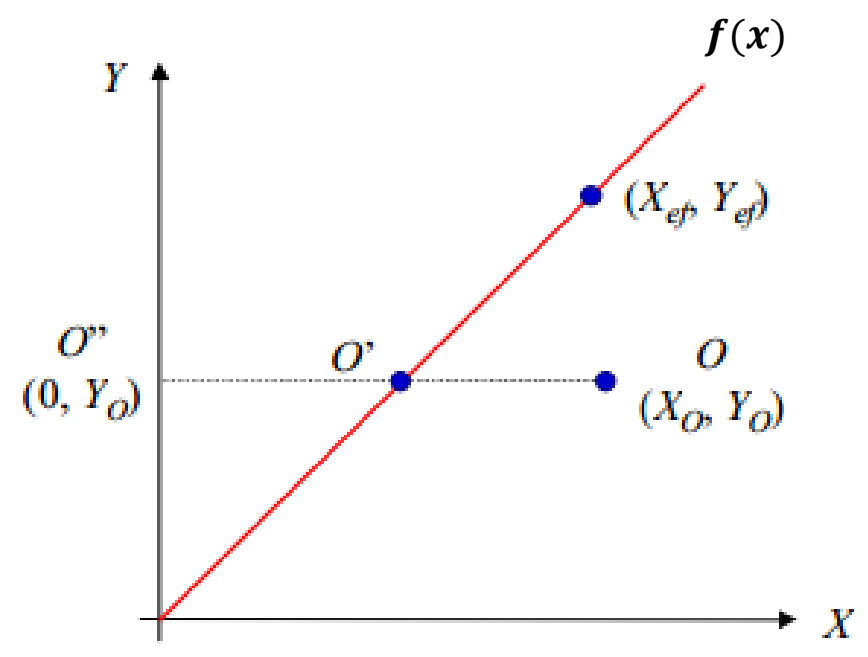

Fonte: Mello et al. (2005)

Tanto a eficiência técnica quanto a eficiência alocativa podem ser mensuradas a partir de duas orientações: orientação à output e orientação à insumo. A eficiência técnica orientada à output considera a habilidade de evitar o desperdício utilizando o mínimo possível de insumos quanto possível para produção. Para tanto, maximiza-se a produção mantendo fixa a quantidade de insumos. A eficiência, neste caso, é dada

Em seu artigo "The Measurement of Productive Efficiency" Farrell (1957) adota o termo eficiência preço para se referir à eficiência alocativa. 
pela razão entre $C P / C D$, variando entre 0 e 1, representada na Figura 2 pelo deslocamento da DMU P para o ponto D.

A mensuração da eficiência orientada à output é dada pela diferença entre o total produzido com os recursos disponíveis e o total que poderia ser produzido considerando a tecnologia disponível. A representação do total a ser produzido é dada pela Fronteira de Possibilidades de Produção (FRIED et al., 2008). A eficiência orientada à insumo está relacionada à habilidade de evitar o desperdício produzindo o máximo possível com os insumos disponíveis. Para tanto, busca-se minimizar os insumos utilizados mantendo fixa a produção. Sua mensuração é dada a partir da diferença entre a quantidade de insumos utilizada para produzir determinado nível de output e o total mínimo de insumos necessários para produzir o mesmo nível de produção com a tecnologia de produção disponível (FRIED et al., 2008). Conforme apresentado na figura 2, a eficiência é mensurada pela razão $A B / A P$, que poderá variar entre 0 e 1 . Assim, a DMU $P$ seria tecnicamente eficiente no ponto $B$.

Figura 2. Orientação à inputs e outputs

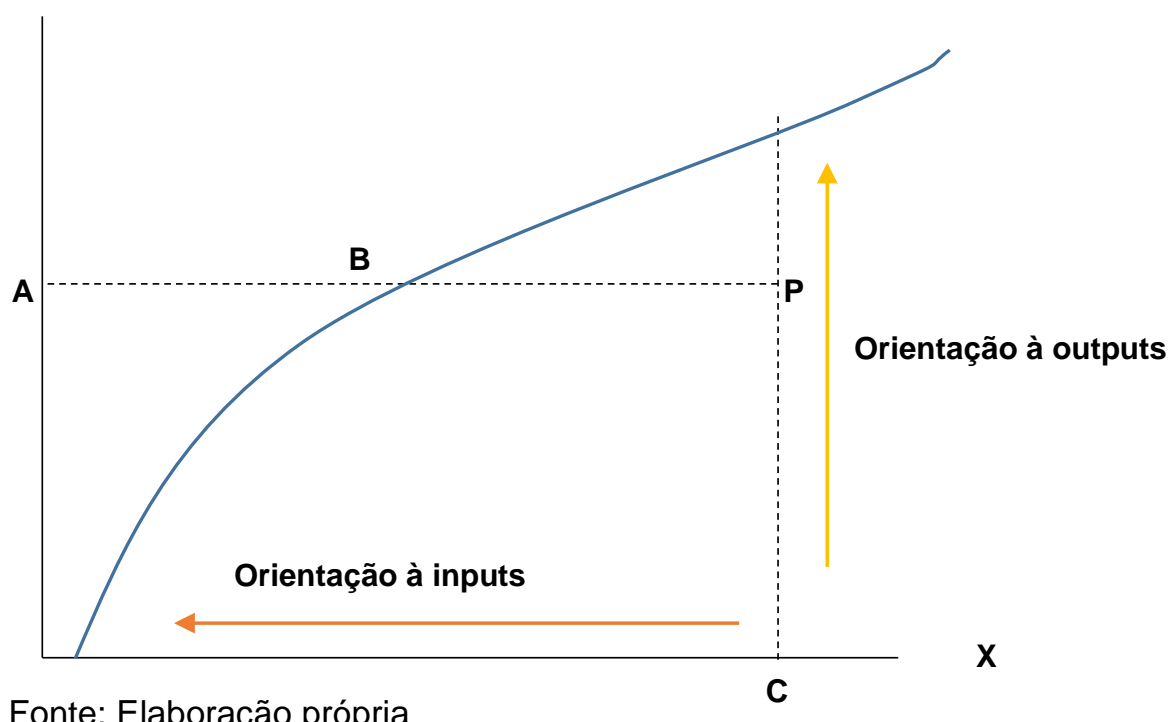

Fonte: Elaboração própria

Desta forma, a definição de eficiência produtiva é baseada na noção de eficiência relativa das unidades consideradas "best performancers" em relação a um grupo de comparações de unidades produtivas. Ademais, diferentemente da eficiência de Pareto e Pareto-Koopmans que mensura a eficiência total, a metodologia de mensuração de eficiência desenvolvida por Farrell, permite mensurar a eficiência 
técnica de cada unidade individualmente em relação à fronteira de produção (DARAIO \& SIMAR, 2007).

Sob o ponto de vista da teoria econômica tradicional, a alocação de recursos Pareto eficiente, ou seja, situação em que não é possível melhorar o bem-estar de nenhuma pessoa sem piorar o bem-estar de outra, é dada pela competição dos mercados. Segundo esta perspectiva, o mercado atuaria como mecanismo de alocação de recursos de maneira eficiente por meio da busca dos indivíduos pela satisfação dos seus próprios interesses que levaria ao alcance do interesse público (INMAN, 1987).

Esse modelo ideal de mercado competitivo caracterizado pela livre concorrência e pela busca da maximização dos lucros somente seria alcançado com o pleno funcionamento do modelo de concorrência perfeita (GRUBER, 2007). Todavia, confrontada com a realidade, a situação de competição perfeita se depara com as mais diversas distorções geradas pela existência de bens públicos, retornos de escala, externalidades, assimetria de informação, mercados incompletos dentre outros fatores que impedem que haja uma alocação de recursos ótima no mercado e consequentemente ineficiência (STIGLITZ, 2000). Esses fatores que impedem que os recursos disponíveis sejam realocados de modo a permitir que pelo menos uma pessoa melhore de situação sem que outra piore são chamados de falhas de mercado.

Dentre as falhas de mercado está a existência de bens públicos que segundo Gruber (2009) são aqueles que são não-rivais e não-excludente em termos de consumo. A primeira característica consiste na premissa de que não há como impedir o consumo do bem público, pois ele está disponível à todos. A segunda consiste na observação de que o bem público, uma vez consumido não sofre redução da disponibilidade do bem para outros indivíduos (GRUBER, 2009). Musgrave (1980) explica que esses tipos de bens não podem ser fornecidos por meio do sistema de mercado, pois os benefícios provenientes do consumo deles não são propriedades específicas de alguns indivíduos, tornando impossível e ineficiente restringir o seu consumo. Além disso, os benefícios dos bens públicos estão disponíveis para todos, e nem todos irão oferecer pagamentos voluntários aos supridores dos bens. Os bens meritórios são aqueles bens que apesar de serem ofertados pelo mercado privado, dada a sua relevância econômica e social, o governo atua em complementação, como no caso da área de saúde e educação. Já que os benefícios dos bens públicos estão 
ao alcance de todos, os consumidores não revelarão suas preferências através de lances no mercado, mas tenderão a agir como "caronas".

Outra falha de mercado apresentada por Wolf (1979) é a falha decorrente da existência de retornos de escala. Essas ocorrem quando atividades econômicas são sujeitas a aumento de retornos e redução de custos marginais. Nesses casos, o mercado poderá falhar na geração de resultados eficientes. Sob condições de redução de custos, o menor custo de produção poderá ser atingida por apenas um produtor. Consequentemente, esse único produtor poderá elevar o nível de preços acima do nível de equilíbrio e restringir o bem estar dos consumidores. Além disso, o produtor do mercado monopolista não têm incentivos para investir em melhorias dos seus produtos e em inovação tecnológica. Esses fatores somados provoca falha e ineficiência no mercado.

Observa-se que a existência de efeitos externos no consumo individual e nas decisões de produção, chamados efeitos de vizinhança (BUCHANAN, 1959) também são consideradas falhas de mercado. Conforme Musgrave e Musgrave (1980) as externalidades podem envolver não apenas benefícios ou externalidades positivas, mas também custos ou malefícios sociais - como no caso da poluição. Essa situação decorre da falta de incentivos aos indivíduos para que considerem as consequências positivas e negativas das suas ações para os outros indivíduos. Assim, em mercados competitivos, há um excesso de oferta de bens que geram externalidades negativas e uma escassez de oferta de bens que geram externalidades positivas.

Dada a presença das falhas de mercado na economia, surge a justificativa para intervenção do Estado como provedor de bens públicos, cabendo ao Estado o preenchimento das falhas provocadas pelo mercado (HICKS, 1939; MUSGRAVE, 1980; STIGLITZ, 2000; SAMUELSON, 2004) atuando como regulador de monopólios, facilitador de transações e corretor de externalidades (PRZEWORSKI, 1997). Assim, a intervenção estatal é vista como solução para as falhas geradas pelo mercado. Essa intervenção seria realizada por meio de três funções: função distributiva, função estabilizadora e função alocativa (MUSGRAVE, 1980)

$\mathrm{Na}$ sua função distributiva o governo atua visando ajustar a distribuição de renda e riqueza de modo a assegurar a sua adequação ao que é considerado como socialmente "justo". Por sua vez, a função estabilizadora está relacionada às ações do governo para controle da elevação dos níveis de emprego, promoção de 
crescimento econômico e estabilização dos níveis de preço e do balanço de pagamentos.

$\mathrm{Na}$ função alocativa cabe ao governo o fornecimento de bens e serviços, ou do processo pela qual a totalidade de recursos é dividida para uso tanto do setor público quanto privado (MUSGRAVE, 1980). Oates (1972) em seu Teorema da Descentralização, argumenta que a proximidade do governo local o torna mais apto a identificar as preferências dos seus habitantes do que o governo central e assim seja capaz de ofertar bens e serviços públicos compatíveis com as necessidades da população local. Ainda segundo este Teorema, essa descentralização permitiria otimizar o bem-estar do cidadão e ofertar bens públicos com eficiência.

Porém, sob o ponto de vista da Teoria da Escolha Pública, a visão do Estado como corretor das falhas de mercado é criticada, por se basear em um "modelo ingênuo de um Estado onisciente e benevolente" (PRZEWORSKI, 1997; p.3). Posner (1987) ressalta que apesar do governo ser capaz de fazer algumas coisas melhor do que o mercado, não há razão para crer que processos democráticos impeçam o governo de exceder os limites da intervenção ótima. Segundo Przeworski (1997), embora o Estado tenha a função de corrigir as falhas de mercado, nem sempre ele irá se comportar de maneira a maximizar o bem-estar social, seja por incapacidade ou falta de disposição, provocando as chamadas "falhas de governo".

Dentre as falhas geradas pela ação governamental estão a informação limitada, controle limitado sobre as respostas do setor privado, controle limitado entre a burocracia e limitações impostas ao processo político (TULLOCK, 2005). De acordo com Downs (1957), os agentes públicos buscam realizar seus interesses privados, possuindo as mesmas motivações de maximização da utilidade de lucro, consumo ou poder que orientam o comportamento dos agentes privados (OATES, 1993; GRUENING 2001; TULLOCK, 2005).

Outro ponto de ineficiência do setor público identificado pelos teóricos da teoria da escolha pública é que o comportamento racional do burocrata favorece a maximização do orçamento disponível e posterior ineficiência. Niskanen (1994) explica que esta prática é decorrente da ausência de competitividade inerente ao setor privado. Segundo Gruening (2001), organizações burocráticas tem um grande número de ineficiências como tendências de acumulação de tarefas e recursos, conservadorismo excessivo e incapacidade legal de acompanhamento de tarefas. 
Desta forma, observa-se que tanto a falha de governo quanto as falhas de sistemas de mercado geram ineficiência na produção de bens e serviços. 


\subsection{MÉTODOS DE MENSURAÇÃO DA EFICIÊNCIA}

Segundo Coelli et al (2005) existem quatro tipos de métodos de mensuração da eficiência: método econométrico de produção mínimos quadrados, fator de produtividade total (TFP), análise por envoltória de dados (DEA) e fronteiras estocásticas.

A Análise por Envoltória de Dados ou Data Envelopment Analysis (DEA) é um método não paramétrico de estimação da eficiência relativa. O método teve origem em 1957 no estudo de Farrell sobre mensuração da eficiência produtiva, e foi posteriormente desenvolvido por Charnes, Cooper e Rhodes em 1978 (COOK \& SEIFORD, 2009). A determinação da eficiência no DEA é realizada com base nos escores de eficiência mensurados a partir das variáveis de entrada e saída de cada uma das unidades que serão objeto de avaliação da eficiência chamadas de unidades de decisão (DMU) ou Decision Making Units (OZCAN, 2008). Por meio destes escores, é possível identificar as DMUs mais eficientes que formarão a fronteira da eficiência (ZHU \& COOK, 2015).

Dentre os modelos de análise de eficiência possíveis de serem realizados com o DEA estão: : retornos constantes de escala (CRS) ou modelo CCR desenvolvido por Charnes et. al (1978) e retornos variáveis de escala (VRS) ou modelo BCC desenvolvido por Banker et al. (1984). No modelo CCR, são consideradas as variações proporcionais que as entradas (inputs) produzem nas saídas (outputs). No modelo BCC, são consideradas as situações de eficiência de produção com variação de escala e sem proporcionalidade entre inputs e outputs, ou seja, DMUs que operam com baixos valores de recursos têm retornos crescentes de escala. Além disso, podese considerar a orientação à inputs ou outputs dependendo do tipo de avaliação que se deseja realizar. No DEA orientado à inputs, a fronteira de eficiência é definida pela minimização dos inputs, mantendo constantes os níveis de output. Por outro lado, a orientação à outputs define a fronteira de eficiência com base na maximização dos outputs mantendo constantes os inputs (EMROUZNEJAD ET al., 2014). O método permite avaliar a eficiência de cada DMU individualmente, por meio de uma medida de eficiência única onde as unidades mais eficientes se tornam referência para as demais DMUs.

Diversos são os modelos de avaliação de eficiência desenvolvidos ao longo dos anos. A abordagem Network DEA se origina do trabalho de Färe e Grosskopf 
(2000) que parte da observação de que os modelos tradicionais de DEA avaliam o desempenho das Unidades de Tomada de Decisão (DMUs) sem considerar seus processos internos de transformação de input em output que ocorrem na chamada black box. Segundo os autores, o detalhamento do processo de transformação de inputs em outputs não é apresentado nos modelos tradicionais, exigindo a adoção de métodos híbridos de avaliação de eficiência. Tone e Tsutsui (2009) argumentam que os modelos tradicionais negligenciam o impacto dos processos internos de divisões específicas na eficiência total, tornando o diagnóstico da eficiência incompleto.

Essa abordagem foi posteriormente complementada com as contribuições de Lewis e Sexton (2004), Kao e Hwang (2010) e Tone and Tsutsui (2009) com a extensão do two-stage DEA, network DEA relacional e Network SBM respectivamente.

Segundo Lozano e Moreno (2014) o método Network DEA considera a existência de produtos intermediários de um processo que são oriundos de um processo e consumidos em outro, conforme apresentada na figura 3. Essa endogenia entre geração e consumo de produtos representa um link entre diferentes estágios e processos.

Figura 3. Representação do modelo DEA Network

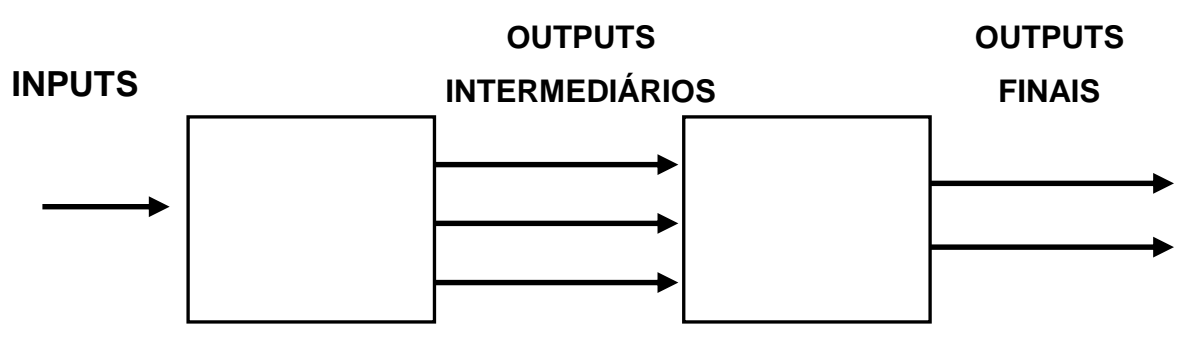

Fonte: Elaboração própria

Nessa abordagem, ao invés de serem assumidos todos os inputs e outputs como um processo único, o sistema pode ser modelado como uma forma de subprocessos distintos, onde cada sub-processo é um sistema que pode ser modelado pelo nível de processo inter-relacionados, cada um com seus próprios inputs e outputs. Conforme Tone e Tsutsui (2009) a avaliação da eficiência é realizada separadamente para cada processo de um conjunto de DMUs onde serão encontrados os benchmarks de cada processo. O Network DEA utiliza a medida de 
eficiência o modelo radial CCR ou BCC para a definição do conjunto de possibilidades de produção.

\section{SAÚDE PÚBLICA NO BRASIL}

Previamente à implementação do Sistema Único de Saúde, a situação de saúde enfrentada pela população brasileira era caracterizada pela falta de cobertura de saúde, altos índices de mortalidade infantil, de doenças parasitárias e infecciosas (PIOLA \& VIANA, 2008). A oferta de serviços médicos-assistenciais à população brasileira só foi possível a partir da criação da Previdência social em 1923. Esses serviços, entretanto, não estavam disponíveis para toda a população, apenas àquela formalmente inserida no mercado de trabalho que em 1964 representava apenas $22 \%$ da população (BAER, 2009).

Em decorrência da configuração do sistema de saúde brasileiro daquele período, a oferta de serviços de saúde era predominantemente privada, cabendo ao setor público apenas ações de controle de endemias e vigilância sanitária. Na década de 70, durante o regime militar, foi criado o Instituto Nacional de Assistência Médica da Previdência Social - INAMPS que prestava serviços e ações de saúde com restrição de acesso às pessoas inseridas no mercado de trabalho formal (RODRIGUES, 2014). Nesta época, o sistema de saúde era caracterizado pela centralização e fragmentação dos serviços de saúde. Simultaneamente foi criado o Movimento de Reforma Sanitária que buscava tornar o sistema de saúde mais eficiente e democrático, em defesa da saúde como um direito universal de cidadania e o Estado como responsável pela garantia do acesso a esse direito (PAIVA; TEIXEIRA, 2014).

Durante o período de transição democrática, conforme as bases políticas do antigo regime se enfraqueciam, o movimento sanitário se fortalecia contra o modelo de assistência à saúde vigente (CARVALHEIRO et al., 2013). Com o decorrer do tempo, o INAMPS iniciou uma estratégia de ampliação de acesso aos serviços de saúde, e em 1960 incorporou a população rural como beneficiária da Previdência Social, provocando custos derivados do aumento no número de internações que passou de 3,2\% da população em 1971 para 8,8\% em 1979 e de consultas por habitante/ano de 0,5\% em 1971 para 1,3\% em 1979. 
Em meados dos anos 80, foi realizada a 8ª Conferência Nacional de Saúde CNS para discutir as divergências com relação à unificação do INAMPS ao Ministério da Saúde e propor os elementos que iriam ser debatidos na Assembleia Nacional Constituinte de 1987 (ESCOREL; TEIXEIRA, 2013). Porém, segundo Paim (2008), a conjuntura de implementação da Reforma Sanitária durante o governo Sarney não se apresentava favorável para adoção dos preceitos formulados na $8^{\text {a }}$ Conferência Nacional de Saúde. Dentre os entraves para a implementação, Paim (2008) cita a crise fiscal do Estado como limitadora do financiamento de serviços públicos e a cultura do patrimonialismo enraizado no modus operandi da máquina pública brasileira. Além disso, Paim (2008, p.180) observou que

o recuo dos movimentos sociais, a disseminação da ideologia neoliberal e a
perda de poder aquisitivo dos trabalhadores de saúde, ensejaram o
aparecimento de uma "operação descrédito" contra o SUS, seja por parte das
classes dirigentes e mídia, seja pelas ações políticas predominantemente
corporativa dos trabalhadores de saúde.

A Reforma Sanitária, que dependia da ampliação da rede pública de serviços para sua efetivação, não era possível sem aumento do valor investido em saúde pública pelo Estado (PAIM, 2008). Enquanto o projeto de lei orgânica da saúde estava em discussão no congresso, a instabilidade econômica se agravava com a hiperinflação e crise fiscal do Estado. Segundo Andrade et al. (2007), o SUS se apresenta no sentido contrário desse discurso neoliberal com o objetivo de universalizar as ações e serviços de saúde de maneira equitativa.

Em 1988, foi instituído pela Constituição Federal, o Sistema Único de Saúde, com a competência de oferecer saúde a todos como "direito de todos e dever do Estado, garantido mediante políticas sociais e econômicas que visem à redução do risco de doença e de outros agravos e ao acesso universal e igualitário às ações e serviços para sua promoção, proteção e recuperação" (art. 196, CONSTITUIÇÃO FEDERAL, 1988).

O período de implementação do SUS foi marcado por transições e contradições políticas e econômicas. Internamente, o país acabava de eleger Fernando Collor de Melo, o primeiro presidente eleito democraticamente no país em meio à uma conjuntura econômica de intensa instabilidade. Este cenário era decorrente da estagnação da produção, agravamento do desequilíbrio fiscal e taxas de inflação de $80 \%$ ao mês (ABREU, 2014). 
A conjuntura internacional de crise da dívida externa de vários países devido aos choques de petróleo ocorridos em 1973 e 1979, e ao aumento dos juros no mercado internacional levaram à redução de investimentos internos e adoção de políticas de ajuste estruturais da economia baseada na abertura dos mercados, Estado mínimo e privatização dos ativos estatais (TAVARES, 1997). Além disso, o mundo assistia o fim da Guerra Fria, que se concretizou com a queda do muro de Berlim e hegemonia do pensamento neoliberal (FALEIROS et al., 2006).

Durante os anos 90 o SUS sofreu pressões típicas de países latino-americanos categorizados por Noronha et al. (2012) em dois grupos de problemas. O primeiro grupo é constituído por problemas de exclusão e heterogeneidade no sistema de saúde. No SUS os altos índices de desigualdade socioeconômica se apresentam nesta categoria. O segundo grupo é composto por problemas institucionais como centralização excessiva, fragmentação institucional, frágil capacidade regulatória e fraca tradição participativa da sociedade. Estas características se retratam no federalismo brasileiro, na fragmentação da cobertura e no modelo privatista de medicina aplicado.

Em 1990 houve a transferência do INAMPS, até então autarquia do Ministério da Previdência, para o Ministério da Saúde por meio do Decreto 99.060, de 7 de março de 1990 (PAIM et al., 2011). Ainda neste período foi publicada a lei 8.080/90 com a finalidade de regulamentar a operacionalização do SUS, estabelecendo sua forma de organização e funcionamento dos serviços de saúde no âmbito do SUS.

A lei orgânica representou uma conquista da sociedade brasileira pelo direito à saúde, garantido por uma lei que especificou os princípios, objetivos, atribuições, competências, direção, organização e gestão do SUS em diversos níveis federativos e o papel do setor privado como ofertante de serviços de caráter suplementar (PAIM, 2008).

Com os vetos do Presidente Collor à nove artigos da proposta original da lei orgânica, novas mobilizações foram iniciadas para a criação de uma nova proposta que regulasse 0 controle social, os repasses intergovernamentais e a descentralização do SUS (PAIM, 2008). No mesmo ano, foi aprovada a proposta de complementação da lei orgânica, a lei 8.142/90 regulamentando os mecanismos de participação social do SUS como os Conselhos de Saúde e as Conferências Nacionais de Saúde definindo os papéis de cada um e os mecanismos de transferência federal de recursos para o financiamento do SUS (PAIM, 2008). Em contrapartida, o então 
Presidente do INAMPS publicou a Norma Operacional Básica (NOB) 01/91 que subvertia as definições previstas na lei 8.142/90, sendo duramente criticada pelo movimento sanitário (PAIM, 2008).

No ano de 1992, ocorreu a 9a Conferência Nacional de Saúde (CNS) em defesa da municipalização da saúde responsabilizando o governo pelo não cumprimento da legislação sanitária. Segundo Paim (2008) havia um contrassenso entre o que estava previsto na Constituição Federal e as ações do Governo Collor que reduzia os recursos destinados à saúde pública, inviabilizando o projeto de implementação do SUS e gerando sucateamento dos serviços públicos de saúde. Com a aprovação do impeachment do Presidente Collor, o governo foi assumido pelo seu vice-presidente Itamar Franco que mesmo enfrentando dificuldades para superar as crises estruturais do pacto federativos, das políticas sociais e da saúde e as finanças públicas, retomou a discussão do projeto da Reforma Sanitária com base na NOB 01/93 (FALEIROS et al., 2006).Entretanto, apesar de ter colaborado com a implementação do SUS, Paim (2008) afirma que a NOB 01/93 não valorizou a integralidade nem redirecionou o modelo de atenção à saúde até então vigente.

No primeiro mandato do governo Fernando Henrique Cardoso (FHC), diante dos projetos propostos pelo governo $\mathrm{FHC}$ de reajuste macroeconômico e de reforma do Estado, o acompanhamento da implantação do SUS não conseguiu obter sucesso gerando persistência da crise no sistema público de saúde. Neste contexto, os trabalhadores de maior renda e a classe média buscavam nos planos de saúde e em outras formas de assistência médica supletiva (AMS) o atendimento de suas demandas de saúde, enquanto ao restante da população excluída deste grupo sobrava apenas a opção de um Sistema de Saúde público sucateado. 


\title{
4.1 PROCESSO DE DESCENTRALIZAÇÃO DO SUS
}

No SUS, a descentralização esteve presente na agenda nacional de saúde sendo relacionada ao esforço de construção de um novo arranjo federativo. A princípio a descentralização foi estabelecida a partir da Constituição Federal de 1988 e posteriormente pela Lei Orgânica da Saúde 8.080/90 e Lei 8.142/90. Nesses normativos a descentralização é entendida como um dos princípios organizativos do SUS. A definição de descentralização em saúde segundo art. 198 da Constituição Federal de 1988 e no artigo 7ํㅡㄹ do Capítulo II da Lei n.. 8.080/1990 como:

\begin{abstract}
processo de transferência de responsabilidades de gestão para os municípios, atendendo às determinações constitucionais e legais que embasam o SUS, definidor de atribuições comuns e competências específicas à União, aos estados, ao Distrito Federal e aos municípios.
\end{abstract}

A descentralização do SUS é dada pela transferência da tomada de decisão a respeito da política de saúde do governo central representado pelo Ministério da Saúde (MS) para os estados (SES) e municípios (SMS). Para tanto, são redefinidas as funções e responsabilidades de cada nível de governo com relação à condução político-administrativa do sistema de saúde, bem como a transferência de recursos financeiros, humanos e materiais (TEIXEIRA \& PAIM,1998).

$O$ processo de descentralização do SUS foi concretamente iniciado com a publicação das Normas Operacionais Básicas (NOBs) de 1991, 1993 e 1996, e posteriormente com a Norma Operacional da Assistência à Saúde (NOAS) de 2002. Em 1990 foi elaborada a primeira NOB, caracterizada por Viana \& Almeida (2009) como uma descentralização tutelada e convenial, baseada no financiamento, controle e fiscalização. Sobre a NOB 1991, Scatena e Tanaka observam que (2001, p.60)

não se evidenciam em seu texto, maiores referências a alguns dos elementos constitutivos da descentralização, como democracia, federalismo e autonomia. Já a centralização e a desconcentração financeiras são elementos que a permeiam, implícita ou explicitamente.

Posteriormente, em 1993 ocorreu a segunda etapa do processo de descentralização, com a publicação da Norma Operacional Básica também conhecida como "a ousadia de cumprir e fazer cumprir a lei" que instituiu as Comissões Intergestores como foros de negociação e deliberação e determinou a implantação da municipalização plena e novas modalidades de transferência de recursos e instrumentos com vistas a um novo arranjo intergovernamental. $O$ foco deste período 
foi a promoção da descentralização com o apoio dos estados e municípios. (VIANA \& MACHADO, 2009).

A Norma Operacional Básica de 1996 enfatizou o Programa Saúde da Família e estratégias de reforço da racionalidade sistêmica que iniciou o processo de municipalização da atenção básica redefinindo as competências tanto do estado quanto do município. A categorização da gestão plena e municipal permitiu avanços no processo de descentralização do SUS e introduziu incentivos para áreas estratégicas do sistema de modo a ampliar a transferência de recursos fundo a fundo (BARATA et al., 2004).

Entretanto, segundo Mendes (2010) o processo de municipalização gerou em diversas regiões do Brasil um crescimento desenfreado de atenção médica desarticulada, aumento no número de hospitais de pequeno porte, pulverização dos recursos públicos, ociosidade de infraestrutura, aumento no número de estabelecimentos de saúde de baixa escala e densidade tecnológica que acarretaram em uma ineficiência sistêmica e na fragmentação do SUS. Mendes (2011, p.167) explica que essa situação foi decorrente da

\begin{abstract}
interpretação predominante na municipalização autárquica, oriunda do enfoque da oferta, é que os serviços a serem ofertados aos cidadãos deveriam ser disponibilizados no município de residência, ao invés de um enfoque de demanda ou de necessidades em que se considera importante garantir o acesso dos cidadãos a serviços de qualidade, independentemente de serem ofertados no município de residência. Esse incentivo implícito, na realidade federativa brasileira de avassaladora maioria de pequenos municípios, levou a uma extrema fragmentação dos serviços de saúde, do que decorreram significativas deseconomias de escala e de escopo e, como consequência, baixa qualidade dos serviços ofertados.
\end{abstract}

Visando mitigar os problemas gerados pela NOB 1996, em 2002, foi publicada a Norma Operacional de Assistência à Saúde (NOAS) caracterizada pela descentralização com regionalização, partilha de funções e com forte regulação (VIANA \& MACHADO, 2009). A partir da NOAS instituiu-se o processo de regionalização como estratégia de hierarquização dos serviços de saúde, baseandose no Plano Diretor de Regionalização (PDR) como instrumento de ordenamento do processo de regionalização da assistência nos estados e DF. A elaboração do PDR deverá estar em consonância com o Plano Estadual de Saúde com aprovação pela Comissão Intergestores Bipartite (CIB) e pelo Conselho Estadual de Saúde. Segundo Barata et al. (2004), o PDR define as áreas geográficas, os fluxos e as pactuações entre os gestores por meio da Programação Pactuada Integrada (PPI). 
Dentre as críticas existentes a respeito da NOAS é que esta permitiu que com base no comando único municipal houvesse competição entre o gestor estadual e os municípios em gestão plena pela gestão de serviços de alta complexidade (BARATA et al. 2004). Com a publicação do Decreto 7.508 de 2011 determinou-se um novo arranjo para a descentralização com a constituição do SUS em Redes de Atenção à saúde. Para tanto foram criadas regiões de saúde e o Contrato Organizativo da Ação Pública da Saúde (COAP) determinada pelo art. 2ª do Decreto 7.508/2011 como

\footnotetext{
I - Região de Saúde - espaço geográfico contínuo constituído por agrupamentos de Municípios limítrofes, delimitado a partir de identidades culturais, econômicas e sociais e de redes de comunicação e infraestrutura de transportes compartilhados, com a finalidade de integrar a organização, 0 planejamento e a execução de ações e serviços de saúde;

II - Contrato Organizativo da Ação Pública da Saúde - acordo de colaboração firmado entre entes federativos com a finalidade de organizar e integrar as ações e serviços de saúde na rede regionalizada e hierarquizada, com definição de responsabilidades, indicadores e metas de saúde, critérios de avaliação de desempenho, recursos financeiros que serão disponibilizados, forma de controle e fiscalização de sua execução e demais elementos necessários à implementação integrada das ações e serviços de saúde.
}

Desde então houve a alteração da definição da oferta de ações e serviços do SUS por regiões de saúde, sendo que cada região formada nos estados deverá garantir a integralidade no atendimento através da parceria entre os municípios componentes, regulado pelo Contrato Organizativo de Ação Pública (COAP).

\subsection{ESFERAS DE PARTICIPAÇÃO SOCIAL NO SUS}

A promulgação da Constituição Federal de 1988 instituiu esferas de participação popular nas mais diversas áreas. No caso da Saúde, essa participação foi definida como uma diretriz da rede regionalizada e hierarquizada do SUS, ao lado da descentralização e integralidade. As formas de participação popular na gestão do SUS foram organizadas a partir da publicação da Lei oㅡ 8.142/90, com a instituição dos Conselhos de Saúde. Segundo essa lei, os Conselhos de Saúde possuem caráter permanente e deliberativo devendo atuar na formulação de estratégias da política de saúde e no controle da execução na instância correspondente. Há também referência na lei sobre as Conferências de Saúde, que passam a ter como competência a avaliação da situação de saúde e proposição de diretrizes para a formulação da política de saúde nos níveis correspondentes (BRASIL, 1990). 
Labra (2006, p. 208) afirma que a instituição dessas esferas criam uma "densa constelação de espaços de participação, interlocução e aprendizado cívico envolvendo milhares de pessoas dedicadas a realizar um trabalho voluntário em prol da defesa do SUS, do controle social e da saúde da população".

Figura 4. Estrutura institucional e decisória do SUS

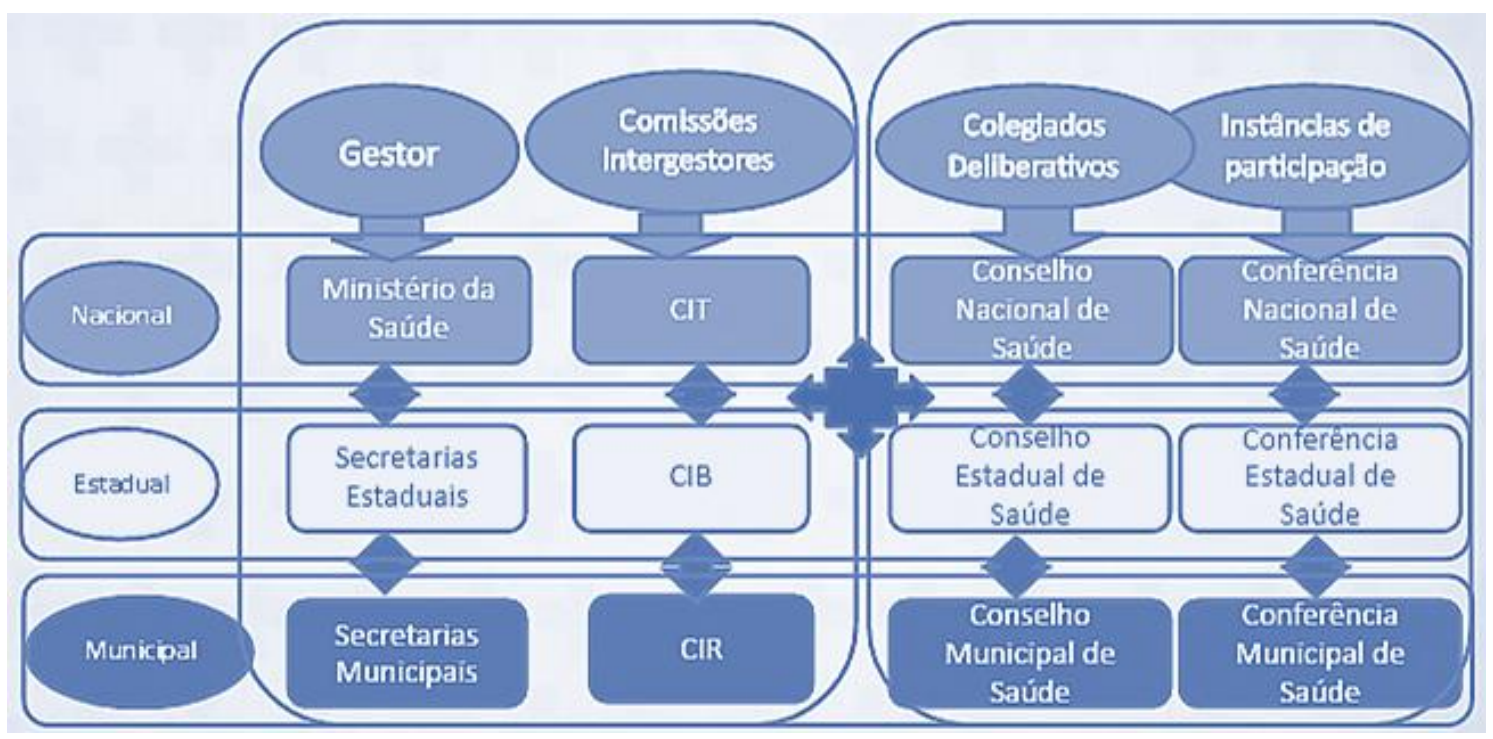

Fonte: DAI/SGEP/MS

Com relação à composição dos Conselhos de Saúde, conforme orientação da Resolução 333/2003 do Conselho Nacional de Saúde, esses deverão contar com representações do governo, prestadores de serviço, profissionais de saúde e usuários, de maneira paritária, e com a distribuição de vagas de maneira que 50\% delas sejam de entidades de usuários; $25 \%$ de entidades dos trabalhadores de Saúde; $25 \%$ de representação de governo, de prestadores de serviços privados conveniados, ou sem fins lucrativos.

Não obstante a existência de instrumentos legais para a constituição dos Conselhos de Saúde, esses não são suficientes para que sejam efetivos (COTTA et al., 2009). Labra (2006) reforça essa afirmação, observando que embora exista uma variedade de espaços públicos para participação e deliberação para a gestão do SUS, esses ainda enfrentam problemas no seu funcionamento. Wendhausen et al. (2006) identificaram alguns casos de funcionamento meramente protocolar por parte de Conselhos Municipais de Saúde que chegam a realizar reuniões registradas por meio de atas apenas para justificar a existência do Conselho de Saúde e a manutenção do recebimento das verbas públicas. 
Diversos são os problemas identificados por estudos empíricos sobre o tema (COTTA et al., 1998; LABRA, 2002 e 2005; WENDHAUSEN; GUIZARDI et al., 2004), dentre eles está a composição dos Conselhos. O processo de escolha dos membros que irão compor os Conselhos de Saúde não são claros e muitas vezes não respeita o critério da paridade estabelecido nos normativos do Conselho Nacional de Saúde, e em alguns casos, um mesmo conselheiro pode chegar a representar tantos segmentos que podem representar grupos opostos como no caso de usuários e prestadores (LABRA, 2006). Até mesmo nos casos em que os critérios são considerados, os membros escolhidos para compor o Conselho não apresentam capacidade de intervenção perante aos grupos que deveriam representar (LABRA, 2002 e 2005; WENDHAUSEN, 2006; GUIZARDI et al. 2004; GUIZARDI, 2006). Em complementação ao problema da composição dos Conselhos, Labra (2006, p. 215) afirma que grande parte dos representantes de usuários são de associações de moradores que

[...] tendem a reproduzir no seu interior traços semelhantes aos que atravessam a sociedade brasileira, como oligarquização da cúpula, clientelismo, escassa participação das comunidades, pouca ou nenhuma transparência nas decisões e prestações de contas etc. Esses vícios, unidos à baixa taxa de renovação dos dirigentes, repercutem no processo de escolha de representantes para o CS e na recondução da mesma pessoa, já que ela a miúdo é feita sem consulta aberta às comunidades.

Essa baixa rotatividade é justificada pela complexidade das matérias relacionada com as atividades dos conselheiros.

\begin{abstract}
é racional que a experiência adquirida se torne um requisito crucial para a mesma pessoa ser reconduzida ao cargo, de forma que acaba se profissionalizando como conselheiro. E como para tanto deve ter um nível de educação e de renda superior à média da comunidade, os representantes dos usuários terminam se constituindo em uma elite profissional reforçada por certos privilégios de status como indicação sistemática como delegado a conferências e outras representações, acesso direto a políticos, facilidades para receber atenção nos serviços de saúde e/ou encaminhar parentes ou conhecidos, etc (LABRA, 2006, p.216).
\end{abstract}

Com relação às atividades exercidas pelos Conselheiros, Cotta et al. (2009) aponta que alguns dos membros do Conselho sequer sabem o seu papel e quais seriam as funções do Conselho de Saúde. Ainda segundo os autores, os conselheiros desconhecem o Plano Municipal de Saúde do município, documento este fundamental para as atividades e programações do Conselho, conforme determinação de lei 8.080/90. Labra (2006) explica que este fato é decorrente do entendimento predominante por parte dos membros do Conselho de que este é um espaço para reivindicação e denúncias. Esse fator toma grande parte do tempo da reunião mensal 
que se concentra na discussão de assuntos internos e desconsidera o debate de assuntos mais estruturantes para a saúde pública local.

A respeito das condições estruturais dos Conselhos de Saúde, Labra (2006) elenca problemas na infraestrutura, comunicação, apoio financeiro e secretarial, afirmando que estes fatores contribuem para a piora do seu funcionamento e abstinência dos membros do Conselho. Sem embargo, outros fatores externos podem influenciar no funcionamento problemático do Conselho, como a elite política local, que pode interferir na ação dos membros do Conselho, coibindo a sua força de expressão (LABRA, 2005; NAVARRETE et al., 2003; CORREIA, 2005; OLIVEIRA \& GUSMÃO, 2004).

O relacionamento do Conselho com as Comissões de Intergestores Bipartite (CIB) também é um entrave ao seu funcionamento. Segundo Labra (2006) a CIB que deveria apoiar a elaboração de propostas para implantação e operacionalização do SUS e submeter ao poder deliberativo e fiscalizador do Conselho Nacional de Saúde e dos Conselhos Estaduais de Saúde acabam por sobrepor os Conselhos Estaduais ao deliberar sobre assuntos que não lhes são atribuídos.

Há também uma baixa adesão da população local aos Conselhos, fato decorrente do desconhecimento das atividades, funções e relevância do Conselho de Saúde. Sobre essa ausência de publicidade das atividades do Conselho, Labra (2006) aponta que grande parte dos Conselhos não realizam a divulgação ampla das suas atividades ou iniciativas no tocante aos programas de saúde, e quando as realizam, limitam-se aos estabelecimentos de saúde em fixação de quadro de notícias.

Como resultante dessas práticas, obtêm-se Conselhos de Saúde que teoricamente representariam um avanço na instituição democrática, mas que na prática estão longe da atuação responsiva às demandas da população e da melhoria das práticas de cidadania, participação e controle social (MARTINS, 2008). Wendhausen et al. (2006), reforçam essa constatação afirmando que diferentemente da expectativa quanto ao funcionamento democrático e representativo dos Conselhos de Saúde, o que se encontra nesses espaços são práticas de manipulação, clientelismo, troca de favores, cooptação e demais práticas não condizentes com uma esfera de participação social. Segundo Labra (2006, p.218) a existência do sigilo, despotismo burocrático, relações clientelistas e prebendarias, desrespeito pela respública só agravam ainda mais o bom funcionamento dos colegiados. Labra (2006) explica ainda que essa dissonância existente entre a atuação dos Conselhos de 
Saúde sob o ponto de vista do seu dever ser teórico e do que de fato o são na prática é proveniente do descompasso entre o processo de adesão formal dos princípios republicanos pelos governantes e seus valores difundidos na sociedade brasileira.

Muito embora haja adesão dos princípios democráticos expressa na Constituição de 1988, os valores democráticos ainda não estão bem consolidados na sociedade brasileira. Segundo a autora, a democracia brasileira ainda é muito jovem, e vem desenvolvendo lentamente os valores de participação social e confiança. Labra (2006, p.219) argumenta que

as células do mundo associativo sofrem o impacto do déficit mais geral da
sociedade brasileira de atributos próprios de "comunidades cívicas" [...] por
uma parte, na sociedade brasileira haveria escasso capital social - ou seja,
relações de confiança, solidariedade e cooperação disseminadas- e,
portanto, escassez de ingredientes indispensáveis para os CS se
constituírem em efetivos canais de democratização das decisões e de
controle social.

Os baixos índices de participação dos brasileiros na vida associativa refletem essa apatia da população com relação à participação social, bem como a descrença na eficácia da participação e do engajamento cívico. Dentre os agravantes dessa situação, Labra (2006) aponta como principais fatores a desigualdade social existente e a fragilidade dos valores políticos que aumentam a desconfiança social sobre o funcionamento da democracia e das instituições. 


\subsection{APLICAÇÕES DA EFICIÊNCIA EM SAÚDE PÚBLICA}

Nos últimos anos a literatura nacional sobre eficiência em saúde pública se concentrou na avaliação da eficiência hospitalar, adotando como variáveis de entrada os recursos disponíveis para produção de bens e serviços de saúde, e como variáveis de saída os serviços e ações gerados, como por exemplo número de procedimentos médicos realizados. O detalhamento desses estudos está apresentado na Tabela 5.

Tabela 5. Principais estudos nacionais sobre eficiência hospitalar

\begin{tabular}{|c|c|c|c|}
\hline Autor & Método & Variáveis de insumo & Variáveis de produto \\
\hline \multirow{3}{*}{ Marinho (2001) } & \multirow{3}{*}{ DEA } & № de pacientes internados; & № de leitos \\
\hline & & № de pacientes ambulatoriais; & № de médicos, \\
\hline & & № de pacientes atendidos & $\begin{array}{l}\text { № de outros profissionais de } \\
\text { saúde }\end{array}$ \\
\hline \multirow{5}{*}{ Marinho (2003) } & \multirow{5}{*}{$\begin{array}{l}\text { DEA e Regressão } \\
\text { tipo tobit }\end{array}$} & $\begin{array}{l}\text { Total de leitos contratados em } \\
\text { hospitais per capita; }\end{array}$ & $\begin{array}{l}\text { Total de internações em hospitais } \\
\text { credenciados per capita; }\end{array}$ \\
\hline & & $\begin{array}{l}\text { Total de hospitais credenciados } \\
\text { per capita; }\end{array}$ & $\begin{array}{l}\text { Total de procedimentos } \\
\text { ambulatoriais per capita }\end{array}$ \\
\hline & & $\begin{array}{l}\text { Total da capacidade ambulatorial } \\
\text { instalada per capita; }\end{array}$ & Taxa de mortalidade \\
\hline & & Valor médio da internação; & \\
\hline & & $\begin{array}{l}\text { Valor médio dos procedimentos } \\
\text { ambulatoriais }\end{array}$ & \\
\hline \multirow{6}{*}{$\begin{array}{l}\text { Proite \& Sousa } \\
(2004)\end{array}$} & \multirow{6}{*}{$\begin{array}{l}\text { DEA, Bootstrap, } \\
\text { Jackknife e } \\
\text { regressão quantílica }\end{array}$} & $\begin{array}{l}\text { № de agentes de saúde, } \\
\text { auxiliares e técnicos }\end{array}$ & $\begin{array}{l}\text { Total de procedimentos não } \\
\text { cirúrgicos realizados; }\end{array}$ \\
\hline & & $\begin{array}{l}\text { № de Enfermeiros, Médicos e } \\
\text { Dentistas, }\end{array}$ & $\begin{array}{l}\text { Total de procedimentos cirúrgicos } \\
\text { realizados }\end{array}$ \\
\hline & & $\begin{array}{l}\text { № de Profissionais de nível } \\
\text { médio e superior; }\end{array}$ & \\
\hline & & $\begin{array}{l}\text { Valor médio total dos serviços } \\
\text { prestados; }\end{array}$ & Inverso do № de óbitos \\
\hline & & $\begin{array}{l}\text { Permanência média dos } \\
\text { procedimentos não cirúrgicos }\end{array}$ & \\
\hline & & $\begin{array}{l}\text { Permanência média relativa às } \\
\text { cirurgias }\end{array}$ & \\
\hline \multirow{5}{*}{$\begin{array}{l}\text { Lins et al. } \\
(2007)\end{array}$} & \multirow{5}{*}{ DEA } & № de funcionários não médicos & $\begin{array}{l}\text { SIPAC (Índice de Alta } \\
\text { Complexidade) }\end{array}$ \\
\hline & & № de médicos & Relação internações/leito \\
\hline & & $\begin{array}{l}\text { Receita média mensal } \\
\text { proveniente do SUS }\end{array}$ & Relação cirurgias/sala \\
\hline & & № total de docentes & $\begin{array}{l}\text { Relação consultas } \\
\text { ambulatoriais/sala }\end{array}$ \\
\hline & & № de docentes com doutorado & $\begin{array}{l}\text { № de alunos de medicina } \\
\text { (graduação) }\end{array}$ \\
\hline
\end{tabular}




\begin{tabular}{|c|c|c|c|}
\hline & & & $\begin{array}{l}\text { № de residentes médicos } \\
\text { № de mestrandos e doutorandos } \\
\text { № de programas de pós- } \\
\text { graduação/medicina }\end{array}$ \\
\hline \multirow{4}{*}{$\begin{array}{l}\text { Gonçalves et } \\
\text { al. (2007) }\end{array}$} & \multirow{4}{*}{ DEA } & Taxa de mortalidade & \% de internação de neoplasias; \\
\hline & & \multirow{3}{*}{$\begin{array}{l}\text { Tempo médio de permanência no } \\
\text { hospital }\end{array}$} & $\begin{array}{l}\text { \% de internação de doenças } \\
\text { infecciosas e parasitárias; }\end{array}$ \\
\hline & & & $\begin{array}{l}\text { \% de internação de doenças do } \\
\text { aparelho circulatório; }\end{array}$ \\
\hline & & & $\begin{array}{l}\text { Valor médio pago pela Autorização } \\
\text { de Internação Hospitalar }\end{array}$ \\
\hline \multirow{3}{*}{$\begin{array}{l}\text { Cesconetto et } \\
\text { al. (2008) }\end{array}$} & \multirow{3}{*}{ DEA } & $\begin{array}{l}\text { № de profissionais por } \\
\text { estabelecimento de saúde }\end{array}$ & \multirow{3}{*}{ № total de altas } \\
\hline & & № de leitos conveniados ao SUS & \\
\hline & & $\begin{array}{l}\text { Valor total pago pela Autorização } \\
\text { de Internação Hospitalar }\end{array}$ & \\
\hline \multirow{4}{*}{$\begin{array}{l}\text { Souza et al. } \\
(2010)\end{array}$} & \multirow{4}{*}{$\begin{array}{l}\text { Fronteira } \\
\text { estocástica de } \\
\text { produção (FE) }\end{array}$} & $\begin{array}{l}\text { Variáveis utilizadas na função de } \\
\text { produção: }\end{array}$ & \multirow{4}{*}{$\mathrm{N} / \mathrm{A}$} \\
\hline & & Taxa de sobrevivência & \\
\hline & & $\begin{array}{l}\text { Gastos com profissionais ligados } \\
\text { diretamente às internações }\end{array}$ & \\
\hline & & № de leitos total & \\
\hline
\end{tabular}

Fonte: Elaboração própria

Em relação ao gasto público em saúde, grande parte dos estudos nacionais avaliaram o uso dos recursos públicos municipais. Faria et al. (2008) avaliaram não só os gastos em saúde, mas também os gastos em educação municipal dos municípios fluminenses entre 1999 e 2000, adotando o método de Análise Envoltória de Dados (DEA) orientado à produtos. Nesse estudo considerou-se a despesa per capita com saúde como única variável de entrada e as variáveis relacionadas com saneamento, alfabetização, esgotamento e rendimento familiar como múltiplas variáveis de saída. Os autores concluíram que a eficiência não está relacionada à disponibilidade maior ou menor de recursos por parte dos municípios, ou seja, municípios pobres podem ser eficientes nos gastos em educação e saúde, enquanto municípios mais ricos podem ser ineficientes.

No estudo de Trompieri Neto et al. (2009), foi utilizado o método DEA combinado com o modelo de regressão com variável dependente censurada (Tobit) para avaliar a eficiência dos gastos públicos em saúde e educação dos municípios cearenses (TROMPIERI-NETO; BARBOSA; HOLANDA, 2009). Neste caso também 
foi adotada uma única variável de entrada, gasto com saúde per capita e múltiplas variáveis de saída: i) número de unidades de saúde per capita; ii) número de profissionais de saúde com nível superior per capita; iii) número de agentes comunitários de saúde per capita e iv) taxa de cobertura do Programa Saúde da Família (PSF). Como resultado do estudo, observou-se que há uma relação positiva entre o Índice de Desenvolvimento Humano (IDH) e a eficiência municipal, onde o aumento de $1 \%$ do IDH gera aumento de $0,94 \%$ no índice de eficiência. Além disso, o estudo apontou que os municípios eficientes em transformar insumo em resultado não necessariamente são eficientes na transformação de insumos em produtos. Os autores explicam que este resultado decorre de falhas de gestão que geram subutilização dos produtos e mau planejamento.

Mais recentemente Benegas \& Silva (2014) avaliaram a eficiência técnica do gasto público em saúde das Unidades Federativas (UFs) em três estágios: Análise de Componentes Principais (ACP) e o Coeficiente de Determinação Generalizado de Yanai para seleção das variáveis; estimação da eficiência das UFs utilizando DEA e insumos não-discricionários para correção de superestimação de eficiência municipal (BENEGAS; SILVA, 2014). No estudo, os insumos não-discricionários foram considerados para captar o efeito das características socioeconômicas da população sobre os serviços de saúde. As variáveis consideradas como insumos nãodiscricionários pelo estudo foram: população; área; densidade demográfica; razão dos sexos; grau de urbanização; população idosa; taxa de analfabetismo; escolaridade < $=1$ ano de estudo; Escolaridade < 1 <anos de estudo $\leq 3 \%$; escolaridade $4 \leq$ anos de estudo< 7; escolaridade: 7 sanos de estudo; e proporção de Pobres. Para a estimação da eficiência foi adotado o gasto público em saúde per capita como única variável de entrada e como saída as variáveis: esperança de vida, taxa de sobrevida infantil, inverso da taxa de mortalidade infantil, número de médicos por mil habitantes, número de leitos por mil habitantes, cobertura vacinal, cobertura de esgotamento sanitário e de coleta de lixo. Os autores observaram que dentre os insumos não-discricionários, o tamanho populacional das UFs foi a única variável que gerou alterações nos resultados de eficiência, provocando maior eficiência na oferta de saúde pública. Além disso, foram identificados como indicadores determinantes para a melhoria na eficiência técnica a esperança de vida para ambos os sexos, número de leitos por mil habitantes, cobertura da vacina tetravalente (preventiva contra difteria, coqueluche, 
tétano e meningite), cobertura da vacina BCG (preventiva contra tuberculose) e cobertura de esgotamento sanitário.

Mazon et al. (2015) avaliaram eficiência técnica da utilização de recursos do

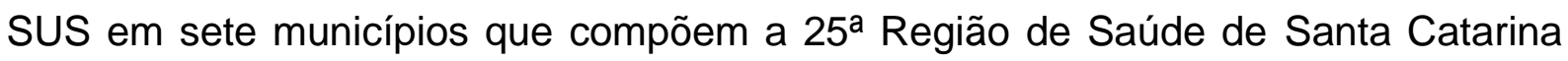
(SC) com o método DEA e o Índice de Eficiência Técnica em Saúde (IETS) (MAZON; MASCARENHAS; DALLABRIDA, 2015). Para tanto, foram consideradas múltiplas variáveis de entrada: gasto per capita do SUS com recursos municipais; transferência federal SUS per capita; equipes de estratégia saúde da família por mil habitantes; leitos hospitalares por mil habitantes; médicos por mil habitantes e enfermeiros por mil habitantes; e múltiplas variáveis de saída: taxa de mortalidade geral por mil habitantes; mortalidade infantil por mil nascidos vivos; taxa de óbitos por doenças do aparelho circulatório, por causas externas, por diabetes mellitus e por doenças transmissíveis por cem mil habitantes. Como resultados os autores verificaram que apesar da região investir percentuais de sua receita em saúde superior às médias do estado, os indicadores de mortalidade não sofrem redução.

Sobre avaliação de eficiência em municípios, Sousa e Stosic (2005) ressaltam que métodos não-paramétricos são seriamente afetados pela presença de outliers e erros de dados que podem gerar uma subestimação dos escores totais de eficiência. No caso da mensuração da eficiência técnica municipal no Brasil, essas distorções são causadas principalmente pela própria configuração do federalismo brasileiro composto por uma grande quantidade de municípios, de diferentes dimensões e características socioeconômicas extremamente heterogênea - e pelos erros de medição e omissão de variáveis presentes na base de dados disponível.

Em um estudo sobre avaliação do gasto público em saúde e educação nos municípios brasileiros, Santos et al. (2007) realizou uma análise sobre os fatores determinantes para a eficiência. Dentre os fatores exógenos que podem influenciar em até $50 \%$ os resultados e gerar superestimação de eficiência está a localização do município. Este fator foi analisado sob dois aspectos: um chamado de "efeito vizinhança" que exerce efeito positivo na eficiência e o outro na localização de Polígono das secas que exerce efeito negativo na eficiência dos municípios. Outro ponto observado foi a relação existente entre qualidade de serviços públicos e as variáveis grau de informatização do município e poder dos conselhos municipais. Os autores explicam que os conselhos fiscalizam a aplicação dos recursos, diminuindo a 
corrupção e o abuso na distribuição de verbas, e o uso de recursos computacionais agiliza processos e diminui custos.

Além disso, os municípios que recebem royalties apresentam em média $15,26 \%$ a menos de eficiência do que os que não recebem. Santos et al. (2007) argumentam que esses municípios não conseguem canalizar os recursos para melhoria dos serviços públicos. Por fim, os autores analisaram a relação entre a eficiência e a idade do município, que se apresentaram proporcionais, ou seja, quanto menor a idade do município pior a eficiência do gasto público. Este resultado é decorrente da ausência de estrutura administrativa e de experiência de gestão, características típicas de municípios jovens.

Almeida e Gasparini (2012) analisaram a relação entre a descentralização fiscal e o desempenho dos serviços de saúde pública no Brasil utilizando o índice de Malmquist e dados de painel. Como resultado o estudo demonstrou que a descentralização de recursos para a saúde está negativamente relacionada com a produtividade desses serviços. Campos (1998) explica que os estados e municípios, em sua grande parte, não possuem capacidade de gestão e recursos técnicos suficientes para conseguir prestar serviços de saúde com a qualidade esperada.

No âmbito internacional, as pesquisas sobre avaliação de desempenho em saúde tiveram início com o trabalho de Evans et al. (2000) que avaliaram os 191 países membros da OCDE, utilizando como método o DEA (EVANS et al., 2000). Foram consideradas como variáveis de entrada os gastos totais com saúde e a escolaridade média da população adulta; e como variáveis de saída apenas a variável expectativa de vida ajustada. Este estudo sofreu várias críticas com relação ao alcance da mensuração e a validade dos resultados (NAVARRO, 2000; WILLIAMS, 2001; GREENE et al., 2004). Apesar disto, o estudo representou um marco para o início do debate científico sobre o desempenho dos sistemas de saúde.

Em revisão da literatura internacional sobre eficiência em saúde, Hollingsworth (2008) avaliou 317 artigos sobre eficiência em saúde e identificou que $48 \%$ dos trabalhos aplicaram a metodologia DEA como método de avaliação da eficiência em saúde (HOLLINGSWORTH, 2008). Hussey et al. (2009) revisaram os métodos de avaliação da eficiência em saúde e identificaram que os métodos mais utilizados na mensuração de eficiência foram a Análise da Fronteira Estocástica (SFA) e Análise Envoltória de Dados (DEA). Nesses estudos, quase todos os trabalhos utilizaram 
como variável de saída serviços de saúde e variáveis de entrada, os recursos físicos disponíveis e os custos de produção.

Gupta et al. (2001) avaliou a eficiência dos gastos públicos em saúde e educação em 37 países da África em comparação com países da Ásia e do ocidente utilizando o método FDH (Free Disposal Hull) (GUPTA; VERHOEVEN, 2001). Os resultados mostraram que o grau de ineficiência e os níveis de gasto do governo são proporcionais, ou seja, quanto maior o gasto público em educação e saúde, maior a ineficiência. Desta forma, os autores sugerem que a ação do governo seja centrada na correção das ineficiências dos gastos públicos e propõem que haja cautela na expansão dos gastos públicos quando este já é elevado.

Afonso \& Aubyn (2005) também avaliaram a eficiência dos países membros da OECD, porém com foco em dois setores: educação e saúde (AFONSO; AUBYN, 2005). Para tanto utilizaram dois métodos não paramétricos: FDH e DEA. Como variáveis adotadas pelo estudo utilizando o método DEA estão o número de médicos, enfermeiras e leitos disponíveis como insumos e a expectativa de vida e taxa de sobrevivência infantil como produto. O estudo conclui que é possível que os países menos eficientes alcancem os mesmos resultados minimizando o uso de insumos.

Pang e Herrera (2005) estimam a eficiência dos gastos para saúde e educação em dois estágios. Como resultados da pesquisa, não foi encontrada nenhuma significância estatística das variáveis institucionais com a eficiência, enfraquecendo a hipótese de que instituições menos corruptas e mais transparentes são mais eficientes (HERRERA; PANG, 2005). Porém, foram encontradas evidências que corroboram os resultados encontrados por Gupta et al. (2001) em que países com níveis mais altos de gasto público em saúde e educação possuem os piores índices de eficiência (GUPTA; VERHOEVEN, 2001). Esse comportamento pode ser observado também quando há folha salarial ou financiamento público maior do que o gasto total do país. Além disso, foram identificadas como negativamente associadas à eficiência as variáveis: incidência de HIV/AIDs, distribuição de renda, razão de dependência de ajuda externa. Apenas a variável taxa de urbanização apresentou associação positiva com a eficiência.

Dentre as iniciativas voltadas para a avaliação de desempenho do SUS está o Índice de Desempenho do SUS - IDSUS apresentado em 2010 como ferramenta de mensuração do desempenho do SUS com relação aos seus princípios e diretrizes (MÉDICI, 2012). Embora o estudo tenha sido realizado apenas para o ano de 2010, o 
índice despertou a atenção tanto dos gestores locais quanto federais com relação à qualidade e eficiência na prestação dos serviços de saúde. O IDSUS foi construído com base no modelo de avaliação proposto por Viacava et al (2004) que desenvolveu uma matriz de dimensões de avaliação de desempenho considerando variáveis diretamente relacionadas à saúde, variáveis socioeconômicas e ambientais (VIACAVA et al., 2004).

Essa iniciativa teve como origem o Relatório Mundial de Saúde publicado em 2000 pela Organização Mundial de Saúde (OMS), que avaliou o desempenho dos sistemas de saúde dos seus 191 países membros, com base em um índice composto por uma média ponderada de três metas intrínsecas do sistema de saúde : melhoria da saúde da população mensurada pelo DALE (disability-adjusted life expectancy at birth), responsividade do sistema de saúde que mensura por aspectos não-médicos da provisão de serviços e garantia da distribuição justa dos encargos financeiros da saúde (TRAVASSOS; BUSS, 2000).

Apesar de ter recebido muitas críticas relacionadas ao processo de desenvolvimento do índice composto (UGÁ et al., 2001), o relatório desencadeou o desenvolvimento de diversos estudos relacionados ao desempenho de sistemas de saúde, bem como estudos avaliando a eficiência desses sistemas. Dentre os tipos de estimação da eficiência, Tandon et al (2003) identificou dois tipos principais: estimação da eficiência em nível micro e nível macro. No nível micro, a eficiência é determinada pelo conjunto de intervenções que ocorrem no sistema de saúde que são capazes de maximizar o output dado os inputs disponíveis. Neste nível, a eficiência está relacionada às intervenções do sistema de saúde, sejam elas programas ou ações de saúde. Sob este aspecto foram desenvolvidos diversos modelos de mensuração da eficiência baseados no custo-benefício da intervenção (HARTZ, 1997, CHEN, 1990; CONTANDRIOUPOLOS, 1990, CHAMPAGNE, 1984).

Com relação ao nível macro de estimação da eficiência, esta é dada tanto pela fronteira determinística quanto pela fronteira estocástica. Existe um consenso na literatura de que, dada a natureza dos dados, os métodos de estimação de fronteira estocástica são preferíveis aos métodos de determinísticos para a avaliação da eficiência de sistemas de saúde (EVANS et al., 2003). Na fronteira determinística, todos os pontos observados são considerados abaixo da linha da eficiência e todos os desvios da fronteira são considerados como ineficientes. 
No caso da fronteira estocástica, alguns desvios são atribuídos a fatores aleatórios. Nesse caso, um sistema de saúde pode ser entendido como uma unidade produtiva que pode ser mensurado em termos de saúde ou em termos de indicadores compostos de produção.

\subsection{DESAFIOS DO SUS}

No decurso das últimas duas décadas, o SUS se consolidou como a maior política de Estado do País, capaz de promover a inclusão e justiça social (PAIM, 2008). Por meio da estratégia do programa Saúde da Família, o SUS ampliou a cobertura de vacinação, a assistência pré-natal, a redução da mortalidade infantil pós-neonatal, e gerou melhorias nos indicadores epidemiológicos. Desta forma foi possível reduzir as mortes por doenças transmissíveis, como tuberculose, hanseníase, malária e Aids (CONASS, 2011).

No contexto mundial, o SUS realiza, em números absolutos, o segundo maior número de transplantes ao ano e possui um dos mais respeitados programas de redução da incidência e promoção da qualidade de vida das pessoas portadoras de HIV/Aids, o Programa Nacional de Doenças Sexualmente Transmissíveis e Aids (PNDST/Aids) (PAIM et al., 2011).

Contudo, o SUS é um sistema de saúde em contínuo desenvolvimento que precisa se ajustar às novas demandas sociais de saúde. No seu âmbito interno, ele enfrenta alguns entraves para o seu funcionamento como: a fragmentação dos sistema que gera falta de acesso, descontinuidade dos serviços e incongruência entre oferta e serviços de saúde; e o subfinanciamento que acarreta em distorções na oferta de serviços de saúde.

No SUS, a fragmentação dos serviços traz consequências na redução da cobertura de ações e serviços de saúde, gera seleção adversa de pacientes por parte dos provedores e de procedimentos por parte dos assegurados, ausência de coordenação entre os mecanismos de promoção, prevenção atenção médica e reabilitação, bem como custos elevados para o Estado (MÉDICI, 2014).

No seu contexto externo, o SUS enfrenta o desafio de acompanhar as demandas de saúde geradas pelas transições demográficas e epidemiológicas e principalmente de implementar políticas sociais de saúde de abrangência nacional no federalismo brasileiro. Segundo Arretche (2004) a diversidade socioeconômica e 
cultural dos estados brasileiros se reflete também nas diferentes necessidades de saúde e perfil epidemiológico de cada região que deverão ser consideradas ao se elaborar e implementar políticas de saúde.

Conforme ressalta Baer (2009), essas desigualdades regionais se refletem nas estatísticas de saúde que em regiões como sudeste e sul apresentam níveis similares à de países desenvolvidos com predomínio em doenças crônicas e nas regiões norte e nordeste apresentam padrões de saúde similares àqueles encontrados nos países subdesenvolvidos com predomínio de doenças infecciosas e parasitárias. Devido à tamanha diversidade regional, há heterogeneidade tanto de necessidades de saúde de determinada população quanto de tipos de ações e serviços para atender as necessidades de saúde (LIMA et al., 2012).

Médici (2014) observa ainda que não há uma estratégia por parte do modelo de atenção à saúde do brasil que consigam promover, prevenir e detectar doenças crônicas de maneira precoce e oportuna. Em decorrência disto surge a demanda por ações de saúde capazes de suprir as necessidades do cenário atual de maneira mais eficiente e menos fragmentada com soluções mais sistêmicas nas ações de saúde.

\subsection{AS REDES DE ATENÇÃO À SAÚDE}

O cenário de baixo desempenho dos sistemas de saúde é explicado pela OPAS (2007) como reflexo da fragmentação dos serviços de saúde que se apresenta na baixa qualidade dos serviços prestados, dificuldade no acesso aos serviços, uso irracional e ineficiente de recursos disponíveis no sistema de saúde, custos desnecessários de produção e consequente baixa satisfação dos usuários. Além desses fatores, o subfinanciamento do sistema, a baixa qualificação de mão de obra e fraca atuação da autoridade sanitária agravam ainda mais o desempenho do sistema. Como alternativa de superação desse cenário, surge a proposta de integração dos serviços de saúde em formato de Redes de Atenção à Saúde.

Apesar da proposição de integração dos sistemas de saúde em rede parecer nova, essa configuração foi idealizada em 1920 como proposta de reforma do sistema de saúde britânico pós Segunda Guerra Mundial. Nessa proposta conhecida como Relatório de Dawson constam os primeiros conceitos relacionados aos serviços de atenção à saúde coordenados e integrados pela Atenção Primária à Saúde (APS). 0 Relatório propunha a delimitação da população a um território de modo a definir a 
oferta de serviços de acordo com as necessidades daquela população específica, a APS como porta de entrada dos serviços de saúde, a atuação central do clínico geral no sistema e a busca pela integração entre a medicina preventiva e curativa.

Apesar de ter inspirado a sua construção no Relatório de Dawson, as Redes de Atenção à Saúde foram estruturadas nos anos 90 sob a concepção de sistemas de saúde integrados dos Estados Unidos. Neste contexto, o conceito de redes foi definido por Shortell et al. (1994, p.47) como "uma rede de organizações que fornece ou se organiza para fornecer uma rede de serviços contínuos e coordenados para uma população definida; e está disposta a se responsabilizar clinicamente e fiscalmente pelos resultados e pelo nível de saúde da população atendida".

A Organização Mundial de Saúde (OMS) a definiu como "a organização e a gestão dos serviços de saúde onde as pessoas podem receber os serviços que precisam, quando precisam e de maneira facilitada, alcançando os resultados desejados" (WHO, 2008; 1; tradução do autor). A Organização Pan-americana de saúde (OPAS), segue na mesma linha, considerando as redes de saúde como

\footnotetext{
Rede de organizações que presta, ou faz arranjos para prestar, serviços de saúde equitativos e integrais a uma população definida e que está disposta a prestar contas por seus resultados clínicos e econômicos e pelo estado de saúde da população a que serve (OPAS, 2010; 9, tradução do autor).
}

A implementação das Redes de saúde pelo mundo decorreu da crise dos sistemas de saúde dos anos 80, que levaram vários países a iniciarem reformas no seus sistema de saúde (ALMEIDA, 1995). Na Europa, foram relatadas experiências de sistemas de saúde integrados na Alemanha (HILDEBRANT e RIPPMAN; 2001), no Reino Unido (HAM, 2007); França (MICALEFF, 2000) e na Espanha que, ainda que tardiamente, também adotou a integração do sistema em rede (SUÑOL et al.,1999; FERNANDEZ, 2004; PERAY, 2003; VASQUEZ et al., 2005; VARGAS et al., 2007; BENGOA, 2008).

$\mathrm{Na}$ América do Norte as experiências de implementação se concentram no Canadá (LEAT ET AL, 1996; CHAMPAGNE, 2003; GIRARD, 1999; MARCHILDON, 2005). Na América latina, foram identificadas algumas iniciativas de integração de sistemas de saúde em rede na Argentina, Bolívia, Chile, Peru, República Dominicana, Uruguai e Venezuela (WHO, 2011).

Diversos estudos identificaram que estas experiências de integração do sistema de saúde em rede resultaram em melhorias no custo-efetividade dos serviços 
de saúde (MCINNES \& MCGHEE, 1995; BERNABEl et al. 1998; SIMON et al. 2001; WAGNER et al. 2000), dos indicadores epidemiológicos (WEINGARTEN et al., 1985; OSMAN et al., 1996) e da satisfação dos serviços de saúde prestados (MCCULLOCH et al.,1998; REUBEN et al. 1999; WAGNER et al. 1999).

No Brasil, esse conceito de redes integradas de saúde já estava previsto desde a Constituição Federal de 1988, em seu art.198:

As ações e os serviços públicos de saúde integram uma rede regionalizada e hierarquizada e constituem um sistema único organizado de acordo com as diretrizes de descentralização, atendimento integral e participação da comunidade

A Lei 8.080 de 1990 que dispôs sobre a organização e funcionamento do SUS reforçou a configuração do SUS em redes integradas de saúde no seu art. 7, inciso II que conceitua a integralidade da assistência como um "conjunto articulado e contínuo das ações e serviços preventivos, curativos, individuais e coletivos" e no art. 10 "arranjos organizacionais para as redes loco-regionais através de consórcios intermunicipais e distritos de saúde como forma de integrar e articular recursos e aumentar a cobertura das ações" (BRASIL, 1990).

A organização do SUS para a implementação das redes teve início em 2002 com a publicação da Norma Operacional de Assistência à Saúde - NOAS que ampliou a responsabilidade dos municípios na Atenção Básica, e estabeleceu o processo de regionalização como estratégia de hierarquização dos serviços de saúde. Entretanto, Pestana e Mendes (2004) relatam que a publicação da NOAS além de não ter atingido os resultados esperados, gerou excesso de instrumentos normativos e indefinições tanto com relação ao papel dos estados quanto com relação à alocação dos recursos de saúde.

O Pacto pela Saúde instituído pela Portaria GM/MS № 399, de 22 de fevereiro de 2006 regulamentou as diretrizes operacionais de implementação do Pacto pela Vida e o Pacto de Gestão. Este último responsabilizou cada ente da federação e estabeleceu diretrizes para a gestão do SUS com ênfase na descentralização e regionalização.

O Pacto pela Saúde foi posteriormente substituído pelo Contrato Organizativo da Ação Pública da Saúde (COAP) por meio do Decreto 7.508/2011 que propôs um acordo de vontades entre entes federados para organizar em redes regionalizadas e hierarquizadas ações e serviços de saúde. 
A partir da publicação da Portaria 4.279 de 30 de Dezembro de 2010 pelo Ministério da Saúde, foram estabelecidas as diretrizes para a organização da Rede de Atenção à Saúde no âmbito do SUS, definida como "arranjos organizativos de ações e serviços de saúde, de diferentes densidades tecnológicas, que integradas por meio de sistemas de apoio técnico, logístico e de gestão, buscam garantir a integralidade do cuidado" (BRASIL, 2010; 4).

Dentre os objetivos previstos para a implementação da RAS no SUS está a promoção da integração das ações e serviços de saúde que deverão ser prestados com qualidade, responsabilidade e de maneira contínua, integral e humanizada. Ademais, busca-se o incremento do desempenho do sistema em termos de acesso, equidade, eficácia clínica e sanitária e com eficiência econômica (BRASIL, 2010).

Figura 5. Características do modelo Hierarquizado versus Modelo de Redes de atenção à saúde

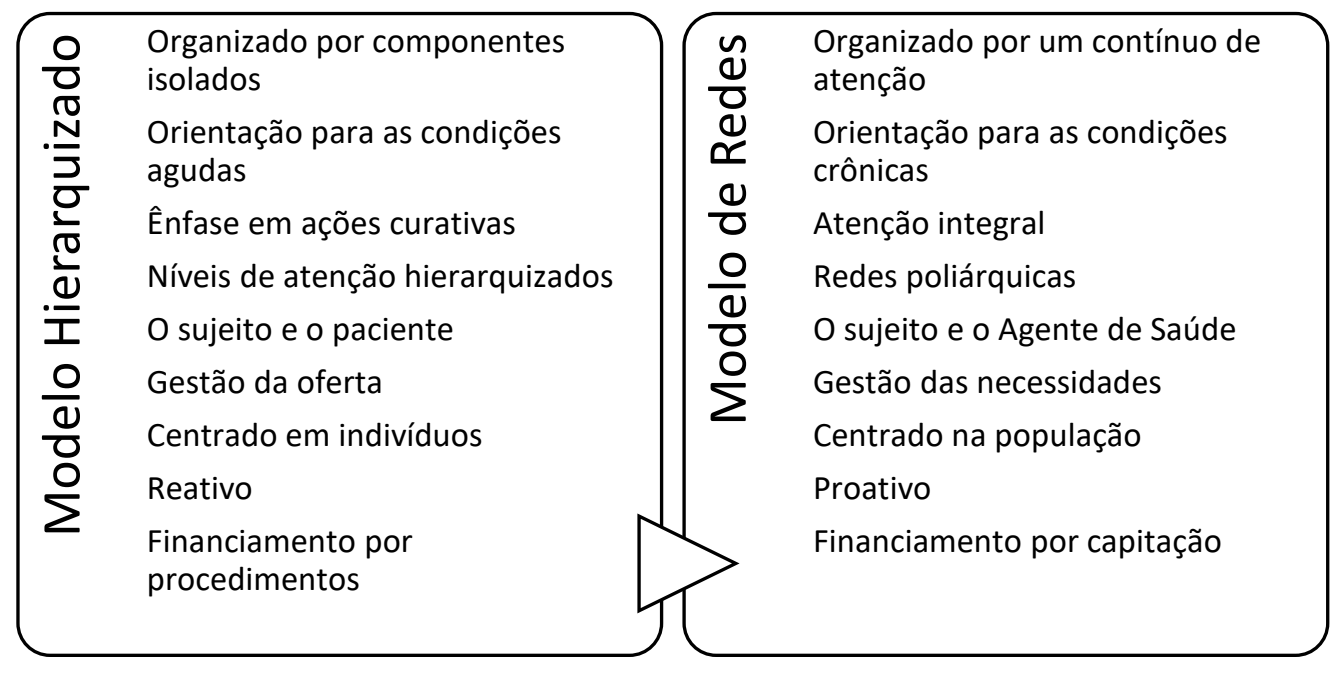

Fonte: Adaptado de Mendes (2011)

Em termos de configuração da rede, esta possui formação de relações horizontais entre os pontos de atenção, considerando a APS como porta de entrada do SUS. A APS atua na coordenação e integração dos fluxos dos usuários, produtos e informações bem como dos outros pontos de atenção à saúde das Redes de Atenção à Saúde (LAVRAS, 2011; MENDES, 2012). Essa primeira característica representa um rompimento das redes com a estrutura hierárquica preestabelecida e define para a APS um papel crítico na rede, conforme apresentado na Figura 8. 
Figura 6. Sistema fragmentado versus Sistema Integrado em Redes
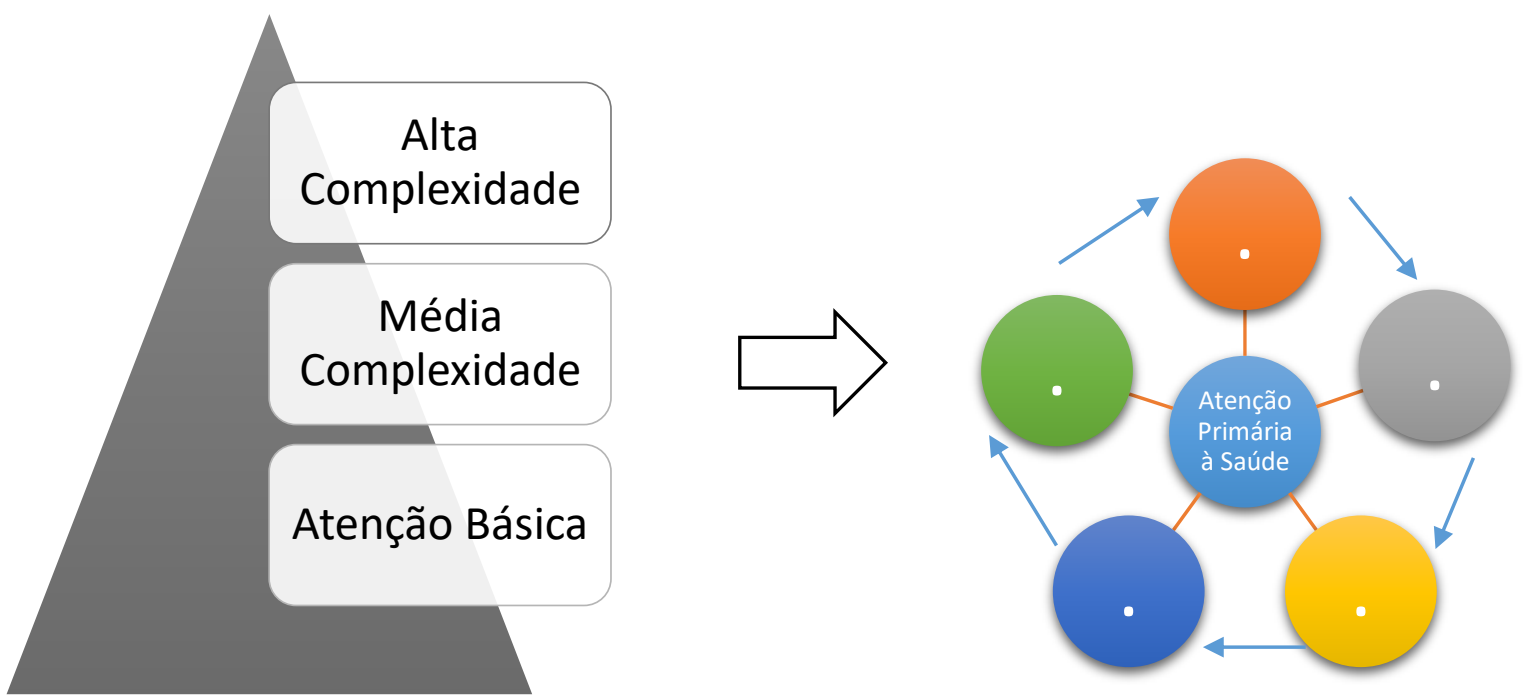

Fonte: Adaptado de Mendes (2011)

Desta forma, o fortalecimento da APS é essencial para o funcionamento efetivo e eficiente das Redes de Atenção à Saúde. Esse fortalecimento depende do alinhamento da estruturação da APS com a participação e controle social do SUS. Nesse contexto, as organizações e movimentos sociais representam papel importante para o exercício do controle social e alinhamento das demandas locais com os serviços prestados, bem como para o alcance dos resultados econômicos e sanitários esperados (MENDES, 2012). Segundo Harzheim (2015, p. 34)

\begin{abstract}
A atenção primária resolutiva é capaz de conduzir à sociedade na definição das necessidades e direitos, incorporando o conceito de empoderamento e capital social. Os cidadãos satisfeitos com os serviços que recebem defenderão o modelo público e aprovarão o financiamento necessário para a manutenção da maior política de inclusão social, que é o Sistema Único de Saúde.
\end{abstract}

Além disso, as RAS são construídas com base na integração vertical e horizontal. A integração vertical ocorre quando há articulação de organizações ou unidades de produção de saúde dos diferentes níveis de complexidade e de esfera administrativa na busca pela gestão única do SUS. A integração horizontal é dada pela articulação ou fusão de unidades e serviços de saúde de mesma natureza ou especialidade de modo a agregar valor para a cadeia produtiva.

Como forma de garantir a resolutividade na rede de atenção, a implementação das RAS no SUS considera os seguintes fundamentos: economia de escala, disponibilidade de recursos, qualidade, suficiência e acesso. Segundo Varian (2004), a 
economia de escala ocorre quando há elevação da produtividade dado o aumento de todos os fatores de produção na mesma proporção. Neste sentido, visando a racionalização dos custos e otimização de resultados, a distribuição de oferta de serviços de saúde na RAS é determinada pela economia de escala de produção relacionada ao serviço.

Desta forma, são concentrados aqueles serviços de saúde que exigem maior densidade tecnológica, possuem maior custo relacionado e onde a distância não impacta no acesso ao serviço. Aqueles com baixa densidade tecnológica, baixo custo relacionado e onde a distância é determinante para o acesso ao serviço - como os serviços de atenção primária - são dispersados na RAS (WHO, 2000).

Da mesma maneira, o grau de disponibilidade de recursos determina a concentração ou dispersão dos recursos na RAS. Assim, quanto maior a escassez do recurso, maior será a sua concentração, e quanto menor, maior será a sua dispersão. O fundamento da qualidade na prestação de serviços de saúde na RAS é composta por seis dimensões: efetividade das ações de saúde; centralidade no respeito ao usuário; pontualidade; eficiência; equidade e segurança nas ações de prevenção e reconhecimento de situações que podem acarretar em danos à saúde (BRASIL, 2010).

A suficiência dos serviços de saúde é entendida como um "conjunto de ações e serviços disponíveis em quantidade e qualidade para atender às necessidades de saúde da população e inclui cuidados primários, secundários, terciários, reabilitação, preventivos e paliativos, realizados com qualidade" (BRASIL, 2010). Desta forma, entende-se que a prestação de serviços deverá ser realizada em quantidade suficiente para o alcance da máxima qualidade.

O acesso é dado pela disponibilidade do serviço que usuário e a sua família necessita; pela comodidade nos serviços de saúde desde o agendamento até o atendimento; e pela aceitabilidade do serviço pelos usuários (BRASIL, 2010).

Além desses fundamentos, para a operacionalização da RAS no SUS, a rede deverá contar com os seguintes elementos constitutivos: população e região de saúde; estrutura operacional e um sistema lógico de funcionamento baseado em um modelo de atenção à saúde.

A população de uma rede é aquela que ocupa uma região de saúde, definida pelo Pacto pela Saúde como um espaço territorial organizado com base nas suas redes de comunicação e infraestrutura de transportes compartilhados do território, bem como pela identidade cultural, econômica e social. Essa população chamada de população 
adscrita é aquela que está sob responsabilidade sanitária e econômica da RAS, ou seja, é a população efetivamente cadastrada na atenção primária à saúde, vivendo em territórios sanitários regulares (MENDES, 2010).

A estrutura operacional da RAS é constituída pelos nós das redes e suas ligações, composta por cinco componentes: centro de comunicação, pontos de atenção secundários e terciários, sistemas de apoio, sistemas logísticos e sistema de governança da rede.

O centro de comunicação é o componente crucial para a existência da rede. Responsável pela entrada dos usuários de serviços de saúde e pela conexão entre os pontos da rede de atenção, o seu papel é realizado pela APS (LAVRAS, 2011).

Os pontos de atenção secundários e terciários são constituídos por unidades de saúde de diferentes complexidades tecnológicas, atuando como apoiadoras da APS. Os sistemas de apoio são comuns a todos os pontos da atenção e são constituídos por sistemas de apoio diagnóstico e terapêutico, sistema de assistência farmacêutica e sistemas de informação em saúde. Já os sistemas logísticos buscam a integração vertical por meio de soluções baseadas em tecnologias da informação, como sistemas de transporte, cartão de identificação dos usuários etc.

O sistema de governança é formado pela ampla participação social de diferentes atores da rede para a gestão do centro de comunicação, dos pontos de atenção secundários e terciários, dos sistemas de apoio e dos sistemas logísticos na busca por maior interdependência entre os atores e melhores resultados sanitários e econômicos para a população adscrita (MENDES, 2011). O modelo de atenção à saúde é

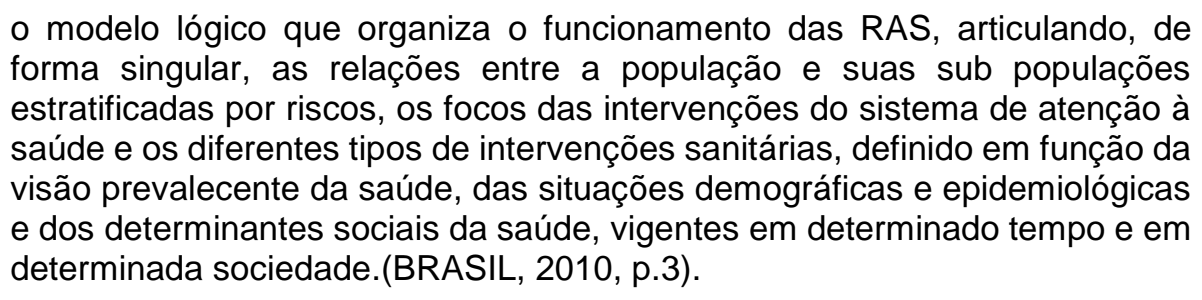

Assim, o modelo de atenção à saúde é adotado conforme o contexto epidemiológico da região de saúde onde se insere a rede, cabendo ao gestor municipal ou estadual a adoção do modelo lógico capaz de atender às demandas de saúde dessa população.

Como estratégia de implementação das RAS foram criadas as Redes Temáticas que consistem em um conjunto de iniciativas de serviços integrados de 
saúde. Em 2011 foi pactuado junto à Comissão Intergestora Tripartite (CIT) a priorização de cinco Redes Temáticas:

- Rede de Atenção às Urgências e Emergências (RUE): tem como finalidade articular e integrar o acesso humanizado e integral aos usuários em situação de urgência nos serviços de saúde, de forma ágil e oportuna.

- Rede de Atenção Psicossocial (Raps): prioriza o enfrentamento do Álcool, Crack, e outras Drogas;

- Rede de Atenção às Doenças e Condições Crônicas (RPDC): possui foco na prevenção e controle do câncer, com ênfase no câncer de mama e colo do útero

- Rede de Cuidado à Pessoa com Deficiência (RCPD): visa garantir a atenção integral às pessoas com deficiência física, visual, auditiva, intelectual, ostomia e múltiplas deficiências.

- Rede Cegonha $(\mathrm{RC})$ : visa assegurar às mulheres o direito ao planejamento reprodutivo e à atenção humanizada à gravidez, ao parto e ao puerpério; e às crianças o direito ao nascimento seguro e ao crescimento e desenvolvimento saudáveis. 
Figura 7. Estrutura operacional das Redes de Atenção à Saúde

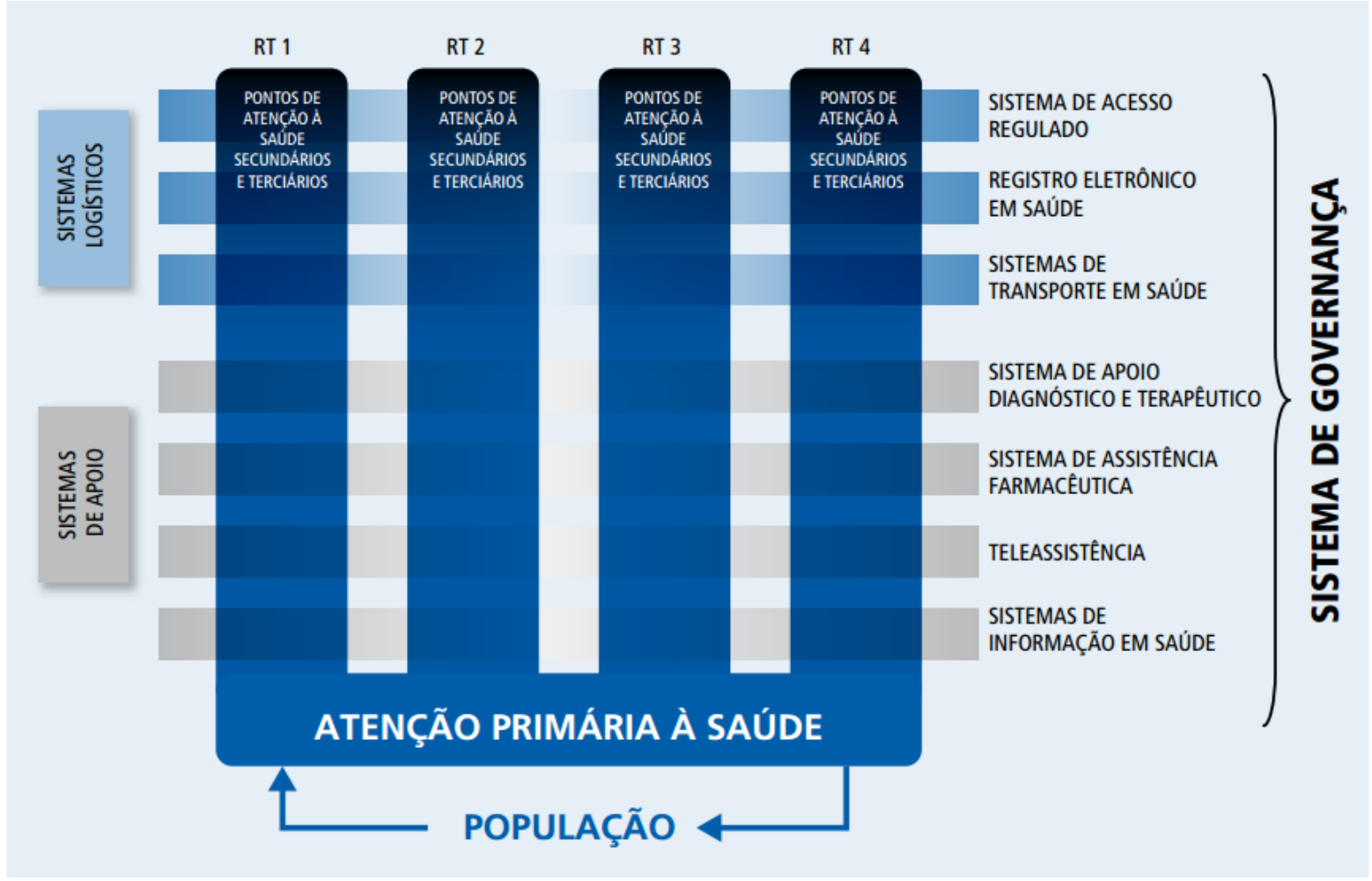

Fonte: Mendes (2012) ${ }^{3}$.

A respeito dos resultados esperados das Redes de Atenção à Saúde, Silva (2011, p. 2756) afirma que

Quanto à otimização dos recursos, as redes de atenção à saúde têm sido consideradas um importante fator de racionalização de gastos e melhor aproveitamento da oferta assistencial disponível. Em sistemas com essa organização, os recursos podem ser mais bem aproveitados desde que sejam aperfeiçoados os mecanismos de incorporação tecnológica e de acesso dos usuários aos diferentes serviços.

Segundo Mendes (2010, p. 2301)

Há evidências de que os sistemas de atenção à saúde baseados numa forte orientação para a atenção primária à saúde, contrastados com os sistemas de baixa orientação para a atenção primária à saúde, são mais adequados por que se organizam a partir das necessidades de saúde da população; mais efetivos porque são a única forma de enfrentar consequentemente a situação epidemiológica de hegemonia das condições crônicas e por impactar significativamente os níveis de saúde da população; mais eficientes por que apresentam menores custos e reduzem procedimentos mais caros; mais equitativos por que discriminam positivamente grupos e regiões mais pobres e diminuem o gasto do bolso das pessoas e famílias; e de maior qualidade por que colocam ênfase na promoção da saúde e na prevenção das doenças e ofertam tecnologias mais seguras para os usuários e profissionais de saúde

${ }^{3} \mathrm{Na}$ figura 9, RT1, RT 2, RT 3 representa Rede Temática 1, 2, n.... 
De acordo com a Organização Mundial de Saúde (OMS, 2011), as redes integradas de saúde contribuem com o desenvolvimento de sistemas de saúde baseados na APS, e, portanto, para a prestação de serviços de saúde mais acessíveis, equitativo, eficiente, de maior qualidade técnica, com maior capacidade de satisfazer as expectativas dos cidadãos.

\section{PROCEDIMENTOS METODOLÓGICOS}

Esta pesquisa classifica-se quanto à natureza como pesquisa aplicada, dado o seu propósito de solucionar problemas de cunho prático (LAKATOS \& MARCONI, 2003). Quanto aos fins, esta pesquisa classifica-se como descritiva, por buscar expor características de determinada população ou fenômeno ou o estabelecimento de relações entre variáveis (GIL, 2007). Segundo Vergara (2000) este tipo de pesquisa não possui o compromisso de explicar os fenômenos que descreve, muito embora possa vir a ser utilizada como base para explicação. Quanto aos meios de investigação, esta pesquisa é documental, caracterizada por Lakatos \& Markoni (2003) pela sua fonte de coleta de dados que é restrita a documentos, escritos ou não das denominadas fontes primárias.

Com relação à abordagem do problema esta pesquisa se classifica como pesquisa quantitativa. Conforme Creswell (2007) a técnica de pesquisa quantitativa se baseia no desenvolvimento do conhecimento a partir da argumentação póspositivista, onde o pesquisador emprega medidas de atitudes que são avaliadas antes e depois de um tratamento experimental, por meio de estratégias de investigação como levantamentos e coletas de dados e instrumentos estatísticos.

Quanto às técnicas de pesquisa, aplicou-se a esta pesquisa a análise de conteúdo, análise estatística e métodos de análise não-paramétrica.

Os dados foram obtidos a partir de coleta de fontes secundárias na base de dados do DATASUS e posteriormente foi realizada uma pesquisa documental relacionada às Redes de Atenção à Saúde.

O universo de pesquisa é formado por 5.570 municípios do Brasil. Entretanto, devido à indisponibilidade de dados de alguns municípios, o número de municípios reduziu para 5340. Deste universo, foram selecionados apenas os municípios que aderiram à Rede Cegonha desde 2011, e os que nunca aderiram, totalizando uma amostra de 918 municípios. 
A construção do modelo de eficiência para a avaliação da eficiência da Rede Cegonha considerou variáveis relacionadas à Atenção Primária em Saúde (APS), devido ao seu papel imprescindível para a organização, coordenação e regulação do acesso e utilização dos serviços necessários para a integralidade do cuidado (OMS, 2008; OPAS, 2011; CECILIO et. al.2012; CONASS, 2015) e também pelo fato de que os dados de atenção primária seriam os que melhor refletem a realidade de saúde municipal.

Com relação as variáveis de input, este estudo adotou apenas um único input - despesa com atenção básica - no modelo Network DEA. Essa escolha se fundamenta na grande quantidade de estudos empíricos sobre avaliação de eficiência em saúde que adotaram despesa com saúde como único input (TROMPIERI NETO et al., 2009; FARIA et al., 2008; SANTOS et al., 2008; FERREIRA e PITTA, 2008).

Para aplicação do modelo de eficiência Network DEA foram consideradas as variáveis intermediárias e outputs. Como variáveis intermediárias do modelo estão: número de médicos, número de enfermeiros, número de auxiliares e técnicos da estratégia saúde da família, da saúde que representam os recursos humanos disponíveis; número de estabelecimentos de saúde de atenção básica como infraestrutura e valor aprovado da produção ambulatorial do SUS como recurso financeiro. Esses dados são informados pelas Secretarias Municipais e Estaduais de Saúde no Sistema de Cadastro Nacional de Estabelecimentos de Saúde (CNES/SUS).

As variáveis selecionadas como output estão relacionadas com as ações da atenção básica nas Redes de Atenção à Saúde e à Rede Cegonha: Cobertura das equipes de atenção básica; cobertura vacinal, número de visitas dividido pela densidade urbana, percentual de partos normais e proporção de nascidos vivos de mães com 7 ou mais consultas de pré-natal.

Com relação à variável despesas com atenção básica, esta se refere aos valores declarados nos relatórios de despesa por subfunção no Sistema de Informações sobre Orçamentos Públicos em Saúde (SIOPS).

Quando ao número de estabelecimentos de saúde de atenção básica, número de médicos, número de enfermeiros e número de técnicos e auxiliares de saúde ESF, estes são apresentados em valores absolutos, a partir do quantitativo declarado pelos gestores locais no Cadastro Nacional de Estabelecimentos de Saúde (CNES). Em relação à variável valor de procedimentos ambulatoriais aprovados, refere-se ao valor 
de produção ambulatorial aprovado para pagamento pelas secretarias de saúde, aplicando-se o filtro de complexidade de atenção básica.

Com relação à cobertura das equipes de atenção básica, esta é calculada com base no número de Equipes de Saúde da Família no município, somado ao número de Equipes de Saúde da Família equivalente multiplicado por 3.000 e dividido por 100 .

A cobertura vacinal é definida a partir do número de crianças com esquema básico completo na idade alvo para determinado tipo de vacina, sobre o número de crianças na idade alvo, multiplicado por 100.

Já o número de visitas pela densidade urbana é dado pelo número de visitas realizadas pelas equipes de atenção básica em valores absolutos dividido pela densidade urbana. Dada a possibilidade de viés oriundos tanto do tamanho do município quanto da concentração populacional, o número de visitas foi dividido pela densidade urbana.

A variável percentual de partos normais é mensurada a partir da divisão entre o número de nascidos vivos por parto normal ocorridos, de mães residentes em determinado local e ano; e o número de nascidos vivos de todos os partos, de mães residentes no mesmo local e ano; multiplicado por 100.

Por sua vez, a proporção de nascidos vivos de mães com 7 ou mais consultas de pré-natal refere-se número de nascidos vivos de mães residentes em determinado local e ano com sete ou mais consultas de pré-natal dividido pelo número de nascidos vivos de mães residentes no mesmo local e período; multiplicado por 100. $\mathrm{Na}$ tabela 3 estão representados o resumo das variáveis adotadas neste estudo. 
Tabela 3. Variáveis selecionadas de input e output

\begin{tabular}{clc}
\hline Variáveis & \multicolumn{1}{c}{ Nome } & Fonte \\
\hline Input $\left(X_{1}\right)$ & Despesas com atenção básica & SIOPS/FNS \\
\hline Intermediário $\left(W_{1}\right)$ & $\begin{array}{l}\text { Número de Estabelecimentos de saúde de atenção } \\
\text { básica }\end{array}$ & CNES \\
\hline Intermediário $\left(W_{2}\right)$ & Número de médicos ESF & CNES \\
\hline Intermediário $\left(W_{3}\right)$ & Número de enfermeiros ESF & CNES \\
\hline Intermediário $\left(W_{4}\right)$ & Número de técnicos e auxiliares de saúde ESF & CNES \\
\hline Intermediário $\left(W_{5}\right)$ & Valor de procedimentos ambulatoriais aprovados (PAB) & CNES \\
\hline Output $\left(Y_{1}\right)$ & Cobertura das equipes de Atenção básica & DATASUS e IBGE. \\
\hline Output $\left(Y_{2}\right)$ & Cobertura vacinal ${ }^{*}$ & DATASUS \\
\hline Output $\left(Y_{3}\right)$ & № de visitas / Densidade urbana & SIA \\
\hline Output $\left(Y_{4}\right)$ & Percentual de partos normais & SINASC \\
\hline Output $\left(Y_{5}\right)$ & $\begin{array}{l}\text { Proporção de nascidos vivos de mães com } 7 \text { ou mais } \\
\text { consultas de pré-natal }\end{array}$ & SINASC \\
\hline
\end{tabular}

Fonte: Elaboração própria

** As taxas de cobertura vacinal acima de $100 \%$ apresentadas no banco de dados do DATASUS, são consequências de erros nas estimativas populacionais, que consideraram a tendência demográfica da década anterior tendendo assim a superestimar o número de menores de um ano de idade (TEIXEIRA \& MOTA, 2010).

Também foram levantadas variáveis relacionadas com a participação do social no SUS como o número de conselhos de saúde municipal cadastrados no Sistema de Acompanhamento dos Conselhos de Saúde (SIACS), número de Planos de Saúde enviados ao Conselho de Saúde, número de ouvidorias implantadas no município e número absoluto do componente municipal do SNA estruturado, todas coletadas dos resultados obtidos pelo Indicadores Municipais do rol de Diretrizes, Objetivos, Metas e Indicadores 2013-2015, disponível no banco de dados do DATASUS. Além dessas variáveis, foram consideradas as variáveis oriundas da pesquisa de informações básicas municipal realizada pelo Instituto Brasileiro de Geografia e Estatística (IBGE): número de reuniões realizadas nos últimos 12 meses e quantidade de dias de existência do Conselho de Saúde). O resumo das variáveis de participação social no SUS estão apresentadas na Tabela 4. 
Tabela 4. Variáveis de relacionadas à participação social no SUS

\begin{tabular}{|c|c|c|}
\hline Variáveis & Nome & Fonte \\
\hline Município c/CMS cadastrado & $\begin{array}{l}\text { Número de conselhos de saúde municipal } \\
\text { cadastrados no SIACS. }\end{array}$ & DATASUS \\
\hline Munic c/envio PMS ao CMS & $\begin{array}{l}\text { Número de Planos de Saúde enviados ao } \\
\text { Conselho de Saúde. }\end{array}$ & DATASUS \\
\hline Munic c/ouvidoria implant. & $\begin{array}{l}\text { Número de Ouvidoria implantada no } \\
\text { município }\end{array}$ & DATASUS \\
\hline Munic c/auditoria estrut. & $\begin{array}{l}\text { Número absoluto do componente } \\
\text { municipal do SNA estruturado }\end{array}$ & DATASUS \\
\hline $\begin{array}{l}\text { Qtd_de_reuniões_nos_últimos_ } \\
\text { 12_meses }\end{array}$ & $\begin{array}{l}\text { Número de reuniões realizadas nos } \\
\text { últimos } 12 \text { meses }\end{array}$ & IBGE \\
\hline $\begin{array}{l}\text { Tempo_de_existência do } \\
\text { Conselho }\end{array}$ & $\begin{array}{l}\text { Quantidade de dias de existência do } \\
\text { Conselho de Saúde }\end{array}$ & IBGE \\
\hline
\end{tabular}

Fonte: Elaboração própria 


\section{O ESTUDO DA REDE CEGONHA}

A Rede Cegonha "consiste em uma rede de cuidados que visa assegurar às mulheres o direito ao planejamento reprodutivo e a atenção humanizada à gravidez, ao parto e ao puerpério e às crianças o direito ao nascimento seguro e ao crescimento e ao desenvolvimento saudáveis" (BRASIL, 2011). Esta rede de cuidados surgiu da necessidade de superação de um modelo de atenção à saúde marcado pela medicalização e por intervenções desnecessárias, pela fragmentação das ações e serviços relacionados à atenção ao parto e ao nascimento, conforme apresentado na figura 8. Cavalcante et al. (2013) apontam as taxas elevadas de morbimortalidades materna e infantil, cesáreas e aborto inseguro como consequências desse modelo de atenção à saúde

Figura 8. Modelo lógico da Rede Cegonha

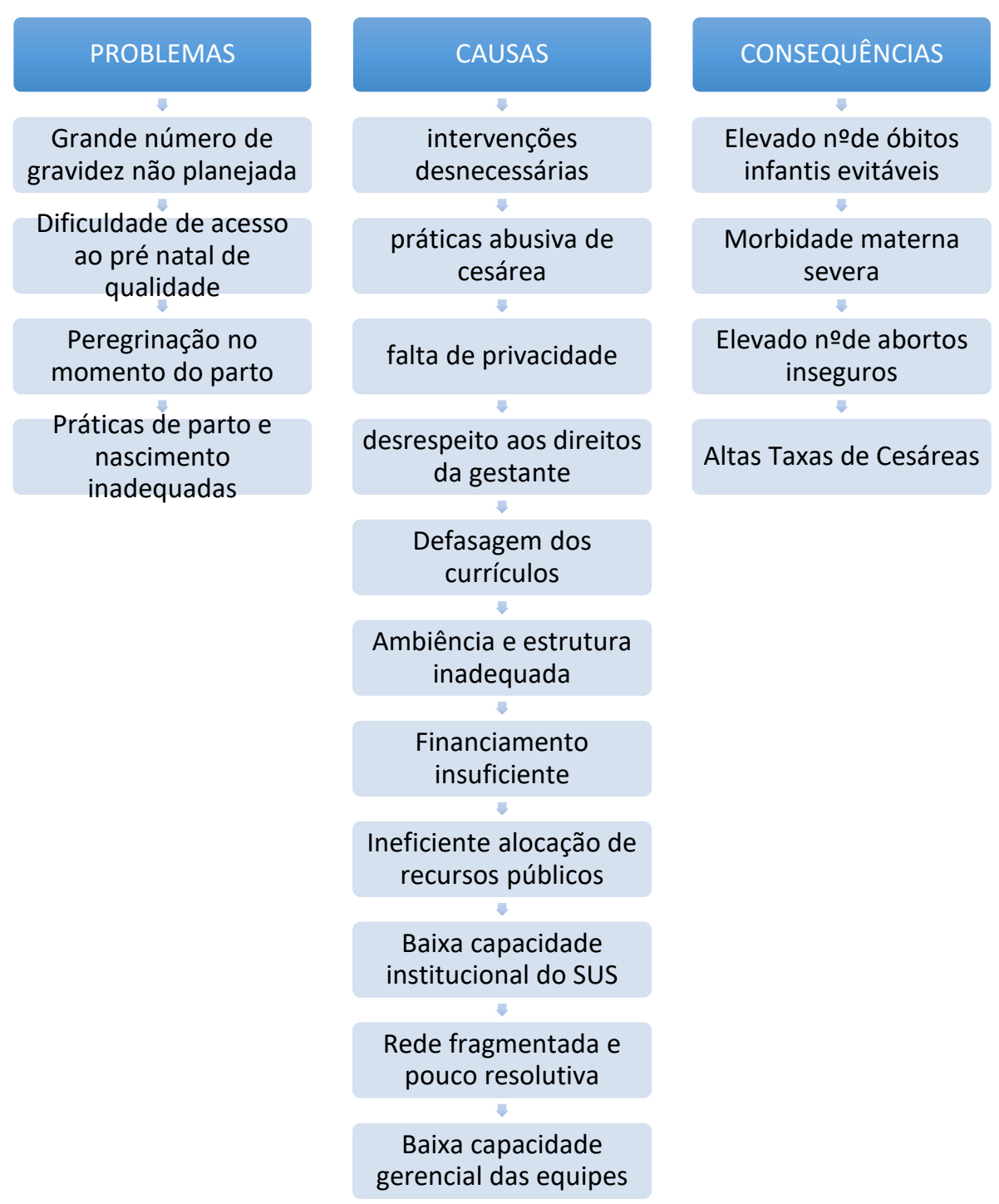

Fonte: adaptado de Cavalcanti et al. (2013) 
Como alternativa de superação deste cenário, a Rede Cegonha $(R C)$ foi instituída no âmbito do SUS em 2011, com o objetivo de incentivar a implementação de um novo modelo de atenção à saúde da mulher e da criança, com foco na redução da mortalidade materna e infantil. Conforme ressalta Santos (2013) a Rede Cegonha tem como objetivo a melhoria da atenção à saúde para a gestante e criança de até 24 meses, indo além do repasse de recursos vinculado ao aumento de leitos ou oferta de procedimentos.

Para tanto, a RC é estruturada nos três elementos constitutivos presentes nas Redes de Atenção à Saúde: população, estrutura operacional e modelo de atenção à saúde (MENDES, 2011). No âmbito de uma Rede de Atenção à Saúde, a população é definida como aquela que "vive em territórios sanitários singulares, organiza-se socialmente em famílias e é cadastrada e registrada em subpopulações por riscos sócio sanitários" (MENDES, 2011, p.87).

A respeito da estrutura operacional, esta é composta pelos nós das redes centro de comunicação, pontos de atenção à saúde secundários e terciários; sistemas de apoio - e suas ligações tangíveis e intangíveis que os conectam - sistemas logísticos e de governança (MENDES, 2011).

No caso da Rede Cegonha, os nós das redes são compostos pela Atenção Primária à Saúde (APS) e pelos pontos de atenção secundários e terciários: Maternidade de risco e de alto risco, Leito Neonatal (UTIN), Unidade de Cuidados Intermediários Convencional (UCINCO), Unidade de Cuidados Intermediários Canguru (UCINCA), Centro de Parto Normal (CPN), e Casa de Gestante, bebê e puérpera (CGBP), conforme representado na figura 9. 
Figura 9. Pontos de atenção da Rede Cegonha

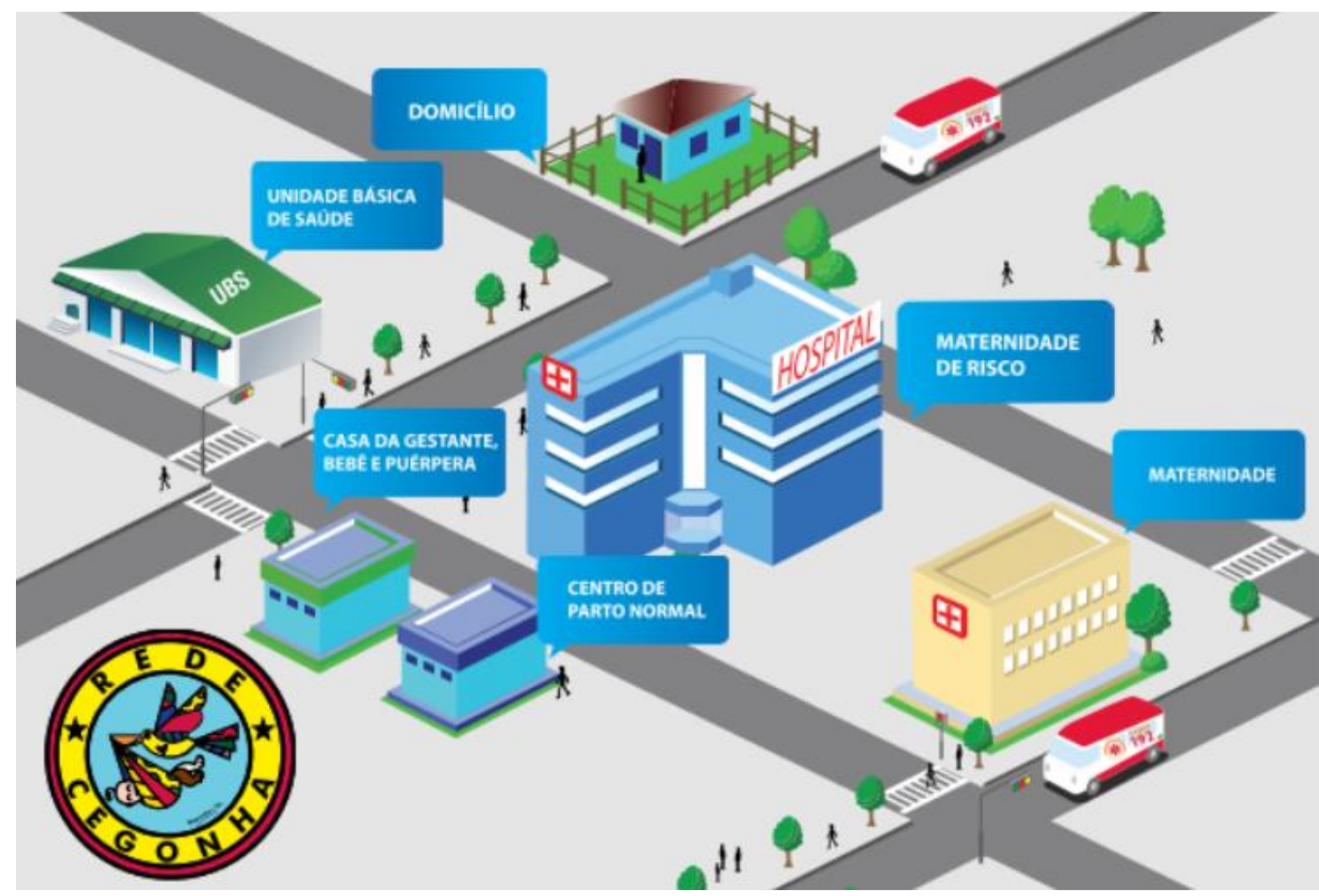

Fonte: Di Giovanni (2013).

Por sua vez, as ligações tangíveis e intangíveis são realizadas pelos sistemas de apoio diagnóstico e terapêutico; assistência farmacêutica; e de informação em saúde como o Sistema de Monitoramento e Avaliação do Pré-Natal, Parto, Puerpério e Criança (SISPRENATAL), Sistema de Informações sobre Mortalidade (SIM), Sistema de Informação sobre Nascidos Vivos (SINASC), Sistema de Informação de Atenção Básica (SIAB), dentre outros. Além desses sistemas, o sistema logístico também está presente sob a forma de registro eletrônico em saúde, cartão de identificação, sistemas de acesso regulado à atenção e os sistemas de transporte em saúde (BRASIL, 2011).

Com relação aos sistemas de governança, a Rede Cegonha está inserida no sistema institucional do SUS, composta pelos entes federados, gestores, instituições de pactuação e pelo controle social exercido pelos cidadãos, conforme representado na figura 10. 
Figura 10. Sistema institucional do SUS

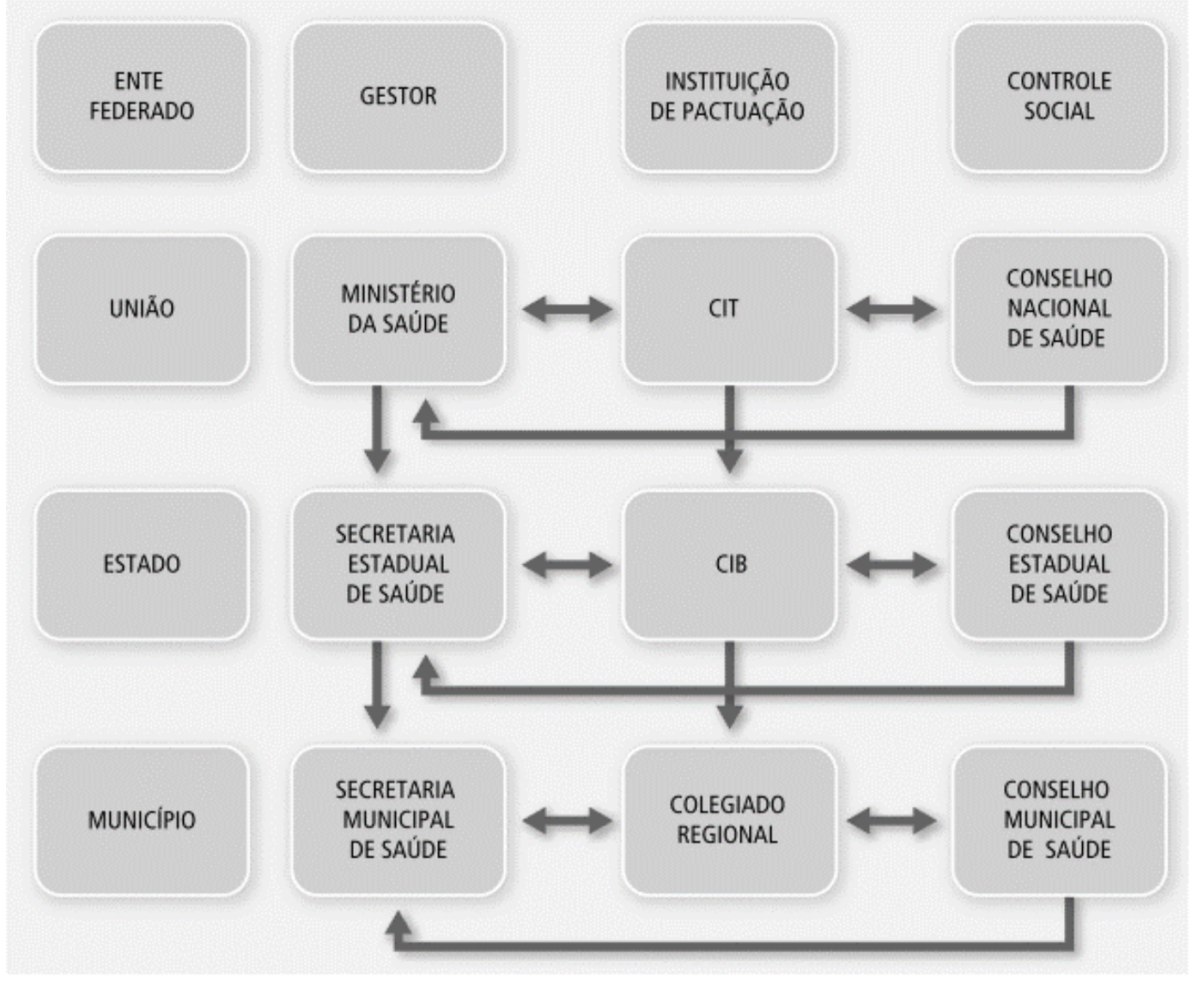

Fonte: Mendes (2011).

Além dos elementos constitutivos próprios das RAS, a Rede Cegonha é operacionalizada a partir de quatro componentes: pré-natal, puerpério e atenção integral à saúde da criança, parto nascimento e sistema logístico. No componente prénatal, as gestantes são cadastradas pela APS e vinculadas à uma maternidade para que seja realizado o acompanhamento da gestação por meio de consultas e exame de pré-natal. Cabe à APS coordenar a comunicação com os demais pontos da rede e estratificar os riscos identificados. No componente puerpério e atenção integral à saúde da criança, as equipes de APS, acompanham a puérpera e a criança, com visitação domiciliar na primeira semana após a realização do parto e nascimento (BRASIL, 2011b).

Nesse componente a APS promove ações de aleitamento materno e alimentação complementar saudável, identificando crianças em situação vulnerável e outras ações de prevenção e orientação sobre saúde sexual e reprodutiva (BRASIL, 2011b). A garantia de acompanhante durante 0 acolhimento e o trabalho de parto, parto e pós-parto imediato e a organização dos recursos disponíveis como leitos 
obstétricos, UTI neonatais, ambiência das maternidades são realizados no componente parto e nascimento.

Em termos de financiamento, o Ministério da Saúde prevê o repasse para o componente parto e nascimento recursos para a construção, ampliação e reforma para adequação da ambiência em serviços que realizam partos, bem como reforma de Centros de Parto Normal (CPN) e Casas de Gestante, Bebê e Puérpera (CGBP) e equipamentos. Como recurso de custeio, está previsto neste componente $100 \%$ de recursos de custeio para CPN, CGBP, Leito Canguru, e $80 \%$ de custeio para ampliação e qualificação dos leitos para Gestantes de Alto Risco (GAR), de UTI adulto e neonatal e UCI neonatal (BRASIL, 2011b). 


\subsection{DADOS E ANÁLISES}

Para proceder à execução metodológica e atingir os objetivos propostos neste estudo realizou-se a avaliação da eficiência técnica em saúde dos municípios brasileiros divididos em dois grupos: municípios com adesão à Rede Cegonha desde 2011 e municípios que nunca aderiram à Rede. A opção pela delimitação da avaliação à rede temática Rede Cegonha se justifica pelo tempo de implementação da rede e pela complexidade de agregação dos dados das diferentes redes temáticas para os 5.570 municípios brasileiros.

Desta forma, foi possível avaliar se houve variação na eficiência técnica entre os municípios pertencentes ao grupo de tratamento e ao grupo de controle. O grupo de tratamento é composto por municípios que aderiram à Rede Cegonha durante os seus cinco anos de implementação. Já no grupo de controle estão concentrados os municípios que nunca aderiram à Rede Cegonha.

Como método para avaliação da eficiência adotou-se o método não paramétrico Data Envelopment Analysis (DEA), pois, além de sua grande adoção na literatura sobre eficiência em saúde, o método apresenta viabilidade de aplicação em contextos com múltiplas variáveis como no caso do setor público em que há dificuldades na mensuração de preço dos insumos e produtos de cada município e de padronização das variáveis envolvidas no processo de produção (RUGGIERO, 1994).

A avaliação da eficiência foi dividida em duas partes. $\mathrm{Na}$ análise estática foi realizada uma avaliação cross section da eficiência técnica em saúde dos municípios brasileiros para o ano de 2015, com o modelo Network DEA, considerando o modelo de eficiência representado na Figura 9. 
Figura 9. Modelo de eficiência para análise estática.

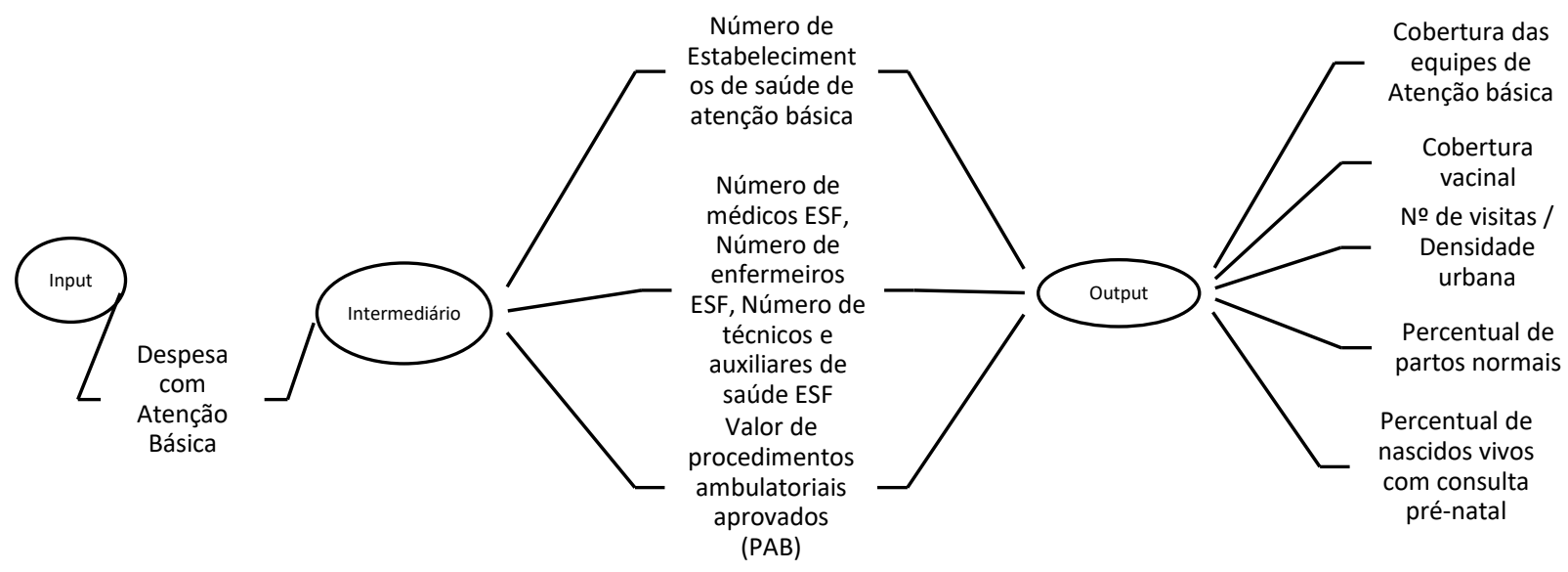

Fonte: Elaboração própria

Em relação à análise dinâmica, avaliou-se a eficiência municipal em saúde com dados de painel divididos em dois triênios: o primeiro triênio foi formado por dados de 2007, 2008 e 2009; e o segundo por 2013, 2014 e 2015. As variáveis utilizadas na análise dinâmica estão representadas na figura 10.

Figura 10. Modelo de eficiência para a análise dinâmica

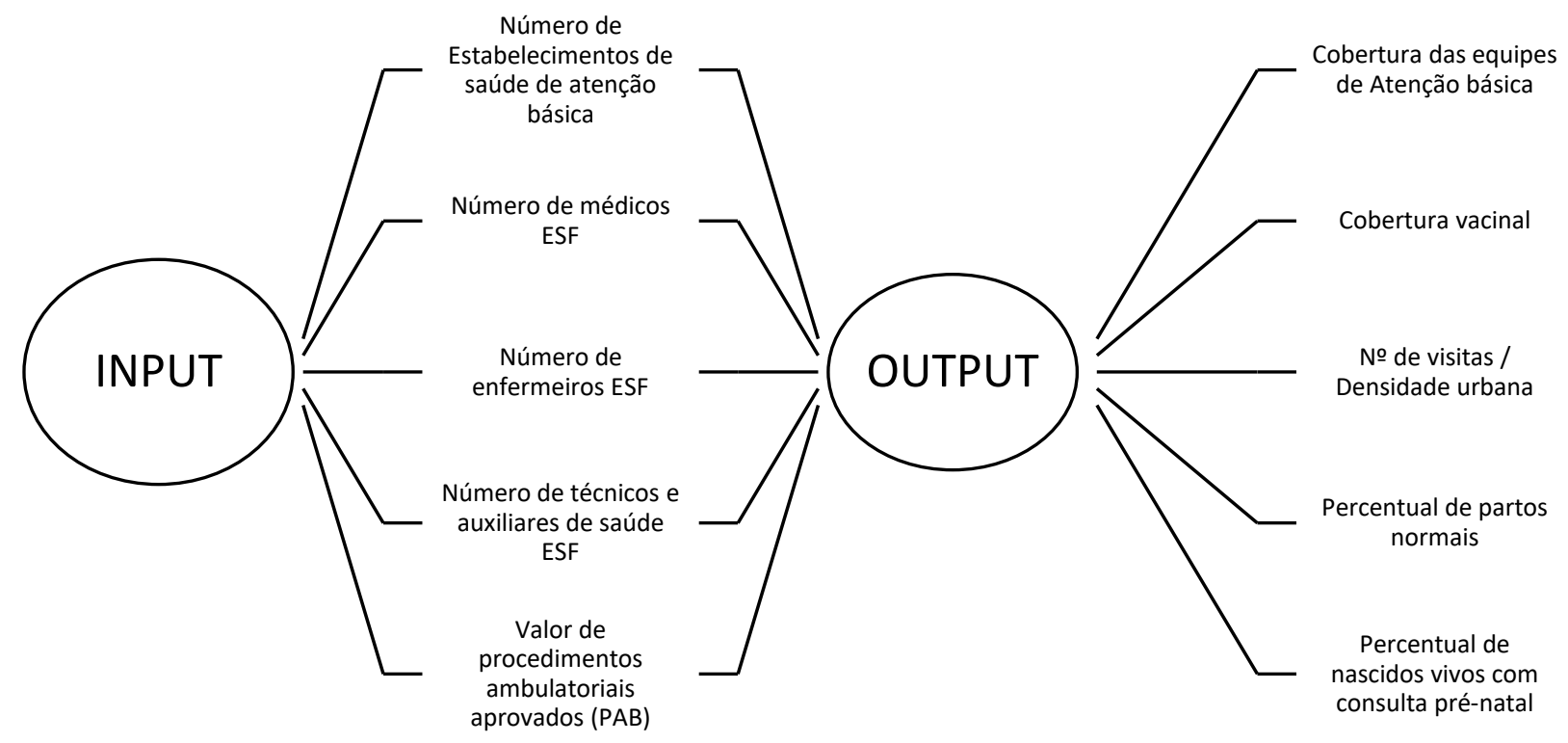

Fonte: Elaboração própria

Para avaliação da evolução da eficiência entre os municípios foi utilizado o método Malmquist-DEA. Após o processamento do método e geração do índice de 
Malmquist, realizou-se um teste estatístico não-paramétrico Mann-Whitney $U$ para duas amostras para avaliar o efeito da Rede Cegonha na eficiência dos grupos de controle e de tratamento municípios.

\subsection{ANÁLISE ESTÁTICA E DINÂMICA}

A análise estática considerou a amostra de dados cross-section para a avaliação da eficiência referente ao ano de 2015, último ano com disponibilidade de dados para as variáveis consideradas no estudo. Para tanto adotou-se o modelo radial, com retornos variáveis, orientado à output que visa maximizar a produção de serviços e ações em saúde dados os recursos disponíveis; e empregou-se a abordagem Network DEA com dois nós por meio do software Max Dea - PRO.

Segundo Lozano e Moreno (2014) o método Network DEA considera a existência de produtos intermediários de um processo que são oriundos de um processo e consumidos em outro. Essa relação entre geração e consumo de produtos representa um link entre diferentes estágios e processos.

Nessa abordagem, ao invés de assumir todos os inputs e outputs como um processo único, o sistema é modelado sob a forma de subprocessos distintos, onde cada subprocesso é um sistema que pode ser modelado pelo nível de processo interrelacionados, cada um com seus próprios inputs e outputs. Assim, a eficiência total é produto da eficiência em cada um dos nós 1 e 2 . No nó 1 são considerados como variáveis de entrada a despesa com atenção básica e como output intermediário o número de médicos, enfermeiros, técnicos/auxiliares, unidades de saúde e valor de produção ambulatorial. No nó 2 são consideradas como variáveis de entrada os outputs intermediários o número de médicos, enfermeiros, técnicos/auxiliares, unidades de saúde, valor de produção ambulatorial e como output a cobertura das equipes de atenção básica, cobertura vacinal, número de visitas/densidade urbana, percentual de partos normais e percentual de nascidos vivos com 7 ou mais consultas de pré-natal. Os municípios considerados eficientes apresentam escore de eficiência igual a 1 e estão localizados na fronteira de eficiência.

Assim, os resultados do nó 1 representam a comparação da habilidade de combinação de insumos e produtos em proporções ótimas. Por sua vez os resultados do nó 2 representam a comparação da eficiência na produção realizada de um município no período com a produção máxima possível dados os recursos disponíveis 
para produção. Em cada um dos processos de produção, foram gerados níveis de eficiência para cada um dos grupos estudados, conforme Tabela 1A. A seguir são apresentadas as distribuições de frequência dos índices de eficiência.

Gráfico 1. Distribuição de frequência dos scores de eficiência agregado para o nó 1.

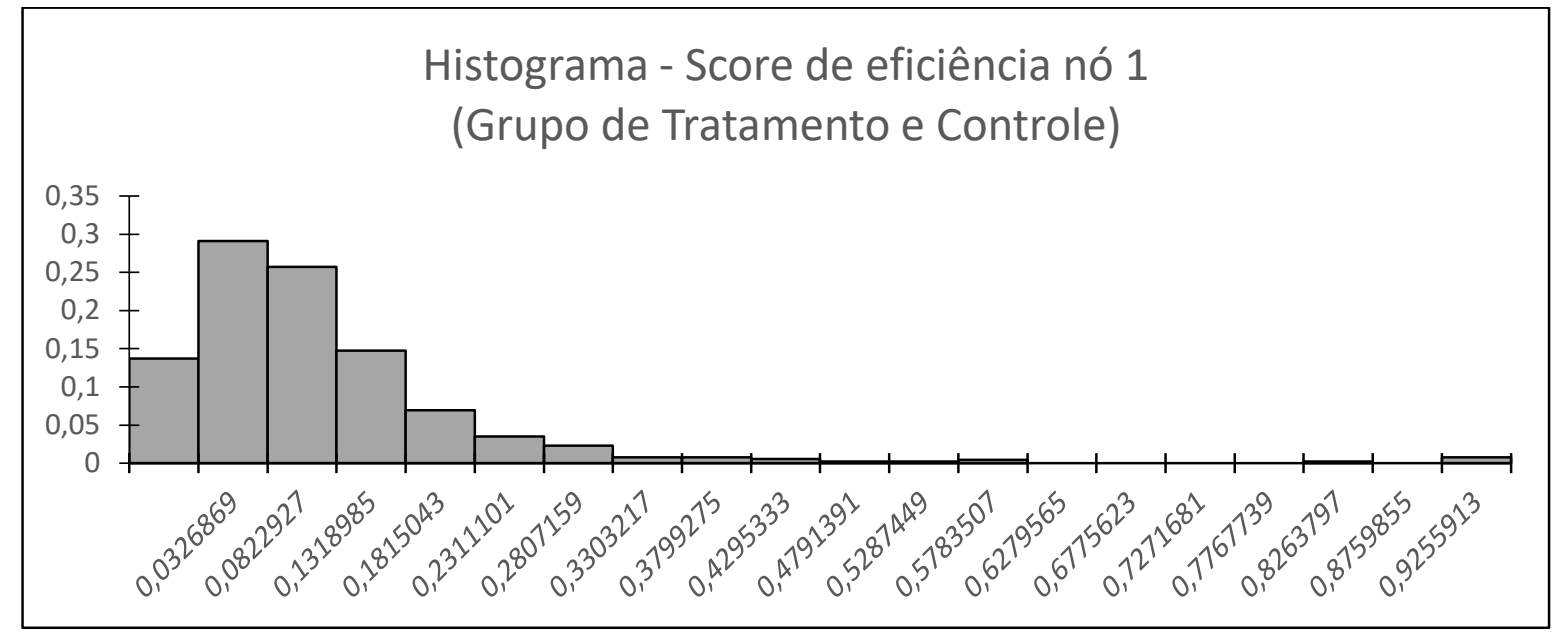

Fonte: Elaboração própria

Gráfico 2. Distribuição de frequência dos scores de eficiência agregado para o nó 2.

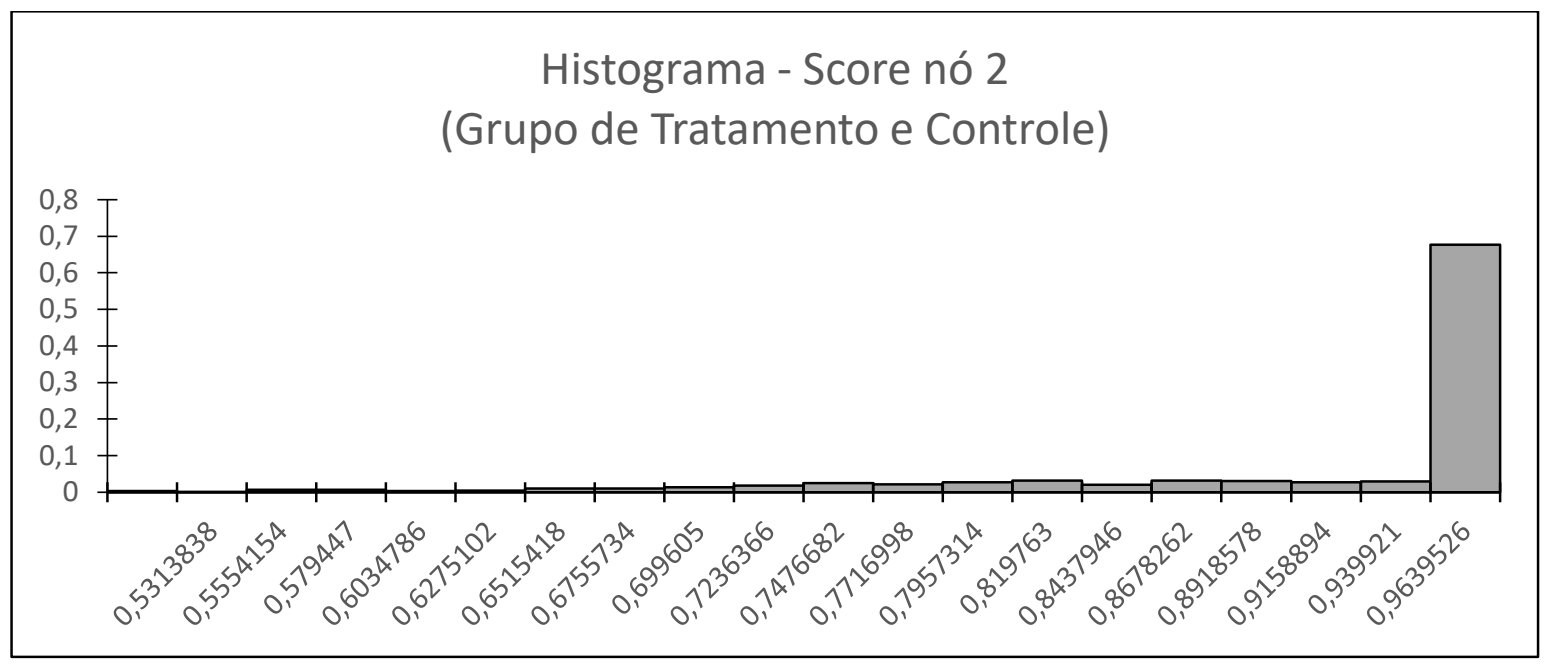

Fonte: Elaboração própria 
Gráfico 3. Distribuição de frequência dos scores de eficiência final agregado

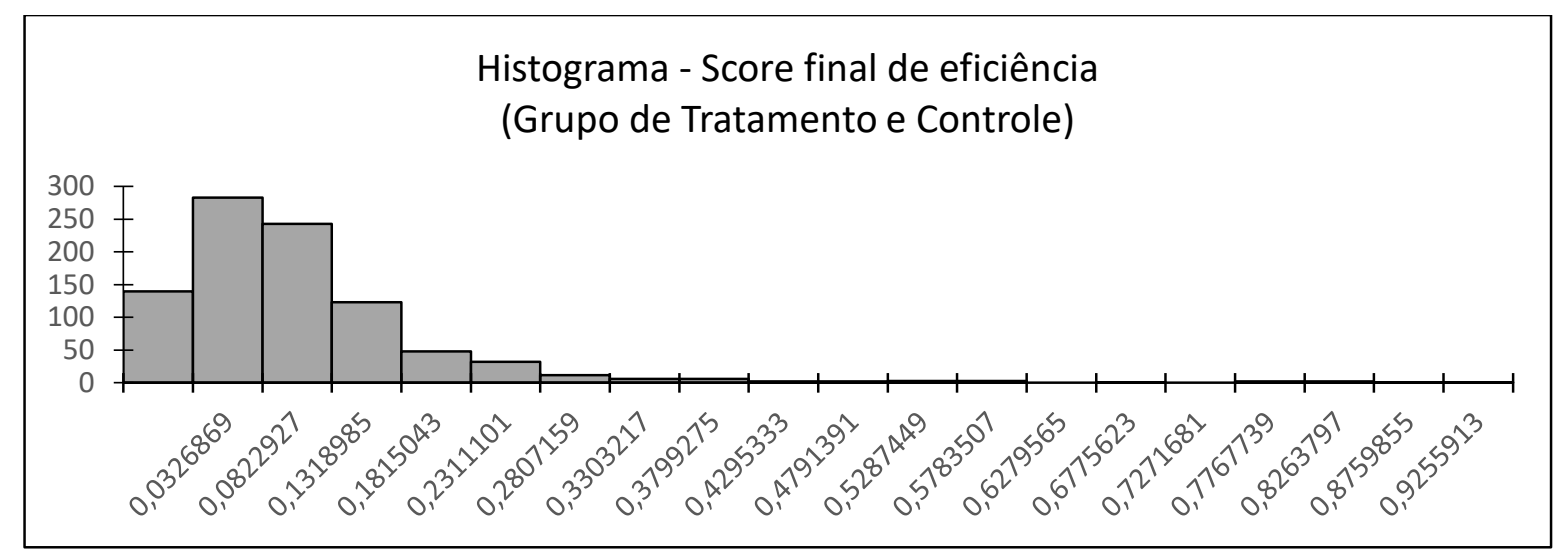

Fonte: Elaboração própria

Gráfico 4. Distribuição de frequência dos scores de eficiência final desagregado por grupo de tratamento e controle
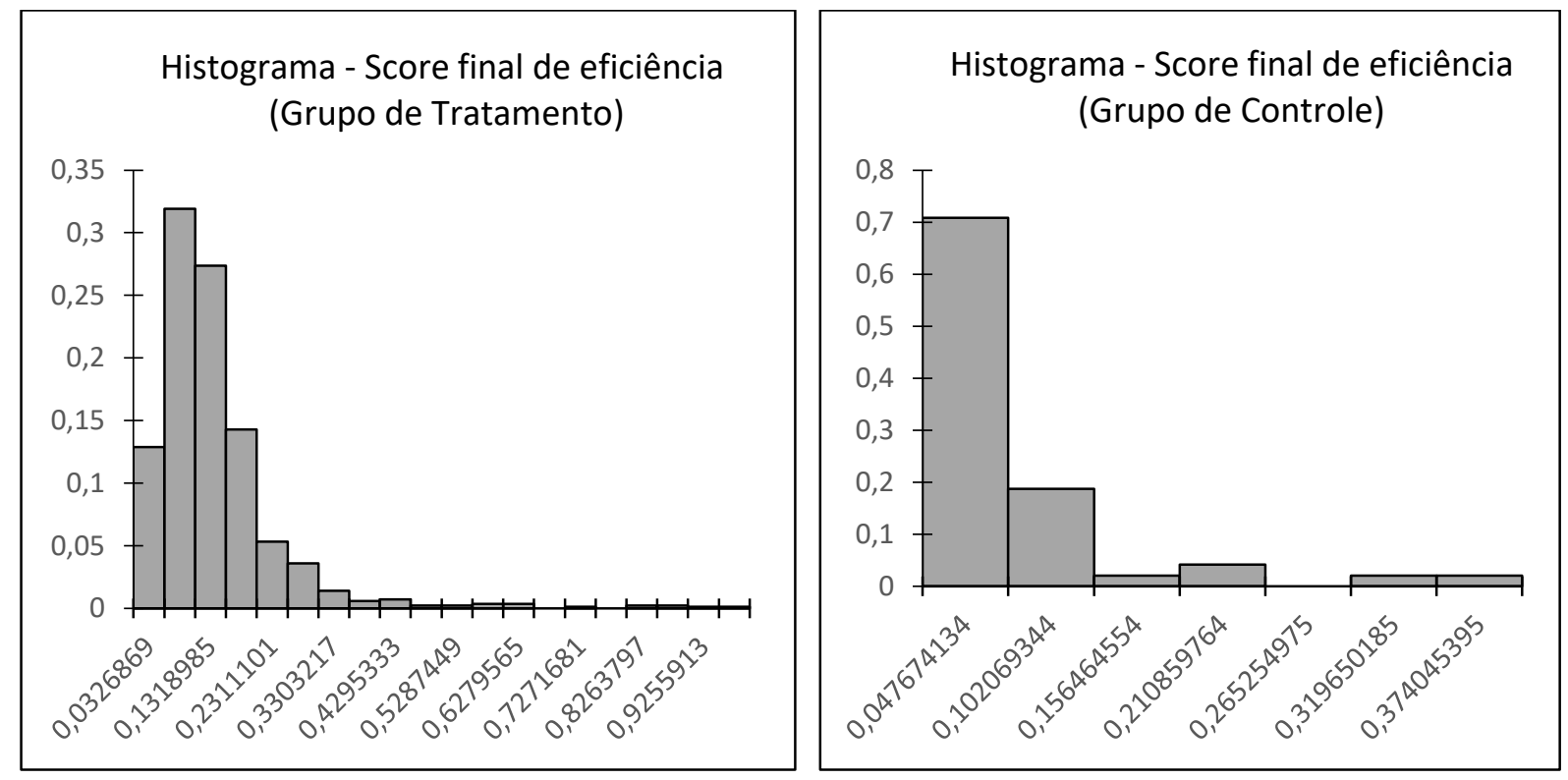

Fonte: Elaboração própria

Conforme apresentado nos gráfico 1 e 2 a distribuição da frequência do score de eficiência diferenciada entre os dois nós ressaltam a importância de se considerar os processos internos relacionados à eficiência final. Observa-se no nó 1 que as distribuições estão dispersas e pouco concentradas nas classes consideradas mais eficientes, ou seja, aquelas próximas ou igual a 1. Essa ineficiência reflete o resultado do processo de utilização do insumo "despesa em atenção básica" para a aquisição de recursos financeiros, humanos e infraestrutura para a execução dos serviços de saúde. A partir destes resultados, pode-se inferir que grande parte dos municípios está apresentando falhas na habilidade de combinar insumos e produtos em 
proporções ótimas, o que pode indicar falhas no planejamento e subutilização de recursos.

Com relação ao nó 2, observa-se o oposto. Há uma concentração de municípios acima de 0,9, o que representaria uma grande quantidade de municípios na classe próxima da eficiência. Este resultado aponta a capacidade dos municípios de produzirem o máximo possível de resultados de saúde dados os recursos disponíveis sejam eles financeiros, humanos e infraestrutura.

Ademais, observa-se que a distribuição de frequência dos scores de eficiência final apresenta novamente uma concentração dos municípios nas faixas de ineficiência. Esse resultado demonstra que muito embora os municípios possam ser eficientes nos processos internos de transformação de insumo de um processo para produto em outro, não necessariamente estes são eficientes na entrega final de serviços e ações de saúde. Além disso, conforme apresentado no gráfico 4, ao desagregar a distribuição por grupo de tratamento e grupo de controle, observa-se que não há diferença entre os scores de eficiência dos grupos de tratamento e de controle.

Como resultado desta análise, nota-se que dentre o conjunto de municípios avaliados, apenas um município do grupo de tratamento atingiu a eficiência total, enquanto os municípios tanto do grupo de tratamento quanto do grupo de controle ficaram abaixo da fronteira de eficiência, o que representaria um retrocesso na eficiência dos municípios de ambos os grupos. Ou seja, muito embora seja responsabilidade do Estado a oferta de bens e saúde, considerados meritórios, e pelo setor privado de maneira complementar, observa-se que a prestação de serviços realizada pelo setor público apresenta ineficiência. Desta forma, visando compreender este resultado, adotou-se a análise dinâmica com o método DEA Malmquist em dois períodos.

$\mathrm{Na}$ análise dinâmica, os dados coletados foram divididos em dois períodos: triênio 1, composto pelos anos 2007-2009 e triênio 2, constituído por 2013-2015 e aplicados no modelo DEA Malmquist. A adoção do modelo DEA Malmquist visou captar as mudanças de eficiência, de tecnologia e de produtividade total dos fatores. A análise dinâmica está representada na figura 11. Considerando que no índice de Malmquist os valores menores que 1, representam retrocesso tecnológico ou perda de eficiência; e que valores maiores que 1, apresentam progresso tecnológico ou 
ganho de eficiência; observa-se que, na média, em ambos os grupos houve evolução na eficiência total entre o triênio 1 e 2, conforme apresentado na Tabela 6.

Tabela 6. Média geométrica da evolução de eficiência, tecnológica e do índice de Malmquist.

\begin{tabular}{c|c|c|c}
\hline Grupo & $\begin{array}{c}\text { Índice de } \\
\text { Malmquist }\end{array}$ & $\begin{array}{c}\text { Variação de } \\
\text { eficiência técnica }\end{array}$ & Variação tecnológica \\
\hline Grupo de tratamento & 1,01055217 & 1,017772187 & 0,99511022 \\
\hline Grupo de Controle & 1,009719462 & 0,975512152 & 0,99392008 \\
\hline
\end{tabular}

Fonte: Elaboração própria

A tabela 6 apresenta os índices de produtividade total dos fatores para todos os dois grupos de um triênio para outro. Muito embora o grupo de tratamento tenha obtido um índice de produtividade um pouco maior do que o grupo de controle, considera-se que tanto o grupo de controle quando o grupo de tratamento evoluíram de um triênio para outro, representando um aumento médio do Fator de Produtividade Total de 1,01055217 e 1,009719462 respectivamente. Esses resultados estão representados percentualmente no gráfico 5 .

Gráfico 5. Percentual médio de evolução dos dois grupos nos componentes do índice de Malmquist

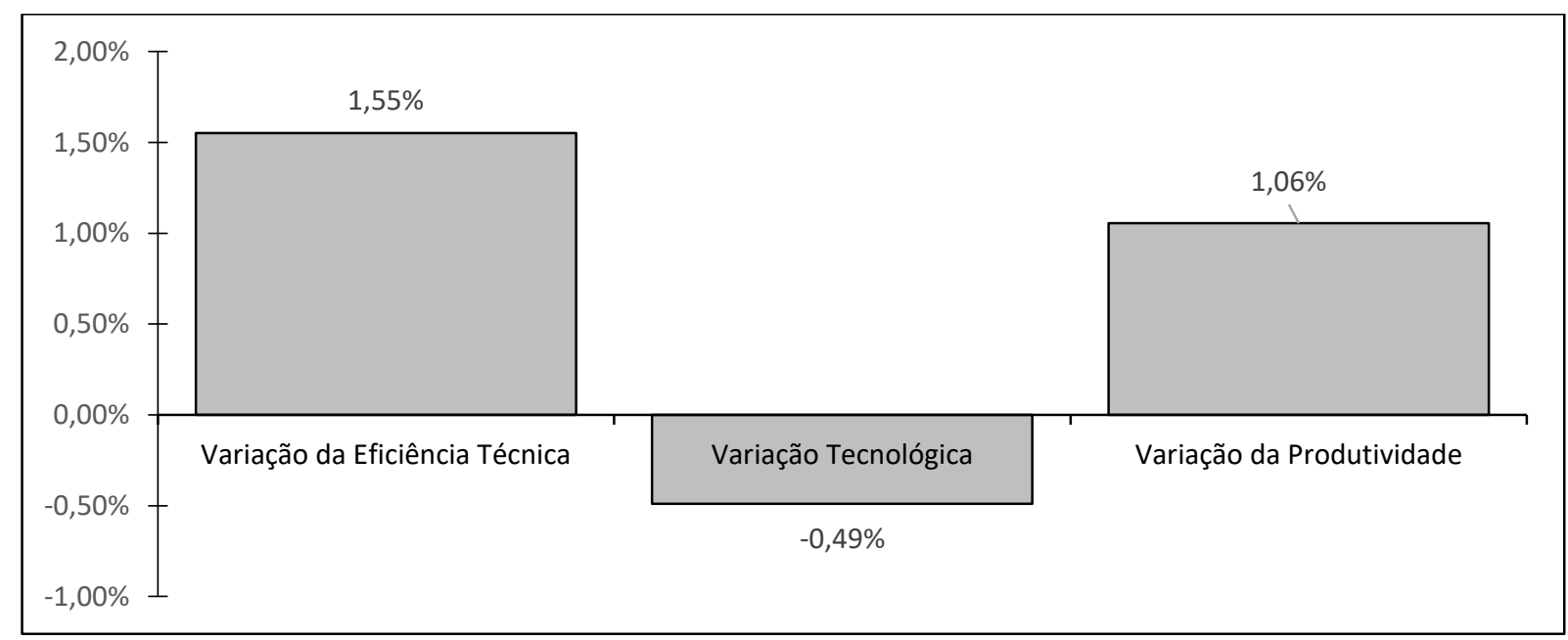

Fonte: Elaboração própria

A decomposição do índice de Malmquist em variação tecnológica e eficiência técnica permite identificar qual componente foi mais relevante para o resultado da produtividade total dos fatores. A eficiência técnica, também chamada de catch-up index mensura a distância entre a posição atual do município e a fronteira de eficiência, representando assim a distância existente entre a eficiência atual e a 
máxima eficiência possível de ser alcançada pelo município caso este consiga utilizar os seus recursos disponíveis da melhor maneira possível.

Ao analisar os componentes do índice a partir do gráfico 5, é possível observar que houve um crescimento de $1,55 \%$ no componente eficiência técnica. 0 componente variação tecnológica reflete a capacidade de modernização do município no setor de saúde. A piora desse índice representa um deslocamento da fronteira da eficiência para baixo. Desta forma, observa-se que grande parte do aumento da produtividade do índice de Malmquist é devido ao crescimento da eficiência técnica, o que representa um aumento no número de municípios que conseguiram alcançar a fronteira de um triênio para outro.

Ao se analisar isoladamente o grupo de tratamento e controle, observa-se que o grupo de tratamento representado no gráfico 6, obteve aumento na produtividade, alcançada pelo aumento da eficiência técnica produtiva dos municípios do grupo de tratamento de um triênio para o outro, explicado pelo crescimento de $1,78 \%$. Não obstante observa-se um retrocesso tecnológico de $0,58 \%$ neste período, o que evidencia um deslocamento para baixo da fronteira da eficiência. Esse resultado evidencia possíveis dificuldades de exploração de novas tecnologias na saúde pública.

Gráfico 6. Percentual médio de evolução isolada do grupo de tratamento nos componentes do índice de Malmquist

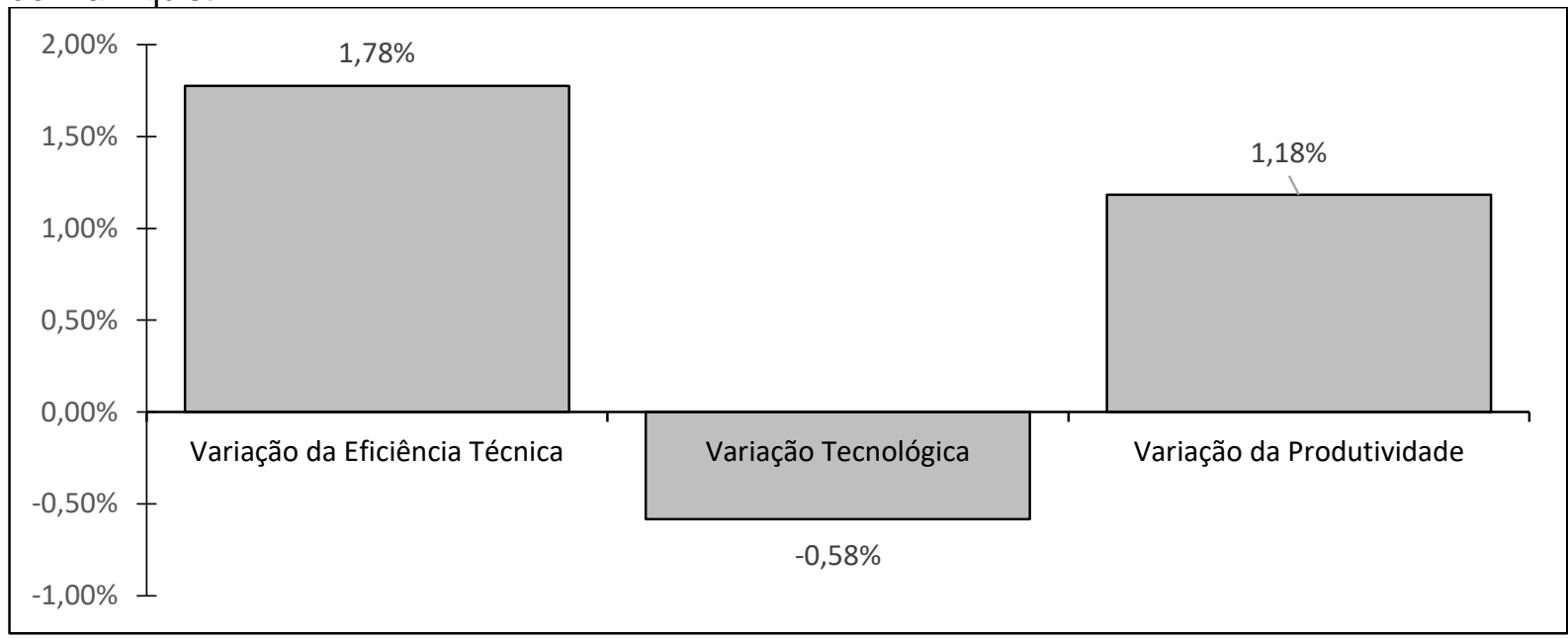

Fonte: Elaboração própria

Com relação ao grupo de controle este apresentou de um triênio para outro uma queda na produtividade total de fatores de 1,23\%, conforme apresentado no gráfico 7. Nota-se que apesar do progresso tecnológico de 1,25\%, houve uma grande 
perda de eficiência técnica dos municípios pertencentes ao grupo de controle que levaram à queda da produtividade total.

Gráfico 7. Percentual médio de evolução isolada do grupo de controle nos componentes do índice de Malmquist

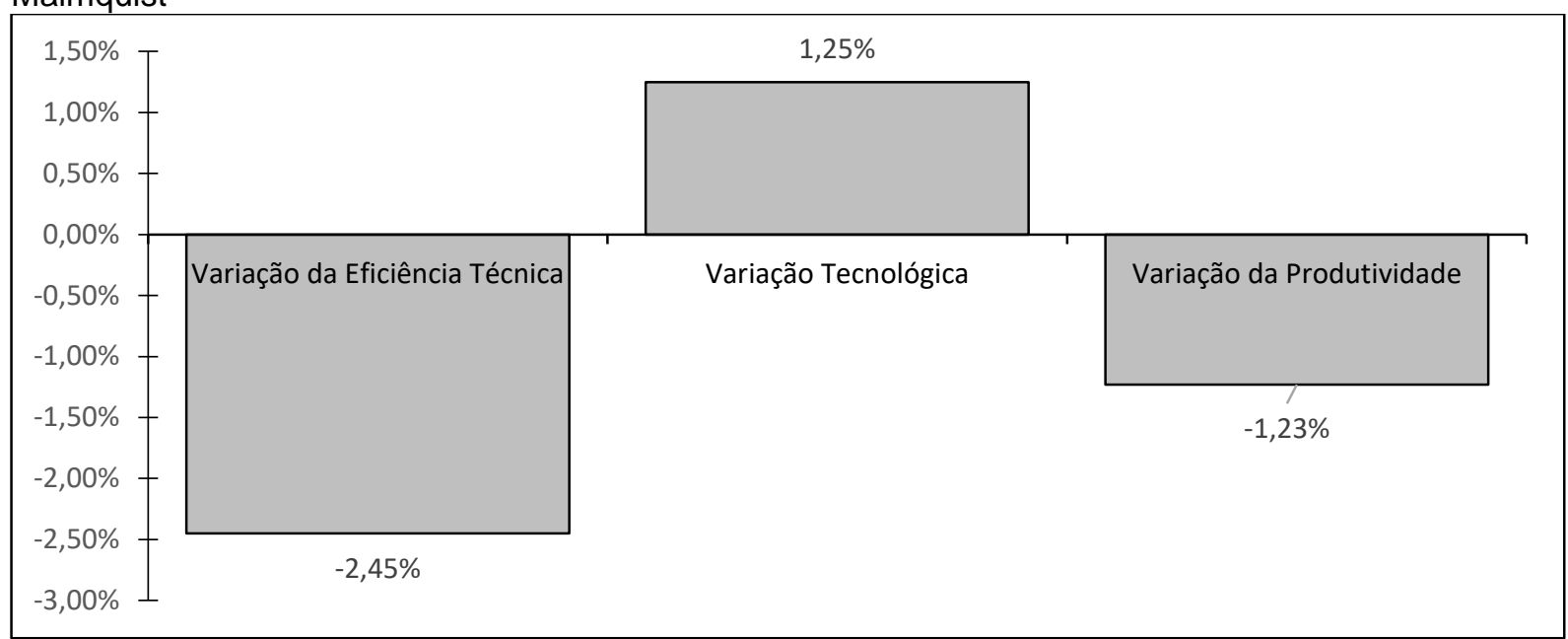

Fonte: Elaboração própria

Com base nos valores obtidos pelo índice de Malmquist, buscou-se avaliar a representatividade estatística do desempenho obtido por cada um dos grupos. Para tanto aplicou-se o teste não-paramétrico de Wilcoxon, equivalente ao teste U de MannWhitney, onde dois conjuntos independentes de dados amostrais derivam de populações com a mesma distribuição.

Assim, caso duas amostras sejam extraídas de populações idênticas e se associam postos a todos os valores individuais combinados em uma única coleção de valores, então os postos altos e baixos devem se distribuir igualmente entre as duas amostras. Se os postos baixos se concentrarem predominantemente em uma amostra e os altos na outra, suspeita-se que as duas populações não sejam idênticas. Essa diferença é demonstrada pelo $p$-valor menor a $5 \%$.

Quadro 1. Resultado do Teste de Mann-Whitney

\begin{tabular}{|c|c|c|c|c|c|c|c|}
\hline & \multirow[b]{3}{*}{ Rede } & \multicolumn{6}{|c|}{ Cases } \\
\hline & & \multicolumn{2}{|c|}{ Valid } & \multicolumn{2}{|c|}{ Missing } & \multicolumn{2}{|c|}{ Total } \\
\hline & & $N$ & Percent & $\mathrm{N}$ & Percent & $N$ & Percent \\
\hline \multirow[t]{2}{*}{ Índice de Malmquist } & NUNCA & 48 & $100,0 \%$ & 0 & $0,0 \%$ & 48 & $100,0 \%$ \\
\hline & SEMPRE & 870 & $100,0 \%$ & 0 & $0,0 \%$ & 870 & $100,0 \%$ \\
\hline
\end{tabular}




\begin{tabular}{|c|c|c|c|c|}
\hline & Null Hypothesis & Test & Sig. & Decision \\
\hline 1 & $\begin{array}{l}\text { The distribution of Eficiencia is the } \\
\text { same across categories of Rede. }\end{array}$ & $\begin{array}{l}\text { Independent- } \\
\text { Samples } \\
\text { Mann- } \\
\text { Whitney U } \\
\text { Test }\end{array}$ & 262 & $\begin{array}{l}\text { Retain the } \\
\text { null } \\
\text { hypothesis. }\end{array}$ \\
\hline
\end{tabular}

Asymptotic significances are displayed. The significance level is ,05.

Quadro 2. Detalhamento do Resultado do Teste de Mann-Whitney

\section{Rede}

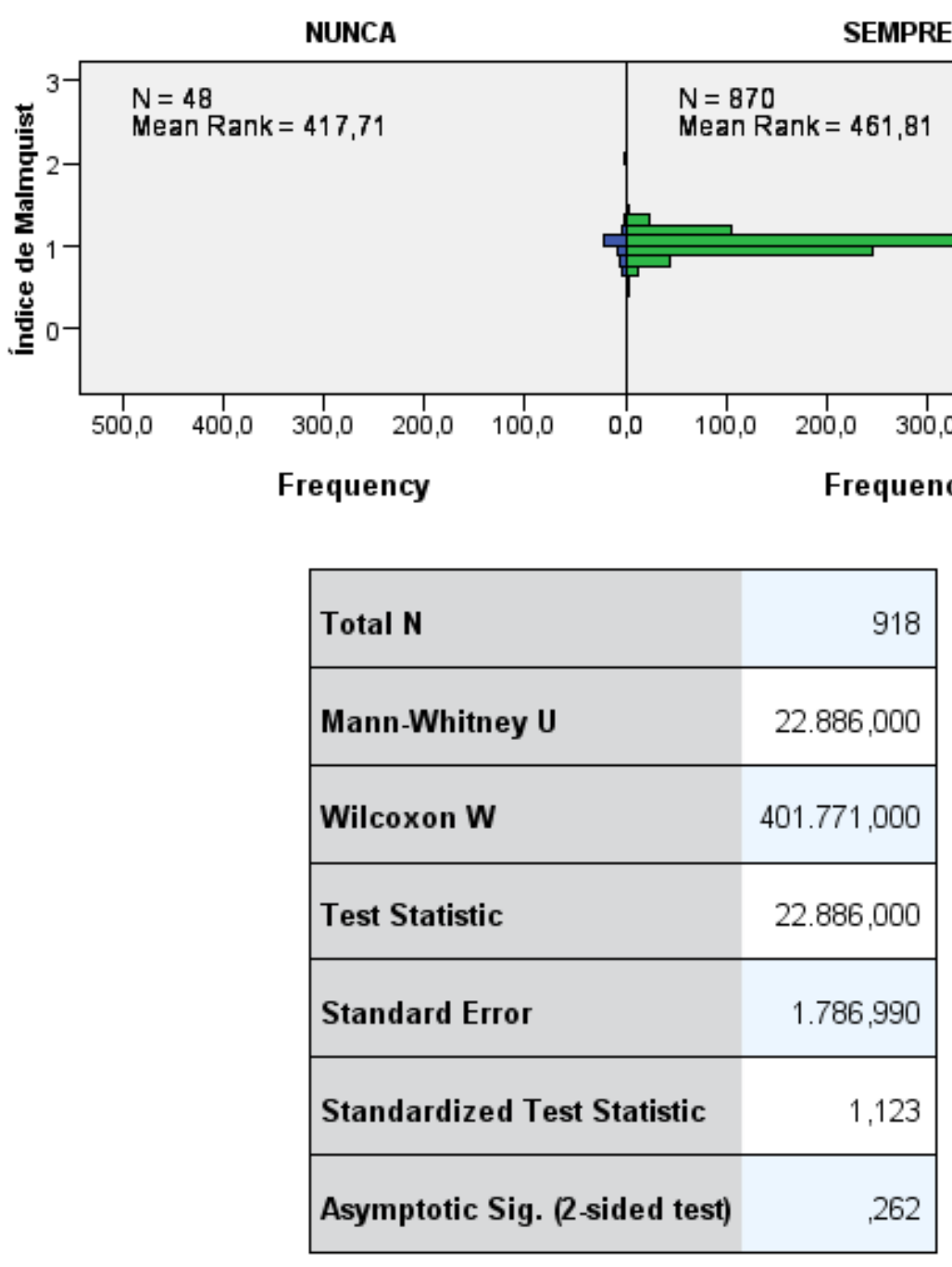

Fonte: Resultados do teste Mann-Whitney 
Gráfico 8. Representação do teste de Mann-Whitney

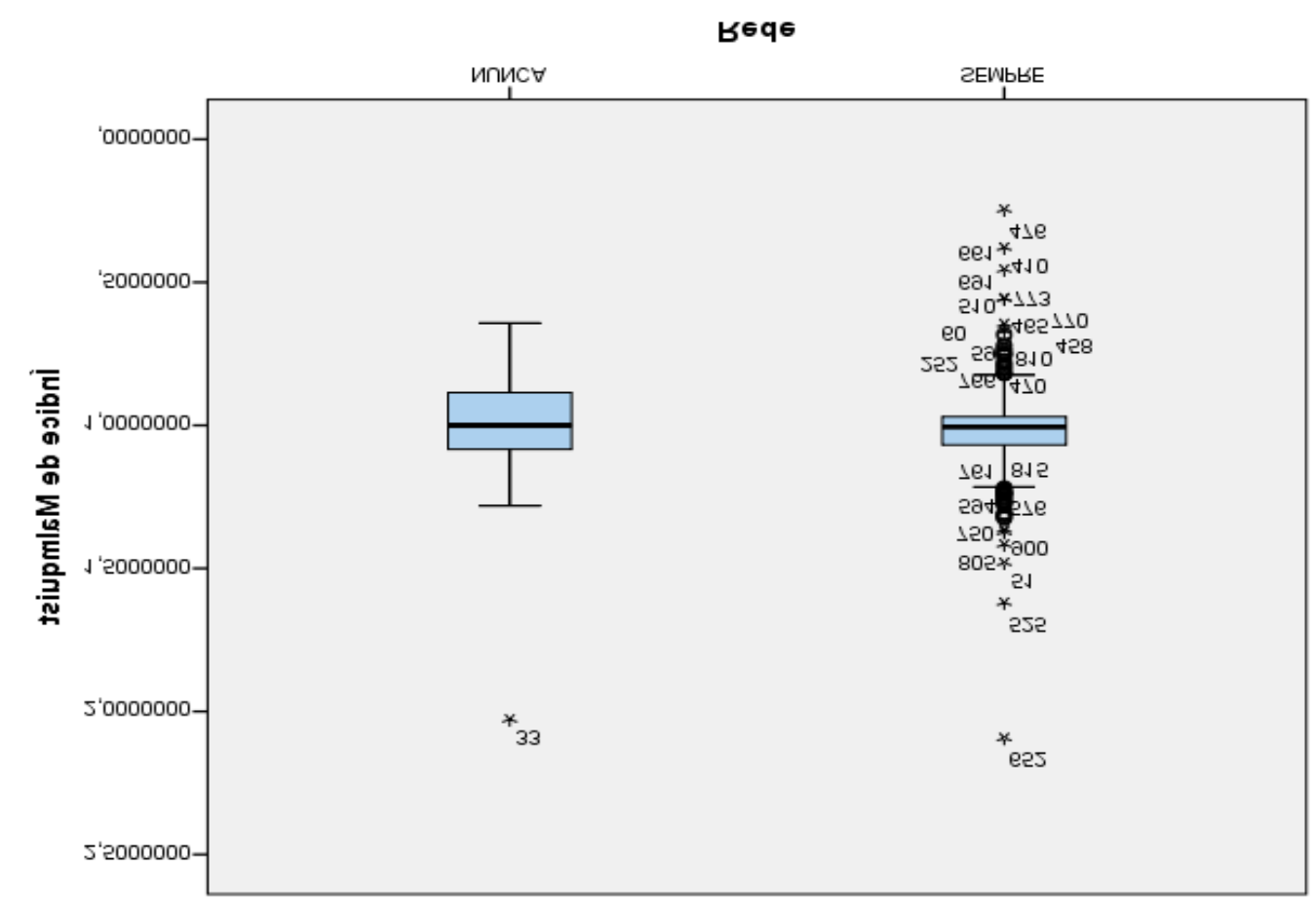

Fonte: Resultados do teste Mann-Whitney

Como resultado do teste estatístico, obteve-se $p$-valor igual a 0,262, valor este superior aos $5 \%$ máximo para que haja significância estatística entre as variáveis apresentadas. Com base nos resultados do teste, observa-se que não há diferença estatisticamente significante entre os grupos de tratamento e controle, ou seja, entre os municípios que sempre participaram da Rede Cegonha e os que nunca participaram.

Desta forma, pode-se afirmar que apesar do Índice de Malmquist indicar que houve uma evolução de eficiência de um triênio para o outro, observa-se que a Rede Cegonha não foi estatisticamente significante para determinar esta evolução, conforme se pode observar no gráfico 3.

Os resultados encontrados refutam a hipótese inicial de que a implantação da Rede de Atenção à Saúde aumentou a eficiência da saúde materno-infantil do SUS e contestam as afirmações de Silva (2011), Mendes (2011) e OPAS (2011) de que as redes integradas de saúde promovem a eficiência nas ações e prestação de serviços de saúde. Além disso, observa-se que as Redes de Atenção à Saúde, que tem como pressuposto o uso eficiente de recursos não está conseguindo alcançar os resultados esperados. Pode-se inferir que a estrutura hierárquica e seus processos tipicamente 
burocráticos continuam arraigados no sistema de saúde de modo a impedir avanços na estrutura administrativa.

Ademais, a RAS depende de integração dos seus atores participantes com fortalecimento da atenção básica como coordenadora das ações e serviços de saúde nos pontos de atenção da Rede por meio de uma estrutura de governança do tipo organização administrativa da rede (OAR), muito embora essa configuração possa tornar o processo mais burocrático gerada pela concentração da confiança em apenas um membro da rede e não mais nos outros participantes, obtendo como consequência a ausência de envolvimento dos membros na tomada de decisões.

Ao se tratar de uma rede constituída por uma série de interações entre diversos participantes, composta de pontos de atenção atuando como atores da rede, que compartilham imagens da realidade com base na interpretação e avaliação dos atores envolvidos um sobre o outro, e consequentemente deveriam compartilhar de confiança para realizar a alocação de recursos financeiros, materiais e humanos na rede e de regras e normativos reguladores do funcionamento da rede. A partir dessa complexidade de interações surge a necessidade da criação de mecanismos que garantam o engajamento dos seus participantes na ação coletiva e solidária, bem como na resolução dos conflitos, para que a alocação de recursos seja realizada de forma eficiente e eficaz.

O pressuposto de uma rede é a integração dos seus participantes em relações horizontais, que facilitariam a comunicação, compartilhando normas, valores e confiança. A partir da perspectiva micro de capital social, essas relações horizontais seriam capazes de fortalecer uma rede de indivíduos que criariam externalidades para toda a sociedade. Assim, quanto maior a participação social em associações locais, maior seria a cultura cívica dos indivíduos, e melhor seria o desempenho do governo.

No entanto, o que se observa é indicativos de relações verticais, baseada em relações de autoridade e dependência, típicas de estruturas clientelistas, dada pela participação social limitada à pequenos grupos e elites; havendo a predominância da desconfiança e consequente corrupção. 


\subsection{ANÁLISE DE CORRELAÇÃO}

Em seguida, adotou-se a correlação de Tau-b de Kendall entre as variáveis de participação social do SUS e o índice de Malmquist resultante da avaliação da evolução da eficiência dos triênios 2007-2009 e 2013-2015. Esta correlação foi realizada visando mensurar o grau de relacionamento entre a evolução da eficiência a partir do índice de Malmquist e a estrutura de participação social existente no município. Conforme apresentado nas Tabelas 7 e 8 a correlação entre o progresso da eficiência entre os triênios foi insignificante tanto para o tempo de existência do Conselho de Saúde e auditoria quanto para a quantidade de reuniões realizadas pelo Conselho.

Tabela 7. Correlação entre eficiência e quantidade de reuniões nos Conselhos de Saúde

\begin{tabular}{|c|c|c|c|c|}
\hline \multicolumn{5}{|c|}{ Correlations } \\
\hline & & & $\begin{array}{r}\text { Malmquist_Index_G } \\
\text { eometric_Mean }\end{array}$ & $\begin{array}{r}\text { Qtd_de_reuniõe } \\
\text { s_nos_últimos_1 } \\
\text { 2_meses }\end{array}$ \\
\hline Kendall's tau_b & $\begin{array}{l}\text { Malmquist_Index_Geometric } \\
\text { _Mean } \\
\text { Qtd_de_reuniões_nos_últim } \\
\text { os_12_meses }\end{array}$ & $\begin{array}{l}\text { Correlation Coefficient } \\
\text { Sig. (2-tailed) } \\
\mathrm{N} \\
\text { Correlation Coefficient } \\
\text { Sig. (2-tailed) } \\
\mathrm{N}\end{array}$ & $\begin{array}{r}1,000 \\
. \\
918 \\
, 023 \\
, 346 \\
913 \\
\end{array}$ & $\begin{array}{r}, 023 \\
, 346 \\
913 \\
1,000 \\
. \\
913 \\
\end{array}$ \\
\hline
\end{tabular}

*. Correlation is significant at the 0.05 level (2-tailed).

Tabela 8. Correlação entre eficiência e tempo de existência dos Conselhos de Saúde

\begin{tabular}{|c|c|c|c|c|}
\hline \multicolumn{5}{|c|}{ Correlations } \\
\hline & & & $\begin{array}{l}\text { Malmquist_Index } \\
\text { Geometric_Mean }\end{array}$ & $\begin{array}{l}\text { Conselho_Temp } \\
\text { o_de_existência }\end{array}$ \\
\hline Kendall's tau_b & $\begin{array}{l}\text { Malmquist_Index_Geometric_ } \\
\text { Mean } \\
\text { Conselho_Tempo_de_existên } \\
\text { cia }\end{array}$ & $\begin{array}{l}\text { Correlation Coefficient } \\
\text { Sig. (2-tailed) } \\
\mathrm{N} \\
\text { Correlation Coefficient } \\
\text { Sig. (2-tailed) } \\
\mathrm{N}\end{array}$ & $\begin{array}{r}1,000 \\
. \\
918 \\
, 058^{*} \\
, 013 \\
912\end{array}$ & $\begin{array}{r}, 058^{*} \\
, 013 \\
912 \\
1,000 \\
. \\
912\end{array}$ \\
\hline
\end{tabular}

*. Correlation is significant at the 0.05 level (2-tailed). 
Os resultados demonstraram que a simples existência de um Conselho de Saúde com reuniões regulares não é determinante para que um município consiga prestar serviços de saúde materno-infantil de forma eficiente. Esses resultados corroboram as afirmações de Labra (2006) a respeito da lacuna existente entre a dimensão micro e macro dos Conselhos de Saúde. Muito embora os Conselhos se constituam em uma esfera de participação popular importante na gestão do SUS, esses não conseguem atuar como efetivos canais de democratização e participação; devido à presença de práticas de manipulação, clientelismo, troca de favores, cooptação e demais práticas não condizentes com uma esfera de participação social (WENDHAUSEN et al., 2006). Essa prática é explicada por Gruening (2001) e Tullock, (2005) como reflexo da existência das falhas do governo. Neste caso, o governo não possui controle do comportamento dos agentes públicos que tendem a agir para beneficiar interesses próprios privados.

Como justificativa para esta situação, Labra (2006) explica que os baixos índices de participação dos brasileiros na vida associativa e a descrença na eficácia da participação e do engajamento cívico acarretaria na escassez de capital social, ou seja, na ausência de relações de confiança, solidariedade e cooperação disseminadas que são recursos indispensáveis para que os Conselhos de Saúde possam ser efetivos. Essas afirmações reforçam as argumentações de Putnam (2002) a respeito das consequências da inexistência da comunidade cívica que ocasionariam a deserção, desconfiança, omissão, exploração, isolamento, desordem e estagnação. Segundo o autor as regiões menos cívicas estão mais sujeitas à corrupção e desconfiança entre os cidadãos, e desta forma, quanto maior o acúmulo de capital social e maior a cultura cívica, maior será o desenvolvimento da região.

A partir destes resultados pode-se analisar que muito embora a descentralização tenha sido adotada como via para assegurar a formulação, execução, monitoramento e avaliação de políticas públicas mais democráticas, dada a sua proximidade da cidadania organizada, visando o uso mais eficiente dos recursos públicos; o que se observa atualmente é a desarticulação dos entes. No caso da saúde, o modelo de descentralização devolutiva que permite que os entes sejam responsabilizados pela saúde local, alocação dos recursos e definição dos programas e políticas de saúde a ser adotada na sua esfera correspondente como alternativa a incapacidade de resposta às demandas da população dos sistemas hierárquicos não foi capaz de aumentar a eficiência dos serviços prestados. 
A não participação da população no processo de tomada de decisão local devido ao seu baixo nível engajamento cívico se reflete na baixa efetividade dos Conselhos de Saúde que acarreta na desarticulação do Sistema de Saúde como um todo. Assim, não obstante a adoção da configuração em Redes integradas de saúde pelo SUS, esta ainda se defronta com os desafios da fragmentação dos serviços e desarticulação municipal que se refletem nas esferas de Colegiado de gestão e promovem falhas na estrutura de governança de organização administrativa da rede como um todo.

Apesar disto, observa-se a existência de uma forte e crescente correlação ao longo do tempo entre o desempenho do SUS em saúde materno-infantil e a existência de estrutura de ouvidoria no município, conforme representada no gráfico 9.

Gráfico 9. Correlação entre ouvidoria e o índice de produtividade de Malmquist

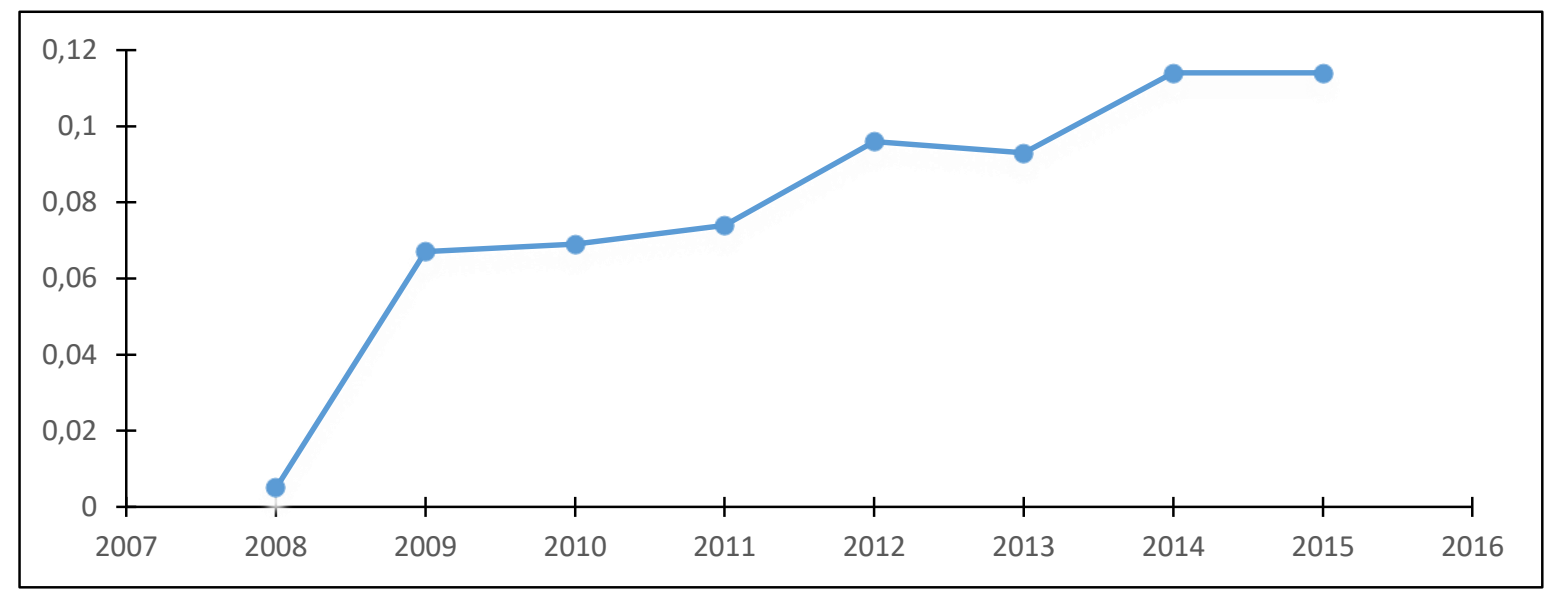

Fonte: Elaboração própria

Em análise do gráfico 9, nota-se que a evolução no coeficiente de correlação entre ouvidoria e o índice Malmquist apresenta uma variação de crescimento maior a partir de 2011. O aumento dessa relação pode ter sido reforçada pela publicação, em 18 de novembro de 2011, da lei 12.527, conhecida como Lei de Acesso à informação (LAl) que instituiu prazos de resposta para que o órgão ou entidade respondam às demandas dos cidadãos que podem ser solicitações, informações, elogios, denúncias e reclamações.

Assim, observa-se que muito embora os espaços de participação social sejam fragilizados dado ao esvaziamento da participação da população e pelo funcionamento incipiente desses espaços, a população encontra nas ouvidorias o canal para expressar suas necessidades de melhoria na saúde pública local. 


\section{CONCLUSÕES}

Dado o objetivo desta pesquisa de compreender a contribuição do modelo de gestão da Rede Cegonha para a eficiência da atenção à saúde materno-infantil, a partir dos resultados encontrados pode-se perceber que a implantação da Rede de Cegonha não foi não foi estatisticamente significante para o aumento da eficiência do SUS em saúde materno-infantil.

Considerando as limitações da análise, determinada principalmente pela indisponibilidade de dados para todos os municípios pode-se concluir que o estudo contribuiu para o preenchimento de uma lacuna relacionada à ausência de estudos quantitativos relacionados à eficiência da Rede de Atenção à Saúde na literatura.

A despeito das hipóteses levantadas, não ficou comprovado que os serviços de saúde se tornaram mais eficientes após a implementação da Rede Cegonha. Contesta-se também a hipótese de que o capital social seria um fator explicativo da eficiência das Redes. Muito embora a Rede Cegonha busque maior economicidade e racionalidade no uso de recursos visando o alcance do princípio de integralidade, ela ainda se defronta com os desafios da fragmentação dos serviços e desarticulação municipal. Para isso torna-se necessário investir em espaços de integração dos atores envolvidos na gestão e no cuidado.

Os resultados apresentados subsidiam e reforçam as argumentações a favor da existência de ineficiência e distorções no processo de formulação, implementação e execução da Redes Cegonha e da necessidade de correção desses entraves. As disparidades e as especificidades regionais, existentes no território brasileiro, condicionaram o desempenho e a ineficiência observada, apontando que a implementação da Redes Cegonha e ainda não possui integração e maturidade suficiente para minimizar o hiato existente entre as regiões do País.

Com relação aos resultados de análise de correlação, percebeu-se que a variável ouvidoria apresentou uma forte correlação com a eficiência do SUS, com comportamento crescente ao longo do tempo. De tal modo, pode-se conjecturar que o fortalecimento da estrutura de ouvidoria pode vir a aumentar a eficiência do SUS. Ademais, pode-se observar que sendo a ouvidoria um canal de participação social, o fortalecimento da sua estrutura poderia gerar aumento de estoque de capital social e assim melhorar o desempenho dos serviços prestados em saúde. 
Assim, sugere-se que pesquisas futuras perscrutem a rede de maneira a verificar as particularidades das relações entre os atores envolvidos na da Redes Cegonha e identificar quais seriam as entraves existentes ao funcionamento da RC no SUS. 


\section{REFERÊNCIAS}

ABREU, M. P. A Ordem do Progresso: Cem Anos de Política Econômica Republicana 1889-1989. Ed. Campus. Brasil, 2014.

ACUNA, K.; CRUZ, T. Avaliação do estado nutricional de adultos e idosos e situação nutricional da população brasileira. Arq Bras Endocrinol Metab, São Paulo, v. 48, n. 3, p. 345-361, June 2004

AGRANOFF, R.; KEAST, R; MANDELL, M. Network Theory in the Public Sector: Building New Theoretical Frameworks. Routledge, 2014

AFONSO, A.; AUBYN, M. ST. Non-parametric approaches to education and health efficiency in OECD countries. Journal of Applied Economics, v. VIII, n. 2, p. 227246, 2005.

AHLEIM, A .Reconsideration of Debreu's "Coefficient of Resource Utilization". In:BÖS, M.R; SEIDL, C.(Orgs.) Welfare and Efficiency in Public

Economics. Heidelberg: Springer-Verlag. 1988.

ASCHAUER, D. Is public expenditure productive? Journal of Monetary Economics, v. 23, p.177-200, 1989.

BAER, W. A Economia Brasileira. São Paulo: Nobel, 2009.

BAHL, R. W. Descentralização fiscal: uma perspectiva mundial. Brasília, DF: Esaf. 1998.

BARATA, L.R.B.; TANAKA, O.Y.; MENDES, J.D.V. Por um processo de descentralização que consolide os princípios do Sistema Único de Saúde.

Epidemiologia e Serviços de Saúde, Brasília, v.13, n.1, 2004.

BERGH, S. Democratic decentralisation and local participation: a review of recent research, Development in Practice, v. 14, n. 6, 2004.

BERNABEI, R. et al. Randomized trial of impact of integrated care and case management of older people living in the community. British Medical Journal, 316, 1998

BENEGAS, M.; SILVA, F. G. F. DA. Estimação da eficiência técnica do SUS nos estados brasileiros na presença de insumos não-discricionários. Revista Brasileira de Economia, v. 68, n. 2, p. 171-196, jun. 2014.

BENNINGTON, J. From private choice to public value. IN: BENNINGTON, J.; MOORE, M.H. Public Value: Theory and Practice.Basingstoke: Palgrave Macmillan, 2011

BOURDIEU, P. The forms of capital. In Richardson J. (Org.) Handbook of Theory and Research for the Sociology of Education. New York, Greenwood.1986.

BRASIL, Conselho Nacional de Secretários de Saúde. As oficinas para a organização das redes de atenção à saúde: CONASS. CONASS Documenta; $n$. 21,2010

BRASIL, Ministério da Saúde. Dispõe sobre as condições para a promoção, proteção e recuperação da saúde, a organização e o funcionamento dos serviços correspondentes e dá outras providências. Lei n. 8.080 de 19 de setembro de 1990 . 
. Divulga o Pacto pela Saúde 2006 - Consolidação do SUS e aprova as Diretrizes Operacionais do Referido Pacto. Portaria no 399/GM de 22 de fevereiro de 2006.

. Regulamenta a Lei no 8.080, de 19 de setembro de 1990, para dispor sobre a organização do Sistema Único de Saúde-SUS, o planejamento da saúde, a assistência à saúde e a articulação interfederativa, e dá outras providências. Decreto no 7.508, de 28 de junho de 2011a.

. Institui, no âmbito do Sistema Único de Saúde - SUS - a Rede Cegonha. Portaria MS/GM no 1.459, de 24 de junho de 2011b.

Secretaria de Atenção à Saúde. Manual prático para implementação da Rede Cegonha. Brasília: 2011c.

BUCHANAN, J.M. Positive economics, welfare economics, and political economy. Journal of Law and economics. v.2, 1959.

BHUYAN, A., A. JORGENSEN, AND S. SHARMA. Taking the Pulse of Policy: The Policy Implementation Assessment Tool. Washington, DC: Futures Group, Health Policy Initiative, 2010.

CROZIER, M. Le Phénomêne bureaucratique. Paris, Seuil, 1971.

CAMARANO, A. A. Novo Regime Demográfico: uma nova relação entre população e desenvolvimento?. Rio de Janeiro: Ipea, 2014

CARVALHEIRO, J. R.; MARQUES, M. C. C.; MOTA, A. A construção da saúde pública no Brasil no século XX e início do século XXI. In: ROCHA, A. A.; CESAR, C. L. G.; RIBEIRO, H. Saúde pública: bases conceituaisl. São Paulo: Atheneu, 2013.

CARTWRIGHT, D., \& HARARY, F. Structural balance: A generalization of Heider's theory. PsychoZogicaZ Review, 1956.

CASTELLS, M. A sociedade em rede. São Paulo: Paz e Terra, 1999.

CAVALCANTI, P. C. DA S. et al. Um modelo lógico da Rede Cegonha. Physis:

Revista de Saúde Coletiva, v. 23, n. 4, p. 1297-1316, 2013.

CESCONETTO, A.; LAPA, J. D. S.; CALVO, M. C. M. Evaluation of productive efficiency in the Unified National Health System hospitals in the State of Santa Catarina, Brazil. Cadernos de saude publica / Ministerio da Saude, Fundacao Oswaldo Cruz, Escola Nacional de Saude Publica, v. 24, n. 10, p. 2407-2417, 2008.

CHEEMA, S. G.; RONDINELLI, D. A. From government decentralization to decentralized governance. Decentralizing Governance. Emerging Concepts and Practices, p. 1-20, 2007.

COELLI, T.; RAO, D.; BATTESE, G. An Introduction to Efficiency and

Productivity Analysis. Massachusetts: Kluwer Academic Publishers, 2002.

COLEMAN, J.S. Social Capital in the Creation of Human Capital. The American Journal of Sociology, v. 94, Supplement: Organizations and Institutions:

Sociological and Economic Approaches to the Analysis of Social Structure, 1988.

CORREIA, M. V. C. Desafios para o controle social: subsídios para a capacitação de conselheiros de saúde. Rio de Janeiro, FIOCRUZ, 2005

COTTA, R. M. M.; CAZAL, M. DE M.; RODRIGUES, J. F. DE C. Participação, 
Controle Social e Exercício da Cidadania: a (des)informação como obstáculo à atuação dos conselheiros de saúde. Physis, v. 19, n. 2, 2009.

DARAIO, C.; SIMAR, L. Advanced Robust and Nonparametric Methods in

Efficiency Analysis: Methodology and Applications. Springer Science \& Business Media, 2007.

DEBREU, G. The Coefficient of Resource Utilization. Econometric Society, v. 19, n. 3, 1951.

DI GIOVANNI, M. DI. Rede Cegonha: da concepção à implantação. 98 f. Monografia (Especialização em Gestão Pública) - Escola Nacional de Administração Pública, Brasília, DF, 2013.

ESCOREL, S.; TEIXEIRA, L.A. História das políticas de saúde no Brasil de 1822 a 1963: do império ao desenvolvimentismo populista. In: GIOVANELLA, L. et al. (org.), Políticas e Sistemas de Saúde no Brasil. Rio de Janeiro: Editora FIOCRUZ, 2013.

EVANS, D. B. et al. The comparative efficiency of National of Health Systems in producing health: An analysis of 191 countries. World Health Organization, v. 29, n. 29, 2000.

FADEL, C. B. et al. Administração pública: o pacto pela saúde como uma nova estratégia de racionalização das ações e serviços em saúde no Brasil. Revista de Administração Pública, v. 43, n. 2, abr. 2009.

FAGUET, J.-P. Does decentralization increase government responsiveness to local needs? Journal of Public Economics, v. 88, n. 3-4, mar. 2004.

FALEIROS, V.P.; SILVA, J.F.S.VASCONCELLOS, L.C.F. SILVEIRA, R.M.G. A construção do SUS: histórias da Reforma Sanitária e do Processo Participativo. Brasília: MS, 2006

FARRELL, M.J. The Measurement of Productive Efficiency. Journal of the Royal Statistical Society. Series A, v. 120, n. 3, 1957.

FERNANDES, A.S.A.A comunidade cívida em Walzer e Putnam. Revista Lua Nova, São Paulo, n. 51, 2000.

FLEURY, S. M. T.; OUVERNEY, A. M. Gestão de Redes: a estratégia de regionalização da política de saúde. Rio de Janeiro: Editora FGV, 2007.

FRIED, H. O.; LOVELL, C. A. K.; SHELTON, S. S. Efficiency and Productivity. In: The Measurement of Productive Efficiency and Productivity Change. Oxford University Press, 2008

GAMA, E. P. N.; SANTOS, A. M. P. Ciudadanía y poder local y el control del Estado. Red Iberoamericana de Investigadores sobre Globalización y Teritório, México 2004.

GIAMBIAGI, F. CASTRO, L.B.; VILLELA, A.; HERMANN, J. Economia Brasileira Contemporânea. Elsevier - Campus, 2011.

GIL, A.C.Como elaborar projetos de pesquisa. São Paulo: Atlas, 2007

GOLANY, B.; ROLL, Y. An Application Procedure For DEA. Omega-international Journal of Management Science, v. 17, n. 3, p. 237-250, 1989.

GRAICUNAS, V.A. Relationship in organization. IN: GULICK, L.; URWICK, L. Papers on the science of administration. New York: Institute of Public Administration. 
1937.

GRÄVINGHOLT, J. et al. Strengthening Participation through Decentralisation. Findings on local economic development in Kyrgyzstan.

GONÇALVES, A. C. et al. Data envelopment analysis for evaluating public hospitals in Brazilian state capitals. Revista De Saude Publica, v. 41, n. 3, p. 427-435, 2007.

GOLDSMITH, S.; EGGERS, W. D. Governar em rede: o novo formato do setor público. Brasília: ENAP, 2006;

GROOTAERT, C; BASTELAER, T.V.Understanding and Measuring Social Capital: A Multi-Disciplinary Tool for Practitioners. Washington, D.C.: World Bank, 2002

GRUBER, J. Public Finance and Public Policy. New York, NY: Worth Publishers, 2009.

GRUENING, G. Origin and theoretical basis of New Public Management, International Public Management Journal, 4, 2001.

GUIZARDI, F.L. et al. Participação da comunidade em espaços públicos de saúde: uma análise das Conferências Nacionais de Saúde. Physis, Rio de Janeiro, v. 14, n. 1, 2004

GULICK, L. Values and public administration. In: Gulick, L. e Urwick, L. Papers on science of administration. Institute of public administration, New York, 1937

GULICK, L.H. Papers on the science of administration. New York: Columbia University, 1937.

GUPTA, S.; VERHOEVEN, M. The efficiency of government expenditure:

experiences from Africa. Journal of Policy Modeling, v. 23, n. 4, p. 433-467, maio 2001.

HANIFAN, L. J. The Rural School Community Centre. Annals of the American Academy of Political and Social Sciences, n. 67, 1916.

HERRERA, S.; PANG, G. Efficiency of Public Spending in Developing Countries: An efficiency frontier approach. Journal of Chemical Information and Modeling, 2005.

HOLLINGSWORTH, B. The measurement of efficiency and productivity of health care delivery. Health Economics, v. 17, n. 10, p. 1107-1128, 2008.

INMAN, R., Markets, Government, and the New Political Economy, in Auerbach, Alan and Feldstein, Martin (Orgs), Handbook of Public Economics, v. II, Cambridge, MA, MIT Press., 1987

JONES, G.; STEWART, J. The Case for Local Government. London: Allen \& Unwin. 1985

KAPUCU, N., ARSLAN, T. AND DEMIROZ, F. Collaborative emergency management and national emergency management network. Disaster Prevention and Management, v.19, n.4, 2010.

KEAST, R.; et al. Network Structures: Working Differently and Changing Expectations. Public Administration Review, v. 64, n. 3, 2004.

KENIS, P.; PROVAN, K. G. TOWARDS AN EXOGENOUS THEORY OF PUBLIC NETWORK PERFORMANCE. v. 87, n. 3, p. 440-456, 2009.

KETTL, D. The Politics of the Administrative Process. Washington: Congressional 
Quarterly Press, 2005.

KLUGMAN, J. Decentralisation: A Survey of Literature from a Human Development Perspective. UNDP Human Development Report Office, 1994.

KOOIMAN, JAN. Modern governance: new government-society interactions. London: Sage Publications, 1993

KOOPMANS T. Activity analysis of production and allocation. John Wiley \& Sons, New York, 1951;

KUSCHNIR R., CHORNY A. Redes de atenção à saúde: contextualizando o debate. Ciência \& Saúde Coletiva.v.15, n.5, 2010.

KULIPOSSA, F.P. Decentralisation and Democracy in Developing Countries: An Overview. Development in Practice, vol. 14, n. 6, 2004.

LABRA, M. E. Capital social y consejos de salud en Brasil: un círculo virtuoso? Cadernos de Saúde Pública, v. 18, n. supl, 2002.

LABRA, M. E. Conselhos de Saúde: Visões "Macro" e "Micro". Civitas, v. 6, n. 1, 2006.

LAKATOS, E. M. de A.; MARCONI, M. de A. Fundamentos da metodologia científica. São Paulo: Atlas, 2003

LAVRAS, C. Atenção primária à saúde e a organização de redes regionais de atenção à saúde no Brasil. Saúde e Sociedade, v. 20, n. 4, p. 867-874, dez. 2011.

LIMA, L. D. de et al . Regionalização e acesso à saúde nos estados brasileiros: condicionantes históricos e político-institucionais. Ciênc. saúde coletiva, Rio de Janeiro, v. 17, n. 11, p. 2881-2892, Nov. 2012

LINS, M. E. et al. O uso da Análise Envoltória de Dados (DEA) para avaliação de hospitais universitários brasileiros. Ciência \& Saúde Coletiva, v. 12, n. 4, p. 985998, 2007.

LITVACK, J.E.; SEDDON, J. Decentralization Briefing Notes. Washington, DC., The World Bank,1999.

LOIOLA, E.; MOURA, S. Análise das redes: uma contribuição aos estudos organizacionais. In: FISCHER, Tânia (org.) Gestão contemporânea: cidades estratégicas e organizações locais. FGV, Rio de Janeiro, 1996.

MANDELL, M. P.; STEELMAN, T. A. Understanding What Can Be Accomplished Through

Interorganizational Innovations. Public Management Review, v. 5, n. 2, 2003.

MARINHO, A. Avaliação da eficiência técnica nos serviços de saúde dos municípios do Estado do Rio de Janeiro. Texto para discussão - IPEA, Rio de Janeiro, n. 842, 2001.

MARINHO, A.Avaliação da eficiência técnica nos serviços de saúde nos municípios do Estado do Rio de Janeiro. Revista Brasileira de Economia, 57(3), 515-534, 2003.

MARSH, D.; RHODES, R. A. Policy networks in British politics: A critique of existing approaches. In: RHODES, R. A.; MARSH, D. Policy networks in British

government. Oxford: Clarendon Press, 1992. 
MARTINS, P. H. Gestão de redes: a estratégia de regionalização da política de saúde. Cadernos de Saúde Pública, v. 24, n. 7, jul. 2008.

MAZON, L. M.; MASCARENHAS, L. P. G.; DALLABRIDA, V. R. Eficiência dos gastos públicos em saúde: desafio para municípios de Santa Catarina, Brasil. Saúde e Sociedade, v. 24, n. 1, p. 23-33, mar. 2015.

MCINNES, G.T. \& MCGHEE, S.M. Delivery of care for hypertension. J. Hum. Hypertens., 9, 1995.

McCULLOCH, D.K. et al. A population-based approach to diabetes management in a primary care setting: early results and lessons learned. Eff. Clin. Pract., 1, 1998.

MENDES, E. V. As redes de atenção à saúde. Ciência \& Saúde Coletiva, v. 15, n. 5, p. 2297-2305, ago. 2010.

MENDES, E.V. As Redes de Atenção à Saúde. Brasília: Organização PanAmericana da Saúde, 2011.

MERTON, R. Estrutura burocrática e personalidade. CAMPOS, E. (org.) Sociologia da Burocracia. Rio de Janeiro: Zahar Editores, 1978.

MUSGRAVE, R.; MUSGRAVE, P. Public finance in theory and practice. McGrawHill, 1980.

NAVARRETE, M. V.; SILVA, M. R. F.; CAMPOS, E. S. et al. Visión de los diferentes agentes sociales sobre la participación social en el sistema de salud en el nordeste de Brasil: una aproximación cualitativa. Rev. Esp. Salud Pública, Madri, v. 76, n. 5, 2003

NISKANEN, W. Bureaucracy and Public Economics. The Locke institute, 1994

NOHRIA, N. Is a network perspective a useful way of studying organizations? In: NOHRIA, N.; ECCLES, R. G.(Org.). Networks and organizations: structure, form, and action. Boston, Massachusetts: Harvard Business School Press, 1992.

NORONHA, J.C. LIMA, T.D. MACHADO, C.V. O Sistema único de Saúde SUS .IN: GIOVANELLA, L. et al.(Orgs). Política e Sistema de Saúde no Brasil. CEBES, Editora FIOCRUZ. Rio de Janeiro 2012.

OATES, W. An essay on fiscal federalism. Journal of economic literature, Nashville, v. 37, n.3. 1999

OLIVER, A. L.; EBERS, M. Networking network studies: Na analysis of conceptual configurations in the study of inter-organizational relationships. Organization Studies, v.19, 1998.

OLIVEIRA, J. B.; GUSMÃO, S. C. A experiência de saúde da família no estímulo à participação social no município de Vitória da Conquista BA. In: SECLEN-PALACIN, J. A.; FERNANDES, A. S. Experiências e desafios da atenção básica e saúde familiar: caso Brasil. Brasília: Organização Pan-Americana da Saúde, 2004 OSBORNE, D.; GAEBLER, T. Reinventando o governo. Brasília: Editora MH Comunicação, 1992.

OSMAN, L.M. et al. Integrated care for asthma: matching care to the patient. Euro Respiratory J., 9, 1996.

O'TOOLE, L. J.; MEIER, K. J. Modeling the Impact of Public Management: 
Implications of Structural Context. Journal of Public Administration Research and Theory, v. 9, n. 4, p. 505-526, 1999.

PAIM, J.S. Reforma sanitária brasileira: contribuição para a compreensão e crítica. Salvador: EDUFBA; Rio de Janeiro: FIOCRUZ, 2008

PAIVA, C.H.A.; TEIXEIRA, L.A. Reforma sanitária e a criação do Sistema Único de Saúde: notas sobre contextos e autores. Hist. cienc. saude-Manguinhos, Rio de Janeiro , v. 21, n. 1, p. 15-36, Mar. 2014

PAULA, A. P; de. Por uma nova gestão pública: limites e potencialidades da experiência contemporânea. Rio de Janeiro: Editora FGV, 2005.

PFIFFNER, J.M.; PRESTHUS, R.V. Public Administration. 1960.

PIOLA, S. F. et al. Gasto tributário e conflito distributivo na saúde. In: CASTRO, J. A.; SANTOS, C. H.; RIBEIRO, J. A. C. Tributação e equidade no Brasil: um registro da reflexão do Ipea no biênio 2008-2009. Brasília: Ipea, 2010.

PIOLA, S. F.; VIANNA, S. M. Saúde no Brasil: algumas questões sobre o Sistema Único de Saúde (SUS), Texto para Discussão n. 1391,Ipea: Brasília, 2008

PROITE, A.; SAMPAIO DE SOUZA, M. C. Eficiência técnica, economias de escala, estrutura da propriedade e tipo de gestão no sistema hospitalar brasileiro. In: ENCONTRO NACIONAL DE ECONOMIA DA ASSOCIAÇÃO NACIONAL DE CENTROS DE PÓS - GRADUAÇÃO EM ECONOMIA, 32., Anais... -ANPEC, 2004

PROVAN, K. G.; MILWARD, H. B. A Preliminary Theory of Interorganizational Network Effectiveness: A Comparative Study of Four Community Mental Health Systems. Administrative Science Quarterly, v. 40, n. 1, 1995.

PROVAN, K.; LEMAIRE, R. Core Concepts and Key Ideas for Understanding Public Sector Organizational Networks: Using Research to Inform Scholarship and Practice.

Public Administration Review. v. 72, n. 5.2012

RAM, R.Government size and economic growth: a new framework and some evidence from cross-section and time-series data. The American Economic Review. v.76, n. 1, 1986.

REUBEN, D.B. et al. A randomized clinical trial of outpatient comprehensive geriatric assessment coupled with an intervention to increase adherence to recommendations. J.Am.Geriatr.Soc., 47, 1999

RIBOT, J.C. LARSON, L.M. Decentralization of natural resources: experiences in Africa, Asia and Latin America. London: Frank Cass, 2005.

RHODES, R. A.W. Beyond Westminster and Whitehall: the subcentral governments of Britain. London: Allen \& Unwin, 1988.

RHODES, R. A. W. The New Governance: Governing Without Government. Political Studies. University of Newcastle-upon-Tyne. n. 44, 1996.

RODRÍGUEZ-POSE, A.; BWIRE, A. The economic (in)efficiency of devolution. Environment and Planning A, v.36, n.11, 2004.

RODRIGUES, L. B. B. et al. Coordenação das redes de atenção à saúde pela atenção primária: validação semântica de um instrumento adaptado. Cadernos de Saúde Pública, v. 30, n. 7, p. 1385-1390, jul. 2014.

RONDINELLI, D.; NELLIS, J.; CHEEMA, G.; WDR. Decentralization in developing 
countries: a review of recent experience. Staff working paper ; $\mathrm{n} .581$. Washington, D.C. : The World Bank, 1983.

ROVERE, M. Redes en Salud: un nuevo paradigma para el abordaje de las organizaciones y la comunidad. Rosario: Ed. Secretaría de Salud Pública/AMR, Instituto Lazarte, 1999.

SAMPAIO DE SOUSA, M. C.; CRIBARI-NETO, F.; STOSIC, B. D. Explaining DEA technical efficiency scores in an outlier corrected environment: the case of public services in Brazilian municipalities. Brazilian review of econometrics, v. 25, Nov. 2005.

SANTOS, F.F.S. Capital Social : Vários conceitos, um só problema. 2003. 84 f. Dissertação (Mestrado) - Fundação Getúlio Vargas, São Paulo, 2003.

SANTOS, J. R. P. Os desafios da conformação das redes de atenção à saúde no Brasil. 2013. 155 f. Dissertação (Mestrado) - Universidade de Brasília, Brasília, 2013

SCATENA, J.H.G.; TANAKA, O.Y. Os instrumentos normatizadores (NOB) no processo de descentralização da saúde no município de Itajaí. Saúde e Sociedade, São Paulo, v.10, n.2, 2001.

SCHNEIDER, A. Decentralization : Conceptualization and Measurement. Studies in Comparative International Development, v. 38, n. 3, p. 32-56, 2003.

SERAGELDIN, I; GROOTAERT, C. Defining Social Capital: An Integrating View. In DASGUPTA P.; SERAGELDIN, I. (Orgs.) Social Capital: A Multifaceted Perspective. Washington, D.C.: World Bank. 2000.

SHIMIZU, H. E. Percepção dos gestores do Sistema Único de Saúde acerca dos desafios da formação das Redes de Atenção à Saúde no Brasil. Physis, Rio de Janeiro, v. 23, n. 4, 2013

SILVA, S.F. Organização de redes regionalizadas e integradas de atenção à saúde: desafios do Sistema Único de Saúde (Brasil). Ciênc. saúde coletiva, Rio de Janeiro, v. 16, n. 6, 2011.

SIMAR, L; WILSON, P. Estimation and Inference in Two-stage, Semi-parametric Models of Production Processes. Journal of Econometrics, v. 136, p. 31-64, 2007.

SIMON, H. A. Administrative behavior: A study of Decision-making Processes in Administrative Organization. New York: The Free Press, 1976.

SIMON, G. E. et al. Cost-effectiveness of a collaborative care program for primary care patients with persistent depression. Am. J. Psychiatry, 158, 2001

SOUZA, C. Governos e sociedades locais em contextos de desigualdades e de descentralização. Rio de Janeiro, Ciência e Saúde Coletiva, v.7, n.3, 2002.

SOUZA, I. V.; NISHIJIMA, M.; ROCHA, F. Eficiência do setor hospitalar nos municípios paulistas. Economia Aplicada, v. 14, n. 1, p. 51-66, 2010.

STARFIELD B, SHI L. Policy relevant determinants of health: an international perspective. Health Policy, 2002.

STIGLITZ, J. Economics of the public sector. Norton, 2000.

TANZI, V. Fiscal federalism and decentralization: a review of some efficiency and 
macroeconomic aspects. The World Bank Research Observer, Annual Conference Supplement, Cary, 1995.

TAVARES, Maria da C. A retomada da hegemonia norte-americana. In: TAVARES, Maria. C. e FIORI, José. L. (Orgs.). Poder e dinheiro: uma economia política da globalização. Rio de Janeiro: Vozes, 1997.

TEIXEIRA, C. F.; PAIM, J. S. \& VILASBOAS, A. L., SUS, modelos assistenciais e vigilância da saúde. Informe Epidemiológico do SUS,n. 7. 1998.

TRAVASSOS, C.; BUSS, P. M. O polêmico relatório da Organização Mundial de Saúde. Cadernos de Saúde Pública, v. 16, n. 4, p. 890-891, dez. 2000.

TROMPIERI-NETO, N.; BARBOSA, M. P.; HOLANDA, M. C. Determinantes da eficiência dos gastos públicos municipais em educação e saúde: $O$ caso do Ceará. In: CARVALHO, E. B. S. (Ed.). . IV Encontro de Economia do Ceará em Debate. Fortaleza,2008.

UGÁ, A. D. et al. Considerations on methodology used in the World Health Organization 2000 Report. Cadernos de Saúde Pública, v. 17, n. 3, p. 705-712, jun. 2001.

VERGARA, Sylvia C. Projetos e relatórios de pesquisa em administração. Rio de Janeiro: Atlas, 2000.

VIACAVA, F. et al. Uma metodologia de avaliação do desempenho do sistema de saúde brasileiro. Ciência \& Saúde Coletiva, v. 9, n. 3, p. 711-724, set. 2004.

VIANA, A.L.; MACHADO, C.V. Descentralização e coordenação federativa: a experiência brasileira na saúde. Ciência \& Saúde Coletiva, v. 14, n. 3, p. 807-17, 2009

WAGNER, E. H. The role of patient care teams in chronic disease management. British Medical Journal, 320, 2000.

WALLIS, J. J., OATES, W. E., OATES, W. E. Decentralization in the Public Sector: An Empirical Study of State and Local Government. Studies in fiscal federalism. Economists of the Twentieth Century series, Aldershot, U.K. and Brookfield, Vt.: Elgar, 1991.

WEBER, M. Economia e sociedade: fundamentos da sociologia compreensiva. São Paulo: Imprensa Oficial, 2004.

WENDHAUSEN, Á. L. P.; BARBOSA, T. M.; BORBA, M. C. DE. Empoderamento e recursos para a participação em conselhos gestores. Saúde e Sociedade, v. 15, n. 3, 2006.

WEINGARTEN, M.A. et al. A pilot study of the multidisciplinary management of childhood asthma in a family practice. Journal of Asthma, 22, 1985 


\section{Apêndice}

Tabela 1.A - Resultado da análise estática com aplicação do Network -DEA

\begin{tabular}{|c|c|c|c|c|c|}
\hline GRUPO & UF & Município & $\begin{array}{l}\text { Score de } \\
\text { Eficiência Total }\end{array}$ & $\begin{array}{l}\text { Score de } \\
\text { Eficiência } \\
\text { (nó 1) }\end{array}$ & $\begin{array}{l}\text { Score de } \\
\text { Eficiência } \\
\text { (nó 2) }\end{array}$ \\
\hline Grupo de Tratamento & MG & Santana do Paraíso & 1 & 1 & 1 \\
\hline Grupo de Tratamento & MG & Belo Horizonte & 0,9366 & 1 & 0,9366 \\
\hline Grupo de Tratamento & $A L$ & Major Isidoro & 0,885735 & 0,885735 & 1 \\
\hline Grupo de Tratamento & $A L$ & Traipu & 0,883182 & 0,883182 & 1 \\
\hline Grupo de Tratamento & SP & Espírito Santo do Pinhal & 0,8425 & 1 & 0,8425 \\
\hline Grupo de Tratamento & SE & Aracaju & 0,8018 & 1 & 0,8018 \\
\hline Grupo de Tratamento & RJ & Rio de Janeiro & 0,723894 & 1 & 0,723894 \\
\hline Grupo de Tratamento & BA & Capela do Alto Alegre & 0,630413 & 0,630413 & 1 \\
\hline Grupo de Tratamento & BA & Salvador & 0,616824 & 1 & 0,616824 \\
\hline Grupo de Tratamento & BA & Sítio do Quinto & 0,604807 & 0,604807 & 1 \\
\hline Grupo de Tratamento & PE & Recife & 0,570357324 & 0,952666 & 0,598696 \\
\hline Grupo de Tratamento & MS & Aquidauana & 0,559349 & 0,559349 & 1 \\
\hline Grupo de Tratamento & SP & Vargem Grande do Sul & 0,554242 & 0,554242 & 1 \\
\hline Grupo de Tratamento & SP & Campinas & 0,529777797 & 0,618538 & 0,8565 \\
\hline Grupo de Tratamento & BA & Central & 0,52052 & 0,52052 & 1 \\
\hline Grupo de Tratamento & BA & Araças & 0,500577 & 0,500577 & 1 \\
\hline Grupo de Tratamento & SP & Atibaia & 0,482441332 & 0,632861 & 0,762318 \\
\hline Grupo de Tratamento & PB & Puxinanã & 0,452992 & 0,452992 & 1 \\
\hline Grupo de Tratamento & MS & Bonito & 0,44735 & 0,44735 & 1 \\
\hline Grupo de Tratamento & BA & Euclides da Cunha & 0,445473 & 0,445473 & 1 \\
\hline Grupo de Tratamento & RN & Areia Branca & 0,43764 & 0,43764 & 1 \\
\hline Grupo de Tratamento & SE & Nossa Senhora do Socorro & 0,429652 & 0,429652 & 1 \\
\hline Grupo de Tratamento & $\mathrm{BA}$ & Conceição do Almeida & 0,419543 & 0,419543 & 1 \\
\hline Grupo de Tratamento & BA & Serra Preta & 0,385805 & 0,385805 & 1 \\
\hline Grupo de Tratamento & $\mathrm{BA}$ & Ibicoara & 0,38386996 & 0,455632 & 0,8425 \\
\hline Grupo de Tratamento & RJ & Niterói & 0,381086477 & 0,466885 & 0,816232 \\
\hline Grupo de Tratamento & MG & Contagem & 0,365616729 & 0,49237 & 0,742565 \\
\hline Grupo de Tratamento & BA & Gongogi & 0,355619 & 0,355619 & 1 \\
\hline Grupo de Tratamento & RO & Cacoal & 0,343433571 & 0,50453 & 0,6807 \\
\hline Grupo de Tratamento & $\mathrm{BA}$ & Sebastião Laranjeiras & 0,342723 & 0,342723 & 1 \\
\hline Grupo de Tratamento & MG & Jaíba & 0,341251 & 0,341251 & 1 \\
\hline Grupo de Tratamento & $\mathrm{BA}$ & Anagé & 0,327227 & 0,327227 & 1 \\
\hline Grupo de Tratamento & BA & Tucano & 0,324134836 & 0,337746 & 0,9597 \\
\hline Grupo de Tratamento & PE & Camaragibe & 0,323146733 & 0,358097 & 0,9024 \\
\hline Grupo de Tratamento & BA & Uauá & 0,31597 & 0,31597 & 1 \\
\hline Grupo de Tratamento & BA & Pedro Alexandre & 0,315065 & 0,315065 & 1 \\
\hline Grupo de Tratamento & MG & Montes Claros & 0,312217 & 0,312217 & 1 \\
\hline Grupo de Tratamento & BA & Pau Brasil & 0,312109 & 0,312109 & 1 \\
\hline Grupo de Tratamento & MG & Betim & 0,307915317 & 0,360177 & 0,8549 \\
\hline
\end{tabular}




\begin{tabular}{|c|c|c|c|c|c|}
\hline Grupo de Tratamento & BA & Conceição da Feira & 0,307730108 & 0,344564 & 0,8931 \\
\hline Grupo de Tratamento & BA & Boa Nova & 0,303364 & 0,303364 & 1 \\
\hline Grupo de Tratamento & MG & Abaeté & 0,302789882 & 0,341018 & 0,8879 \\
\hline Grupo de Tratamento & PA & Belém & 0,29867242 & 0,477723 & 0,6252 \\
\hline Grupo de Tratamento & BA & Tremedal & 0,298507 & 0,298507 & 1 \\
\hline Grupo de Tratamento & MG & Datas & 0,294768 & 0,294768 & 1 \\
\hline Grupo de Tratamento & $\mathrm{BA}$ & Remanso & 0,289671726 & 0,386693 & 0,7491 \\
\hline Grupo de Tratamento & PR & Londrina & 0,284249196 & 0,345425 & 0,822897 \\
\hline Grupo de Tratamento & BA & Pojuca & 0,283510775 & 0,284478 & 0,9966 \\
\hline Grupo de Tratamento & MG & Sete Lagoas & 0,283331922 & 0,338428 & 0,8372 \\
\hline Grupo de Tratamento & SP & Jundiaí & 0,282629431 & 0,325126 & 0,869292 \\
\hline Grupo de Tratamento & BA & Serra do Ramalho & 0,281780924 & 0,282799 & 0,9964 \\
\hline Grupo de Tratamento & BA & Nova Canaã & 0,280308 & 0,280308 & 1 \\
\hline Grupo de Tratamento & $\mathrm{BA}$ & Olindina & 0,279117649 & 0,291903 & 0,9562 \\
\hline Grupo de Tratamento & $\mathrm{BA}$ & Palmeiras & 0,276716 & 0,276716 & 1 \\
\hline Grupo de Tratamento & $\mathrm{BA}$ & Teodoro Sampaio & 0,275116 & 0,275116 & 1 \\
\hline Grupo de Tratamento & MG & Diamantina & 0,273621641 & 0,300485 & 0,9106 \\
\hline Grupo de Tratamento & $A L$ & Girau do Ponciano & 0,272454 & 0,272454 & 1 \\
\hline Grupo de Tratamento & BA & Aporá & 0,270558 & 0,270558 & 1 \\
\hline Grupo de Tratamento & $\mathrm{BA}$ & Itiúba & 0,267409918 & 0,284998 & 0,938287 \\
\hline Grupo de Tratamento & PA & Ananindeua & 0,267257743 & 0,333156 & 0,8022 \\
\hline Grupo de Tratamento & MG & Espinosa & 0,26554684 & 0,266774 & 0,9954 \\
\hline Grupo de Tratamento & BA & Sento Sé & 0,265454634 & 0,282609 & 0,9393 \\
\hline Grupo de Tratamento & BA & Caravelas & 0,26498 & 0,26498 & 1 \\
\hline Grupo de Tratamento & RJ & Itaguaí & 0,264349542 & 0,295693 & 0,894 \\
\hline Grupo de Tratamento & BA & Araci & 0,263774461 & 0,308779 & 0,85425 \\
\hline Grupo de Tratamento & BA & João Dourado & 0,262066908 & 0,291992 & 0,897514 \\
\hline Grupo de Tratamento & MG & São João do Oriente & 0,261059 & 0,261059 & 1 \\
\hline Grupo de Tratamento & PB & Campina Grande & 0,261057205 & 0,288461 & 0,905 \\
\hline Grupo de Tratamento & BA & Sátiro Dias & 0,257809 & 0,257809 & 1 \\
\hline Grupo de Tratamento & BA & Guajeru & 0,257168 & 0,257168 & 1 \\
\hline Grupo de Tratamento & RJ & Nilópolis & 0,256955142 & 0,304305 & 0,8444 \\
\hline Grupo de Tratamento & MG & Várzea da Palma & 0,254476 & 0,254476 & 1 \\
\hline Grupo de Tratamento & BA & Morro do Chapéu & 0,251147 & 0,251147 & 1 \\
\hline Grupo de Tratamento & MG & Monte Azul & 0,248891 & 0,248891 & 1 \\
\hline Grupo de Tratamento & BA & Itaparica & 0,246356 & 0,246356 & 1 \\
\hline Grupo de Tratamento & BA & Lajedo do Tabocal & 0,246 & 0,246 & 1 \\
\hline Grupo de Tratamento & RN & Florânia & 0,241235 & 0,241235 & 1 \\
\hline Grupo de Tratamento & MG & Sabará & 0,240315322 & 0,32364 & 0,742539 \\
\hline Grupo de Tratamento & $\mathrm{BA}$ & Gentio do Ouro & 0,240132 & 0,240132 & 1 \\
\hline Grupo de Tratamento & PB & Pocinhos & 0,239414 & 0,239414 & 1 \\
\hline Grupo de Tratamento & RN & Tenente Ananias & 0,239123 & 0,239123 & 1 \\
\hline Grupo de Tratamento & MG & Padre Paraíso & 0,236591 & 0,236591 & 1 \\
\hline Grupo de Tratamento & $\mathrm{BA}$ & Monte Santo & 0,235634 & 0,235634 & 1 \\
\hline Grupo de Tratamento & MG & Matozinhos & 0,23450969 & 0,262022 & 0,895 \\
\hline
\end{tabular}




\begin{tabular}{|c|c|c|c|c|c|}
\hline Grupo de Tratamento & BA & Governador Mangabeira & 0,232559 & 0,232559 & 1 \\
\hline Grupo de Tratamento & BA & Teixeira de Freitas & 0,23207693 & 0,288617 & 0,8041 \\
\hline Grupo de Tratamento & RJ & São Gonçalo & 0,23191024 & 0,325357 & 0,712787 \\
\hline Grupo de Tratamento & BA & Sobradinho & 0,231642 & 0,231642 & 1 \\
\hline Grupo de Tratamento & $\mathrm{BA}$ & Feira de Santana & 0,230116287 & 0,343611 & 0,6697 \\
\hline Grupo de Tratamento & MS & Campo Grande & 0,229491671 & 0,328522 & 0,698558 \\
\hline Grupo de Tratamento & BA & Nova Viçosa & 0,228518779 & 0,231646 & 0,9865 \\
\hline Grupo de Tratamento & MG & Curral de Dentro & 0,228393 & 0,228393 & 1 \\
\hline Grupo de Tratamento & MA & São José dos Basílios & 0,226314 & 0,226314 & 1 \\
\hline Grupo de Tratamento & MG & Governador Valadares & 0,223173546 & 0,279561 & 0,7983 \\
\hline Grupo de Tratamento & MG & Novo Oriente de Minas & 0,22268 & 0,22268 & 1 \\
\hline Grupo de Tratamento & MG & Santo Antônio do Retiro & 0,222404 & 0,222404 & 1 \\
\hline Grupo de Tratamento & RS & Fortaleza dos Valos & 0,22127 & 0,22127 & 1 \\
\hline Grupo de Tratamento & BA & São Félix & 0,221065 & 0,221065 & 1 \\
\hline Grupo de Tratamento & $\mathrm{BA}$ & Itamaraju & 0,220974019 & 0,248449 & 0,889414 \\
\hline Grupo de Tratamento & RJ & Duque de Caxias & 0,220136675 & 0,369443 & 0,595861 \\
\hline Grupo de Tratamento & MG & Engenheiro Caldas & 0,21924 & 0,21924 & 1 \\
\hline Grupo de Tratamento & $\mathrm{BA}$ & Mundo Novo & 0,218362119 & 0,257092 & 0,849354 \\
\hline Grupo de Tratamento & MG & Rio Preto & 0,2183 & 0,2183 & 1 \\
\hline Grupo de Tratamento & SP & Franca & 0,217970084 & 0,276449 & 0,788464 \\
\hline Grupo de Tratamento & RO & Pimenta Bueno & 0,216974166 & 0,284743 & 0,762 \\
\hline Grupo de Tratamento & $\mathrm{BA}$ & Quixabeira & 0,216132 & 0,216132 & 1 \\
\hline Grupo de Tratamento & MG & Alpinópolis & 0,215918 & 0,215918 & 1 \\
\hline Grupo de Tratamento & MG & Cristália & 0,215366 & 0,215366 & 1 \\
\hline Grupo de Tratamento & BA & Ipupiara & 0,215352883 & 0,222656 & 0,9672 \\
\hline Grupo de Tratamento & $\mathrm{BA}$ & Baixa Grande & 0,212788307 & 0,224358 & 0,948432 \\
\hline Grupo de Tratamento & MG & Ibirité & 0,21242938 & 0,239411 & 0,8873 \\
\hline Grupo de Tratamento & MG & Curvelo & 0,210718534 & 0,223077 & 0,9446 \\
\hline Grupo de Tratamento & $\mathrm{BA}$ & Jaguaripe & 0,210503 & 0,210503 & 1 \\
\hline Grupo de Tratamento & BA & Santa Bárbara & 0,208147 & 0,208147 & 1 \\
\hline Grupo de Tratamento & $\mathrm{BA}$ & Barra do Choça & 0,20706 & 0,20706 & 1 \\
\hline Grupo de Tratamento & RO & Novo Horizonte do Oeste & 0,206626138 & 0,228039 & 0,9061 \\
\hline Grupo de Tratamento & BA & Poções & 0,206561 & 0,206561 & 1 \\
\hline Grupo de Tratamento & MG & São Romão & 0,205786 & 0,205786 & 1 \\
\hline Grupo de Tratamento & BA & Taperoá & 0,205417 & 0,205417 & 1 \\
\hline Grupo de Tratamento & PE & Jaboatão dos Guararapes & 0,205182215 & 0,316145 & 0,649013 \\
\hline Grupo de Tratamento & $\mathrm{BA}$ & Itaberaba & 0,204207283 & 0,263936 & 0,7737 \\
\hline Grupo de Tratamento & MG & Rio Manso & 0,203825 & 0,203825 & 1 \\
\hline Grupo de Tratamento & RN & Pau dos Ferros & 0,201559 & 0,201559 & 1 \\
\hline Grupo de Tratamento & CE & Senador Pompeu & 0,201233 & 0,201233 & 1 \\
\hline Grupo de Tratamento & MG & Padre Carvalho & 0,200925 & 0,200925 & 1 \\
\hline Grupo de Tratamento & BA & Nova Soure & 0,200475817 & 0,219088 & 0,915047 \\
\hline Grupo de Tratamento & MG & Itamarandiba & 0,20027 & 0,20027 & 1 \\
\hline Grupo de Tratamento & $\mathrm{BA}$ & Saubara & 0,200221916 & 0,222865 & 0,8984 \\
\hline Grupo de Tratamento & BA & Mascote & 0,200074 & 0,200074 & 1 \\
\hline
\end{tabular}




\begin{tabular}{|c|c|c|c|c|c|}
\hline Grupo de Tratamento & BA & Mata de São João & 0,198541893 & 0,257579 & 0,7708 \\
\hline Grupo de Tratamento & BA & Crisópolis & 0,198221 & 0,198221 & 1 \\
\hline Grupo de Tratamento & BA & Itapicuru & 0,197777182 & 0,214221 & 0,923239 \\
\hline Grupo de Tratamento & $\mathrm{BA}$ & Várzea Nova & 0,196707 & 0,196707 & 1 \\
\hline Grupo de Tratamento & BA & Mortugaba & 0,196464 & 0,196464 & 1 \\
\hline Grupo de Tratamento & BA & Cansanção & 0,194971 & 0,194971 & 1 \\
\hline Grupo de Tratamento & $\mathrm{BA}$ & Conde & 0,194965 & 0,194965 & 1 \\
\hline Grupo de Tratamento & BA & Urandi & 0,194854937 & 0,209125 & 0,931763 \\
\hline Grupo de Tratamento & MG & Juvenília & 0,19402 & 0,19402 & 1 \\
\hline Grupo de Tratamento & BA & Glória & 0,19359 & 0,19359 & 1 \\
\hline Grupo de Tratamento & MG & Araçuaí & 0,192993 & 0,192993 & 1 \\
\hline Grupo de Tratamento & MG & Três Marias & 0,191728 & 0,191728 & 1 \\
\hline Grupo de Tratamento & PI & Demerval Lobão & 0,190914 & 0,190914 & 1 \\
\hline Grupo de Tratamento & $\mathrm{BA}$ & Coronel João Sá & 0,190709 & 0,190709 & 1 \\
\hline Grupo de Tratamento & BA & Ribeira do Amparo & 0,190529 & 0,190529 & 1 \\
\hline Grupo de Tratamento & BA & Amargosa & 0,189661282 & 0,237641 & 0,7981 \\
\hline Grupo de Tratamento & BA & Wanderley & 0,189521 & 0,189521 & 1 \\
\hline Grupo de Tratamento & BA & Guanambi & 0,189353562 & 0,226961 & 0,8343 \\
\hline Grupo de Tratamento & PE & Gravatá & 0,189188605 & 0,231565 & 0,817 \\
\hline Grupo de Tratamento & $\mathrm{BA}$ & Miguel Calmon & 0,188834136 & 0,190127 & 0,9932 \\
\hline Grupo de Tratamento & PB & Guarabira & 0,18773 & 0,18773 & 1 \\
\hline Grupo de Tratamento & BA & Amélia Rodrigues & 0,185501303 & 0,221547 & 0,8373 \\
\hline Grupo de Tratamento & MG & Serra dos Aimorés & 0,185051 & 0,185051 & 1 \\
\hline Grupo de Tratamento & BA & São Sebastião do Passé & 0,183571415 & 0,216629 & 0,8474 \\
\hline Grupo de Tratamento & $\mathrm{BA}$ & Riachão do Jacuípe & 0,183110691 & 0,184606 & 0,9919 \\
\hline Grupo de Tratamento & $A L$ & Maceió & 0,182858566 & 0,352079 & 0,519368 \\
\hline Grupo de Tratamento & $\mathrm{BA}$ & Curaçá & 0,18281303 & 0,2002 & 0,913152 \\
\hline Grupo de Tratamento & BA & Boa Vista do Tupim & 0,182544 & 0,182544 & 1 \\
\hline Grupo de Tratamento & $\mathrm{BA}$ & Iramaia & 0,181904 & 0,181904 & 1 \\
\hline Grupo de Tratamento & PE & Abreu e Lima & 0,181431555 & 0,204476 & 0,8873 \\
\hline Grupo de Tratamento & MG & Capelinha & 0,180691 & 0,180691 & 1 \\
\hline Grupo de Tratamento & PB & Umbuzeiro & 0,180408 & 0,180408 & 1 \\
\hline Grupo de Tratamento & MG & Chapada do Norte & 0,179513 & 0,179513 & 1 \\
\hline Grupo de Tratamento & BA & São Francisco do Conde & 0,178561 & 0,178561 & 1 \\
\hline Grupo de Tratamento & MG & Veredinha & 0,177778 & 0,177778 & 1 \\
\hline Grupo de Tratamento & MG & Cônego Marinho & 0,177225 & 0,177225 & 1 \\
\hline Grupo de Tratamento & BA & Brejões & 0,177218 & 0,177218 & 1 \\
\hline Grupo de Tratamento & BA & Itaju do Colônia & 0,177213 & 0,177213 & 1 \\
\hline Grupo de Tratamento & MG & São João da Ponte & 0,176286 & 0,176286 & 1 \\
\hline Grupo de Tratamento & $\mathrm{BA}$ & Encruzilhada & 0,176125 & 0,176125 & 1 \\
\hline Grupo de Tratamento & PE & Igarassu & 0,175984505 & 0,194501 & 0,9048 \\
\hline Grupo de Tratamento & MG & Coronel Murta & 0,175958 & 0,175958 & 1 \\
\hline Grupo de Tratamento & MG & Passos & 0,175807945 & 0,217023 & 0,810089 \\
\hline Grupo de Tratamento & $\mathrm{BA}$ & Eunápolis & 0,175231536 & 0,18834 & 0,9304 \\
\hline Grupo de Tratamento & PB & Pitimbu & 0,175101 & 0,175101 & 1 \\
\hline
\end{tabular}




\begin{tabular}{|c|c|c|c|c|c|}
\hline Grupo de Tratamento & $A L$ & Barra de Santo Antônio & 0,175017 & 0,175017 & 1 \\
\hline Grupo de Tratamento & MG & Divisópolis & 0,174983463 & 0,181801 & 0,9625 \\
\hline Grupo de Tratamento & MG & Itacambira & 0,173754 & 0,173754 & 1 \\
\hline Grupo de Tratamento & $\mathrm{BA}$ & Antônio Gonçalves & 0,173606 & 0,173606 & 1 \\
\hline Grupo de Tratamento & BA & Conceição do Jacuípe & 0,173497759 & 0,213247 & 0,8136 \\
\hline Grupo de Tratamento & MG & Sarzedo & 0,17317 & 0,17317 & 1 \\
\hline Grupo de Tratamento & MG & São Sebastião do Maranhão & 0,173155 & 0,173155 & 1 \\
\hline Grupo de Tratamento & MG & Ouro Preto & 0,172927 & 0,172927 & 1 \\
\hline Grupo de Tratamento & BA & Santa Maria da Vitória & 0,172803055 & 0,192796 & 0,8963 \\
\hline Grupo de Tratamento & BA & Santa Cruz Cabrália & 0,172234 & 0,172234 & 1 \\
\hline Grupo de Tratamento & $\mathrm{BA}$ & Planalto & 0,171843314 & 0,173509 & 0,9904 \\
\hline Grupo de Tratamento & BA & Alagoinhas & 0,171705687 & 0,23526 & 0,729855 \\
\hline Grupo de Tratamento & SP & Indaiatuba & 0,171324366 & 0,202952 & 0,844162 \\
\hline Grupo de Tratamento & MG & Paineiras & 0,171126 & 0,171126 & 1 \\
\hline Grupo de Tratamento & MG & Minas Novas & 0,171029602 & 0,175884 & 0,9724 \\
\hline Grupo de Tratamento & MG & Santo Antônio do Jacinto & 0,170955 & 0,170955 & 1 \\
\hline Grupo de Tratamento & MG & Frei Gaspar & 0,170813 & 0,170813 & 1 \\
\hline Grupo de Tratamento & BA & Vera Cruz & 0,170684087 & 0,200404 & 0,8517 \\
\hline Grupo de Tratamento & SP & Mococa & 0,17052844 & 0,189996 & 0,897537 \\
\hline Grupo de Tratamento & $\mathrm{BA}$ & Água Fria & 0,170323 & 0,170323 & 1 \\
\hline Grupo de Tratamento & BA & Ipirá & 0,169564851 & 0,207003 & 0,819142 \\
\hline Grupo de Tratamento & $\mathrm{BA}$ & Pindobaçu & 0,169528 & 0,169528 & 1 \\
\hline Grupo de Tratamento & BA & Bonito & 0,169218 & 0,169218 & 1 \\
\hline Grupo de Tratamento & MG & Angelândia & 0,169107 & 0,169107 & 1 \\
\hline Grupo de Tratamento & BA & Xique-Xique & 0,169046 & 0,169046 & 1 \\
\hline Grupo de Tratamento & BA & Canavieiras & 0,168360652 & 0,219134 & 0,7683 \\
\hline Grupo de Tratamento & MG & Mamonas & 0,168234 & 0,168234 & 1 \\
\hline Grupo de Tratamento & $\mathrm{BA}$ & Novo Triunfo & 0,168123 & 0,168123 & 1 \\
\hline Grupo de Tratamento & MG & Janaúba & 0,167307 & 0,167307 & 1 \\
\hline Grupo de Tratamento & MG & Claro dos Poções & 0,166691 & 0,166691 & 1 \\
\hline Grupo de Tratamento & MG & São João das Missões & 0,166133 & 0,166133 & 1 \\
\hline Grupo de Tratamento & BA & Camamu & 0,166087329 & 0,19758 & 0,840608 \\
\hline Grupo de Tratamento & MG & Caeté & 0,165889999 & 0,215216 & 0,770807 \\
\hline Grupo de Tratamento & BA & Santa Teresinha & 0,165608 & 0,165608 & 1 \\
\hline Grupo de Tratamento & PB & Esperança & 0,165557 & 0,165557 & 1 \\
\hline Grupo de Tratamento & MG & Florestal & 0,165324 & 0,165324 & 1 \\
\hline Grupo de Tratamento & BA & Cícero Dantas & 0,16511154 & 0,202383 & 0,815837 \\
\hline Grupo de Tratamento & $\mathrm{BA}$ & Capim Grosso & 0,164709 & 0,164709 & 1 \\
\hline Grupo de Tratamento & MG & Uberaba & 0,16428888 & 0,222012 & 0,74 \\
\hline Grupo de Tratamento & MG & São Domingos das Dores & 0,163505 & 0,163505 & 1 \\
\hline Grupo de Tratamento & PB & Barra de Santana & 0,16326 & 0,16326 & 1 \\
\hline Grupo de Tratamento & MG & Itabirito & 0,163194 & 0,163194 & 1 \\
\hline Grupo de Tratamento & BA & Lamarão & 0,163154 & 0,163154 & 1 \\
\hline Grupo de Tratamento & MG & Sabinópolis & 0,162622 & 0,162622 & 1 \\
\hline Grupo de Tratamento & PE & Araçoiaba & 0,161965 & 0,161965 & 1 \\
\hline
\end{tabular}




\begin{tabular}{|c|c|c|c|c|c|}
\hline Grupo de Tratamento & BA & Canarana & 0,161839 & 0,161839 & 1 \\
\hline Grupo de Tratamento & MG & Marliéria & 0,161677 & 0,161677 & 1 \\
\hline Grupo de Tratamento & MG & Santana de Pirapama & 0,161487 & 0,161487 & 1 \\
\hline Grupo de Tratamento & PE & Itapissuma & 0,161005 & 0,161005 & 1 \\
\hline Grupo de Tratamento & MG & Teófilo Otoni & 0,160635674 & 0,190259 & 0,8443 \\
\hline Grupo de Tratamento & RJ & Belford Roxo & 0,159990305 & 0,297419 & 0,537929 \\
\hline Grupo de Tratamento & BA & Várzea do Poço & 0,159933366 & 0,179818 & 0,889418 \\
\hline Grupo de Tratamento & MS & Sete Quedas & 0,15985806 & 0,172131 & 0,9287 \\
\hline Grupo de Tratamento & MG & Santana do Riacho & 0,159515 & 0,159515 & 1 \\
\hline Grupo de Tratamento & PE & Brejo da Madre de Deus & 0,159139429 & 0,238135 & 0,668274 \\
\hline Grupo de Tratamento & MG & Jaboticatubas & 0,158501473 & 0,161046 & 0,9842 \\
\hline Grupo de Tratamento & MG & Ribeirão das Neves & 0,158149078 & 0,205781 & 0,768531 \\
\hline Grupo de Tratamento & BA & Jussari & 0,158054 & 0,158054 & 1 \\
\hline Grupo de Tratamento & BA & Cipó & 0,15784 & 0,15784 & 1 \\
\hline Grupo de Tratamento & PE & Pombos & 0,15780392 & 0,171526 & 0,92 \\
\hline Grupo de Tratamento & BA & Lauro de Freitas & 0,157767236 & 0,21764 & 0,7249 \\
\hline Grupo de Tratamento & BA & Boninal & 0,157297264 & 0,178544 & 0,881 \\
\hline Grupo de Tratamento & BA & Muquém de São Francisco & 0,157102 & 0,157102 & 1 \\
\hline Grupo de Tratamento & $\mathrm{BA}$ & Banzaê & 0,156987 & 0,156987 & 1 \\
\hline Grupo de Tratamento & $\mathrm{BA}$ & Salinas da Margarida & 0,156749 & 0,156749 & 1 \\
\hline Grupo de Tratamento & BA & Nova Itarana & 0,15671 & 0,15671 & 1 \\
\hline Grupo de Tratamento & MG & Belo Oriente & 0,156533 & 0,156533 & 1 \\
\hline Grupo de Tratamento & PI & São José do Piauí & 0,156349 & 0,156349 & 1 \\
\hline Grupo de Tratamento & BA & Livramento de Nossa Senhora & 0,156181514 & 0,184639 & 0,845875 \\
\hline Grupo de Tratamento & MG & Cordisburgo & 0,155343 & 0,155343 & 1 \\
\hline Grupo de Tratamento & MG & Salinas & 0,155177 & 0,155177 & 1 \\
\hline Grupo de Tratamento & BA & Cafarnaum & 0,154529921 & 0,167466 & 0,922754 \\
\hline Grupo de Tratamento & BA & Cruz das Almas & 0,154299391 & 0,213445 & 0,7229 \\
\hline Grupo de Tratamento & $\mathrm{BA}$ & Madre de Deus & 0,153831 & 0,153831 & 1 \\
\hline Grupo de Tratamento & MG & Santa Cruz de Salinas & 0,153825 & 0,153825 & 1 \\
\hline Grupo de Tratamento & MG & Almenara & 0,153672 & 0,153672 & 1 \\
\hline Grupo de Tratamento & BA & Serra Dourada & 0,153619 & 0,153619 & 1 \\
\hline Grupo de Tratamento & $\mathrm{BA}$ & Teofilândia & 0,153161 & 0,153161 & 1 \\
\hline Grupo de Tratamento & BA & Itaeté & 0,15292 & 0,15292 & 1 \\
\hline Grupo de Tratamento & BA & Buerarema & 0,152225 & 0,152225 & 1 \\
\hline Grupo de Tratamento & MG & Santa Bárbara & 0,152179 & 0,152179 & 1 \\
\hline Grupo de Tratamento & PA & Tucuruí & 0,151536205 & 0,166304 & 0,9112 \\
\hline Grupo de Tratamento & MG & Esmeraldas & 0,151528961 & 0,184454 & 0,8215 \\
\hline Grupo de Tratamento & MG & São João do Pacuí & 0,150846 & 0,150846 & 1 \\
\hline Grupo de Tratamento & PB & Alagoa Grande & 0,150404 & 0,150404 & 1 \\
\hline Grupo de Tratamento & SP & Amparo & 0,150182166 & 0,166832 & 0,9002 \\
\hline Grupo de Tratamento & BA & Santa Luzia & 0,150027 & 0,150027 & 1 \\
\hline Grupo de Tratamento & BA & São Desidério & 0,149983 & 0,149983 & 1 \\
\hline Grupo de Tratamento & MG & Araújos & 0,149577478 & 0,151917 & 0,9846 \\
\hline Grupo de Tratamento & MG & Urucuia & 0,149443 & 0,149443 & 1 \\
\hline
\end{tabular}




\begin{tabular}{|c|c|c|c|c|c|}
\hline Grupo de Tratamento & $\mathrm{BA}$ & Jacobina & 0,149252913 & 0,208835 & 0,714693 \\
\hline Grupo de Tratamento & $\mathrm{BA}$ & Alcobaça & 0,148916 & 0,148916 & 1 \\
\hline Grupo de Tratamento & RS & Frederico Westphalen & 0,148867 & 0,148867 & 1 \\
\hline Grupo de Tratamento & $\mathrm{BA}$ & Condeúba & 0,148827 & 0,148827 & 1 \\
\hline Grupo de Tratamento & BA & Macururé & 0,148337 & 0,148337 & 1 \\
\hline Grupo de Tratamento & MG & Santa Maria de Itabira & 0,148074 & 0,148074 & 1 \\
\hline Grupo de Tratamento & BA & Cachoeira & 0,147673 & 0,147673 & 1 \\
\hline Grupo de Tratamento & MG & Inimutaba & 0,147579 & 0,147579 & 1 \\
\hline Grupo de Tratamento & $\mathrm{BA}$ & Maetinga & 0,147441 & 0,147441 & 1 \\
\hline Grupo de Tratamento & BA & Porto Seguro & 0,147313069 & 0,164614 & 0,8949 \\
\hline Grupo de Tratamento & MG & Varzelândia & 0,147048 & 0,147048 & 1 \\
\hline Grupo de Tratamento & BA & Coração de Maria & 0,146601 & 0,146601 & 1 \\
\hline Grupo de Tratamento & BA & Malhada de Pedras & 0,146512 & 0,146512 & 1 \\
\hline Grupo de Tratamento & BA & Tanquinho & 0,146319 & 0,146319 & 1 \\
\hline Grupo de Tratamento & MG & Ipatinga & 0,146270036 & 0,180558 & 0,8101 \\
\hline Grupo de Tratamento & PE & Moreno & 0,145816889 & 0,239177 & 0,609661 \\
\hline Grupo de Tratamento & PB & Aroeiras & 0,145746 & 0,145746 & 1 \\
\hline Grupo de Tratamento & RJ & Nova Iguaçu & 0,14574486 & 0,250098 & 0,582751 \\
\hline Grupo de Tratamento & $A L$ & Limoeiro de Anadia & 0,14572 & 0,14572 & 1 \\
\hline Grupo de Tratamento & $\mathrm{BA}$ & Jussara & 0,144976494 & 0,14502 & 0,9997 \\
\hline Grupo de Tratamento & BA & Jeremoabo & 0,144863369 & 0,157238 & 0,9213 \\
\hline Grupo de Tratamento & PE & Glória do Goitá & 0,144596232 & 0,176165 & 0,8208 \\
\hline Grupo de Tratamento & MG & São Joaquim de Bicas & 0,144261 & 0,144261 & 1 \\
\hline Grupo de Tratamento & $\mathrm{BA}$ & Marcionílio Souza & 0,143685 & 0,143685 & 1 \\
\hline Grupo de Tratamento & MG & Água Boa & 0,143564 & 0,143564 & 1 \\
\hline Grupo de Tratamento & BA & Chorrochó & 0,143355 & 0,143355 & 1 \\
\hline Grupo de Tratamento & $\mathrm{BA}$ & Abaíra & 0,142475 & 0,142475 & 1 \\
\hline Grupo de Tratamento & MS & Três Lagoas & 0,142197193 & 0,187786 & 0,75723 \\
\hline Grupo de Tratamento & MG & Bonfim & 0,141924 & 0,141924 & 1 \\
\hline Grupo de Tratamento & RJ & Queimados & 0,141914428 & 0,244098 & 0,581383 \\
\hline Grupo de Tratamento & MS & Jardim & 0,141787 & 0,141787 & 1 \\
\hline Grupo de Tratamento & MG & Nova Porteirinha & 0,141629 & 0,141629 & 1 \\
\hline Grupo de Tratamento & $\mathrm{BA}$ & Laje & 0,141479836 & 0,152786 & 0,926 \\
\hline Grupo de Tratamento & MG & Eugenópolis & 0,140794 & 0,140794 & 1 \\
\hline Grupo de Tratamento & MG & São Pedro do Suaçuí & 0,140737 & 0,140737 & 1 \\
\hline Grupo de Tratamento & BA & Guaratinga & 0,140507 & 0,140507 & 1 \\
\hline Grupo de Tratamento & BA & Cravolândia & 0,140449 & 0,140449 & 1 \\
\hline Grupo de Tratamento & $\mathrm{BA}$ & Juazeiro & 0,14044228 & 0,152142 & 0,9231 \\
\hline Grupo de Tratamento & MG & Mirabela & 0,14042 & 0,14042 & 1 \\
\hline Grupo de Tratamento & $\mathrm{BA}$ & Mairi & 0,140313 & 0,140313 & 1 \\
\hline Grupo de Tratamento & MG & Carlos Chagas & 0,140198582 & 0,140691 & 0,9965 \\
\hline Grupo de Tratamento & $A L$ & Arapiraca & 0,139713497 & 0,155531 & 0,8983 \\
\hline Grupo de Tratamento & PE & Chã Grande & 0,139569 & 0,139569 & 1 \\
\hline Grupo de Tratamento & $\mathrm{BA}$ & Conceição do Coité & 0,139475225 & 0,199764 & 0,6982 \\
\hline Grupo de Tratamento & $\mathrm{BA}$ & Casa Nova & 0,13898756 & 0,180389 & 0,770488 \\
\hline
\end{tabular}




\begin{tabular}{|c|c|c|c|c|c|}
\hline Grupo de Tratamento & MG & Berilo & 0,138717 & 0,138717 & 1 \\
\hline Grupo de Tratamento & BA & Santaluz & 0,138516496 & 0,174476 & 0,7939 \\
\hline Grupo de Tratamento & MG & Pedro Leopoldo & 0,13842957 & 0,183813 & 0,7531 \\
\hline Grupo de Tratamento & PR & Palotina & 0,138409 & 0,138409 & 1 \\
\hline Grupo de Tratamento & $\mathrm{BA}$ & Belo Campo & 0,137826 & 0,137826 & 1 \\
\hline Grupo de Tratamento & PI & Bertolínia & 0,137597 & 0,137597 & 1 \\
\hline Grupo de Tratamento & RS & Nonoai & 0,137153599 & 0,212694 & 0,64484 \\
\hline Grupo de Tratamento & BA & Acajutiba & 0,137133 & 0,137133 & 1 \\
\hline Grupo de Tratamento & SP & Várzea Paulista & 0,13709383 & 0,171372 & 0,799978 \\
\hline Grupo de Tratamento & RN & Caicó & 0,13707 & 0,13707 & 1 \\
\hline Grupo de Tratamento & MG & Coração de Jesus & 0,136751 & 0,136751 & 1 \\
\hline Grupo de Tratamento & MG & Berizal & 0,136511 & 0,136511 & 1 \\
\hline Grupo de Tratamento & MG & Virginópolis & 0,136391 & 0,136391 & 1 \\
\hline Grupo de Tratamento & $\mathrm{BA}$ & Ponto Novo & 0,136319 & 0,136319 & 1 \\
\hline Grupo de Tratamento & BA & Antônio Cardoso & 0,136289 & 0,136289 & 1 \\
\hline Grupo de Tratamento & BA & Santo Amaro & 0,135939711 & 0,179702 & 0,756473 \\
\hline Grupo de Tratamento & $\mathrm{BA}$ & Maracás & 0,135876981 & 0,175799 & 0,772911 \\
\hline Grupo de Tratamento & $\mathrm{BA}$ & Mutuípe & 0,135439133 & 0,157341 & 0,8608 \\
\hline Grupo de Tratamento & RJ & Tanguá & 0,134987644 & 0,141452 & 0,9543 \\
\hline Grupo de Tratamento & BA & Barro Alto & 0,134722 & 0,134722 & 1 \\
\hline Grupo de Tratamento & $\mathrm{BA}$ & Irecê & 0,134709489 & 0,162418 & 0,8294 \\
\hline Grupo de Tratamento & $\mathrm{BA}$ & Licínio de Almeida & 0,134347 & 0,134347 & 1 \\
\hline Grupo de Tratamento & MG & José Raydan & 0,134258 & 0,134258 & 1 \\
\hline Grupo de Tratamento & BA & Várzea da Roça & 0,134055 & 0,134055 & 1 \\
\hline Grupo de Tratamento & BA & Itanhém & 0,133966 & 0,133966 & 1 \\
\hline Grupo de Tratamento & $\mathrm{BA}$ & Iaçu & 0,133853 & 0,133853 & 1 \\
\hline Grupo de Tratamento & $\mathrm{BA}$ & Muniz Ferreira & 0,133653 & 0,133653 & 1 \\
\hline Grupo de Tratamento & MG & Ponto Chique & 0,133403 & 0,133403 & 1 \\
\hline Grupo de Tratamento & $\mathrm{BA}$ & Camaçari & 0,133184595 & 0,192047 & 0,6935 \\
\hline Grupo de Tratamento & $\mathrm{BA}$ & Maiquinique & 0,133138864 & 0,164385 & 0,809921 \\
\hline Grupo de Tratamento & $\mathrm{BA}$ & Dias d'Ávila & 0,133041531 & 0,179519 & 0,7411 \\
\hline Grupo de Tratamento & MG & Coronel Fabriciano & 0,132808704 & 0,18528 & 0,7168 \\
\hline Grupo de Tratamento & BA & Esplanada & 0,13268431 & 0,136369 & 0,97298 \\
\hline Grupo de Tratamento & BA & Itatim & 0,132454 & 0,132454 & 1 \\
\hline Grupo de Tratamento & $\mathrm{BA}$ & Itapé & 0,132361 & 0,132361 & 1 \\
\hline Grupo de Tratamento & BA & Wenceslau Guimarães & 0,132294 & 0,132294 & 1 \\
\hline Grupo de Tratamento & $\mathrm{BA}$ & Milagres & 0,131854403 & 0,181823 & 0,72518 \\
\hline Grupo de Tratamento & PB & Bayeux & 0,131809418 & 0,152328 & 0,8653 \\
\hline Grupo de Tratamento & BA & Itapebi & 0,131761 & 0,131761 & 1 \\
\hline Grupo de Tratamento & RJ & Mesquita & 0,131291003 & 0,183778 & 0,7144 \\
\hline Grupo de Tratamento & MG & Baldim & 0,130657 & 0,130657 & 1 \\
\hline Grupo de Tratamento & BA & Ibiquera & 0,130642 & 0,130642 & 1 \\
\hline Grupo de Tratamento & BA & Entre Rios & 0,130555642 & 0,164061 & 0,795775 \\
\hline Grupo de Tratamento & $\mathrm{BA}$ & Lagoa Real & 0,129905 & 0,129905 & 1 \\
\hline Grupo de Tratamento & $\mathrm{BA}$ & Ibipeba & 0,129507 & 0,129507 & 1 \\
\hline
\end{tabular}




\begin{tabular}{|c|c|c|c|c|c|}
\hline Grupo de Tratamento & MG & Frei Inocêncio & 0,129432 & 0,129432 & 1 \\
\hline Grupo de Tratamento & MG & Lagoa dos Patos & 0,129212 & 0,129212 & 1 \\
\hline Grupo de Tratamento & SP & Mogi Mirim & 0,128799468 & 0,157471 & 0,817925 \\
\hline Grupo de Tratamento & MG & Barão de Monte Alto & 0,128768 & 0,128768 & 1 \\
\hline Grupo de Tratamento & MG & Lontra & 0,12862 & 0,12862 & 1 \\
\hline Grupo de Tratamento & MG & Itinga & 0,128386 & 0,128386 & 1 \\
\hline Grupo de Tratamento & PI & Floriano & 0,128294 & 0,128294 & 1 \\
\hline Grupo de Tratamento & BA & Adustina & 0,128102 & 0,128102 & 1 \\
\hline Grupo de Tratamento & BA & Catu & 0,127311347 & 0,156826 & 0,8118 \\
\hline Grupo de Tratamento & BA & Fátima & 0,127092 & 0,127092 & 1 \\
\hline Grupo de Tratamento & MG & Jequitibá & 0,126505 & 0,126505 & 1 \\
\hline Grupo de Tratamento & $\mathrm{BA}$ & Andaraí & 0,126458 & 0,126458 & 1 \\
\hline Grupo de Tratamento & MG & Aimorés & 0,126451 & 0,126451 & 1 \\
\hline Grupo de Tratamento & MG & Mantena & 0,126269 & 0,126269 & 1 \\
\hline Grupo de Tratamento & MG & Oliveira & 0,1261015 & 0,144116 & 0,875 \\
\hline Grupo de Tratamento & MG & Pedra Azul & 0,1261 & 0,1261 & 1 \\
\hline Grupo de Tratamento & MG & Augusto de Lima & 0,125927 & 0,125927 & 1 \\
\hline Grupo de Tratamento & MG & Fruta de Leite & 0,125643 & 0,125643 & 1 \\
\hline Grupo de Tratamento & BA & Santa Cruz da Vitória & 0,125411312 & 0,127192 & 0,986 \\
\hline Grupo de Tratamento & BA & Macaúbas & 0,125150147 & 0,153766 & 0,8139 \\
\hline Grupo de Tratamento & MG & Catuti & 0,124941 & 0,124941 & 1 \\
\hline Grupo de Tratamento & MG & Felixlândia & 0,12476 & 0,12476 & 1 \\
\hline Grupo de Tratamento & PE & Olinda & 0,124476826 & 0,20633 & 0,60329 \\
\hline Grupo de Tratamento & BA & Itaquara & 0,124265 & 0,124265 & 1 \\
\hline Grupo de Tratamento & $\mathrm{BA}$ & Irará & 0,12421255 & 0,161428 & 0,769461 \\
\hline Grupo de Tratamento & BA & Pé de Serra & 0,124184 & 0,124184 & 1 \\
\hline Grupo de Tratamento & $\mathrm{BA}$ & Ibirataia & 0,12396 & 0,12396 & 1 \\
\hline Grupo de Tratamento & MG & Itaobim & 0,12382 & 0,12382 & 1 \\
\hline Grupo de Tratamento & MG & Virgem da Lapa & 0,123762 & 0,123762 & 1 \\
\hline Grupo de Tratamento & BA & Lapão & 0,123676 & 0,123676 & 1 \\
\hline Grupo de Tratamento & RN & Jucurutu & 0,123464 & 0,123464 & 1 \\
\hline Grupo de Tratamento & MG & Serra Azul de Minas & 0,123415 & 0,123415 & 1 \\
\hline Grupo de Tratamento & MG & Ibiá & 0,123224 & 0,123224 & 1 \\
\hline Grupo de Tratamento & PB & Boqueirão & 0,123173 & 0,123173 & 1 \\
\hline Grupo de Tratamento & BA & São Gonçalo dos Campos & 0,123158372 & 0,127414 & 0,9666 \\
\hline Grupo de Tratamento & MG & Fronteira dos Vales & 0,122973 & 0,122973 & 1 \\
\hline Grupo de Tratamento & PR & Laranjeiras do Sul & 0,122623 & 0,122623 & 1 \\
\hline Grupo de Tratamento & MG & Manhumirim & 0,122527078 & 0,125953 & 0,9728 \\
\hline Grupo de Tratamento & MG & Manhuaçu & 0,12218751 & 0,155534 & 0,7856 \\
\hline Grupo de Tratamento & BA & Prado & 0,122153 & 0,122153 & 1 \\
\hline Grupo de Tratamento & BA & Pintadas & 0,122146 & 0,122146 & 1 \\
\hline Grupo de Tratamento & BA & Serrinha & 0,121979107 & 0,208191 & 0,5859 \\
\hline Grupo de Tratamento & MG & Mateus Leme & 0,120799395 & 0,130467 & 0,9259 \\
\hline Grupo de Tratamento & MG & Piedade de Caratinga & 0,120786 & 0,120786 & 1 \\
\hline Grupo de Tratamento & SP & Itatiba & 0,120733642 & 0,136978 & 0,881409 \\
\hline
\end{tabular}




\begin{tabular}{|c|c|c|c|c|c|}
\hline Grupo de Tratamento & MG & Montalvânia & 0,120709 & 0,120709 & 1 \\
\hline Grupo de Tratamento & SP & Itapira & 0,120462913 & 0,150447 & 0,8007 \\
\hline Grupo de Tratamento & MG & Monte Formoso & 0,120238 & 0,120238 & 1 \\
\hline Grupo de Tratamento & $\mathrm{BA}$ & Camacan & 0,12008 & 0,12008 & 1 \\
\hline Grupo de Tratamento & MG & Novorizonte & 0,119834 & 0,119834 & 1 \\
\hline Grupo de Tratamento & PB & Belém & 0,119616 & 0,119616 & 1 \\
\hline Grupo de Tratamento & MG & Araçaí & 0,119578 & 0,119578 & 1 \\
\hline Grupo de Tratamento & $\mathrm{BA}$ & Almadina & 0,119256 & 0,119256 & 1 \\
\hline Grupo de Tratamento & MG & São Gonçalo do Rio Preto & 0,119136 & 0,119136 & 1 \\
\hline Grupo de Tratamento & BA & Planaltino & 0,118993 & 0,118993 & 1 \\
\hline Grupo de Tratamento & MG & João Monlevade & 0,118934557 & 0,151317 & 0,785996 \\
\hline Grupo de Tratamento & PE & Vitória de Santo Antão & 0,118826609 & 0,163358 & 0,7274 \\
\hline Grupo de Tratamento & BA & Biritinga & 0,118698 & 0,118698 & 1 \\
\hline Grupo de Tratamento & BA & Jaguaquara & 0,118589273 & 0,123698 & 0,9587 \\
\hline Grupo de Tratamento & MG & Santa Fé de Minas & 0,118527 & 0,118527 & 1 \\
\hline Grupo de Tratamento & PB & Caaporã & 0,118299 & 0,118299 & 1 \\
\hline Grupo de Tratamento & SP & Serra Negra & 0,11810869 & 0,123261 & 0,9582 \\
\hline Grupo de Tratamento & BA & Itiruçu & 0,11810519 & 0,122975 & 0,9604 \\
\hline Grupo de Tratamento & MG & Gonzaga & 0,117979 & 0,117979 & 1 \\
\hline Grupo de Tratamento & $\mathrm{BA}$ & Ipecaetá & 0,117908 & 0,117908 & 1 \\
\hline Grupo de Tratamento & MG & Botumirim & 0,117526 & 0,117526 & 1 \\
\hline Grupo de Tratamento & MG & Josenópolis & 0,117391 & 0,117391 & 1 \\
\hline Grupo de Tratamento & MG & Aricanduva & 0,117184 & 0,117184 & 1 \\
\hline Grupo de Tratamento & BA & Vitória da Conquista & 0,117155842 & 0,165945 & 0,705992 \\
\hline Grupo de Tratamento & MG & Campo Azul & 0,116416 & 0,116416 & 1 \\
\hline Grupo de Tratamento & MG & Matias Cardoso & 0,116121 & 0,116121 & 1 \\
\hline Grupo de Tratamento & MG & Luislândia & 0,115383 & 0,115383 & 1 \\
\hline Grupo de Tratamento & $\mathrm{BA}$ & Itarantim & 0,11526475 & 0,138606 & 0,8316 \\
\hline Grupo de Tratamento & MG & Bela Vista de Minas & 0,114952 & 0,114952 & 1 \\
\hline Grupo de Tratamento & MG & Brasília de Minas & 0,11481887 & 0,120003 & 0,9568 \\
\hline Grupo de Tratamento & MS & Japorã & 0,114519 & 0,114519 & 1 \\
\hline Grupo de Tratamento & BA & Uibaí & 0,114494 & 0,114494 & 1 \\
\hline Grupo de Tratamento & $\mathrm{BA}$ & Arataca & 0,114465 & 0,114465 & 1 \\
\hline Grupo de Tratamento & BA & Caldeirão Grande & 0,114274 & 0,114274 & 1 \\
\hline Grupo de Tratamento & MS & Nova Andradina & 0,113479588 & 0,146492 & 0,774647 \\
\hline Grupo de Tratamento & MG & Pintópolis & 0,113224 & 0,113224 & 1 \\
\hline Grupo de Tratamento & BA & Piraí do Norte & 0,113061669 & 0,120715 & 0,9366 \\
\hline Grupo de Tratamento & $\mathrm{BA}$ & Itapitanga & 0,112973 & 0,112973 & 1 \\
\hline Grupo de Tratamento & MG & Catuji & 0,112773 & 0,112773 & 1 \\
\hline Grupo de Tratamento & MG & Vespasiano & 0,11273847 & 0,115145 & 0,9791 \\
\hline Grupo de Tratamento & RS & Ijuí & 0,112556239 & 0,123444 & 0,9118 \\
\hline Grupo de Tratamento & BA & Santo Antônio de Jesus & 0,11249051 & 0,139428 & 0,8068 \\
\hline Grupo de Tratamento & BA & Macarani & 0,112425457 & 0,128545 & 0,8746 \\
\hline Grupo de Tratamento & MG & Grão Mogol & 0,112217 & 0,112217 & 1 \\
\hline Grupo de Tratamento & $\mathrm{BA}$ & Nilo Peçanha & 0,112028 & 0,112028 & 1 \\
\hline
\end{tabular}




\begin{tabular}{|c|c|c|c|c|c|}
\hline Grupo de Tratamento & BA & Castro Alves & 0,111899 & 0,111899 & 1 \\
\hline Grupo de Tratamento & BA & Presidente Jânio Quadros & 0,11188 & 0,11188 & 1 \\
\hline Grupo de Tratamento & MG & Felício dos Santos & 0,111715 & 0,111715 & 1 \\
\hline Grupo de Tratamento & $\mathrm{BA}$ & Mirante & 0,1116 & 0,1116 & 1 \\
\hline Grupo de Tratamento & MA & Central do Maranhão & 0,111069 & 0,111069 & 1 \\
\hline Grupo de Tratamento & BA & Dom Basílio & 0,111021 & 0,111021 & 1 \\
\hline Grupo de Tratamento & MG & Jaguaraçu & 0,110691 & 0,110691 & 1 \\
\hline Grupo de Tratamento & MG & Patis & 0,110644 & 0,110644 & 1 \\
\hline Grupo de Tratamento & BA & Ourolândia & 0,110602 & 0,110602 & 1 \\
\hline Grupo de Tratamento & MG & Mata Verde & 0,110587 & 0,110587 & 1 \\
\hline Grupo de Tratamento & BA & Itaguaçu da Bahia & 0,110482 & 0,110482 & 1 \\
\hline Grupo de Tratamento & MG & Miravânia & 0,110368 & 0,110368 & 1 \\
\hline Grupo de Tratamento & MG & Jacinto & 0,110228 & 0,110228 & 1 \\
\hline Grupo de Tratamento & MG & Ninheira & 0,110223 & 0,110223 & 1 \\
\hline Grupo de Tratamento & BA & Filadélfia & 0,110194 & 0,110194 & 1 \\
\hline Grupo de Tratamento & PI & Flores do Piauí & 0,110027 & 0,110027 & 1 \\
\hline Grupo de Tratamento & MG & Rio do Prado & 0,109896 & 0,109896 & 1 \\
\hline Grupo de Tratamento & MG & Coroaci & 0,109183 & 0,109183 & 1 \\
\hline Grupo de Tratamento & BA & Santa Brígida & 0,109169 & 0,109169 & 1 \\
\hline Grupo de Tratamento & MG & Biquinhas & 0,109011 & 0,109011 & 1 \\
\hline Grupo de Tratamento & $\mathrm{BA}$ & América Dourada & 0,108993 & 0,108993 & 1 \\
\hline Grupo de Tratamento & BA & Teolândia & 0,108909 & 0,108909 & 1 \\
\hline Grupo de Tratamento & MG & Águas Vermelhas & 0,108877 & 0,108877 & 1 \\
\hline Grupo de Tratamento & MG & Rio Novo & 0,108785 & 0,108785 & 1 \\
\hline Grupo de Tratamento & $\mathrm{BA}$ & Cabaceiras do Paraguaçu & 0,108464 & 0,108464 & 1 \\
\hline Grupo de Tratamento & $\mathrm{BA}$ & Itabuna & 0,108458803 & 0,183922 & 0,5897 \\
\hline Grupo de Tratamento & BA & Utinga & 0,108374024 & 0,109127 & 0,9931 \\
\hline Grupo de Tratamento & MG & Indaiabira & 0,1075 & 0,1075 & 1 \\
\hline Grupo de Tratamento & BA & Brejolândia & 0,107243 & 0,107243 & 1 \\
\hline Grupo de Tratamento & MG & Comercinho & 0,10718 & 0,10718 & 1 \\
\hline Grupo de Tratamento & MG & Prudente de Morais & 0,107107258 & 0,139608 & 0,7672 \\
\hline Grupo de Tratamento & MG & Riacho dos Machados & 0,107104 & 0,107104 & 1 \\
\hline Grupo de Tratamento & MG & Medina & 0,107038 & 0,107038 & 1 \\
\hline Grupo de Tratamento & MS & Dourados & 0,106938023 & 0,141415 & 0,7562 \\
\hline Grupo de Tratamento & BA & Itabela & 0,106578 & 0,106578 & 1 \\
\hline Grupo de Tratamento & PI & Pavussu & 0,106577 & 0,106577 & 1 \\
\hline Grupo de Tratamento & BA & Campo Formoso & 0,10651423 & 0,128687 & 0,8277 \\
\hline Grupo de Tratamento & RJ & Silva Jardim & 0,106485 & 0,106485 & 1 \\
\hline Grupo de Tratamento & MG & Itacarambi & 0,106287 & 0,106287 & 1 \\
\hline Grupo de Tratamento & $\mathrm{BA}$ & Cairu & 0,105918 & 0,105918 & 1 \\
\hline Grupo de Tratamento & SP & São José do Rio Pardo & 0,105149252 & 0,116668 & 0,901269 \\
\hline Grupo de Tratamento & RJ & Rio Bonito & 0,105074836 & 0,114063 & 0,9212 \\
\hline Grupo de Tratamento & MG & Ubaporanga & 0,104736 & 0,104736 & 1 \\
\hline Grupo de Tratamento & PI & Pajeú do Piauí & 0,104681 & 0,104681 & 1 \\
\hline Grupo de Tratamento & MG & Cuparaque & 0,104596 & 0,104596 & 1 \\
\hline
\end{tabular}




\begin{tabular}{|c|c|c|c|c|c|}
\hline Grupo de Tratamento & MG & Mato Verde & 0,104401 & 0,104401 & 1 \\
\hline Grupo de Tratamento & MG & Serro & 0,104161 & 0,104161 & 1 \\
\hline Grupo de Tratamento & BA & Andorinha & 0,103953 & 0,103953 & 1 \\
\hline Grupo de Tratamento & MG & Santo Antônio do Monte & 0,10394506 & 0,109612 & 0,9483 \\
\hline Grupo de Tratamento & PB & Taperoá & 0,103811 & 0,103811 & 1 \\
\hline Grupo de Tratamento & MG & São Francisco & 0,103660168 & 0,108841 & 0,9524 \\
\hline Grupo de Tratamento & RJ & Magé & 0,103600315 & 0,153119 & 0,6766 \\
\hline Grupo de Tratamento & PE & Paulista & 0,103454095 & 0,182227 & 0,567721 \\
\hline Grupo de Tratamento & SP & São João da Boa Vista & 0,103313112 & 0,114449 & 0,9027 \\
\hline Grupo de Tratamento & PB & Tacima & 0,103275 & 0,103275 & 1 \\
\hline Grupo de Tratamento & BA & Jitaúna & 0,10315 & 0,10315 & 1 \\
\hline Grupo de Tratamento & MG & Pirapora & 0,103127416 & 0,116898 & 0,8822 \\
\hline Grupo de Tratamento & MG & Tumiritinga & 0,103019 & 0,103019 & 1 \\
\hline Grupo de Tratamento & MG & Umburatiba & 0,102972 & 0,102972 & 1 \\
\hline Grupo de Tratamento & MG & Materlândia & 0,102961 & 0,102961 & 1 \\
\hline Grupo de Tratamento & MG & Gameleiras & 0,10255 & 0,10255 & 1 \\
\hline Grupo de Tratamento & RJ & Itaboraí & 0,102320659 & 0,153132 & 0,668186 \\
\hline Grupo de Tratamento & $\mathrm{BA}$ & Valença & 0,102071538 & 0,150373 & 0,678789 \\
\hline Grupo de Tratamento & BA & Saúde & 0,101894 & 0,101894 & 1 \\
\hline Grupo de Tratamento & MG & Vargem Alegre & 0,101739 & 0,101739 & 1 \\
\hline Grupo de Tratamento & MG & Córrego Novo & 0,101519 & 0,101519 & 1 \\
\hline Grupo de Tratamento & MG & Francisco Sá & 0,101491 & 0,101491 & 1 \\
\hline Grupo de Tratamento & MG & Jenipapo de Minas & 0,101424 & 0,101424 & 1 \\
\hline Grupo de Tratamento & MG & Carbonita & 0,101098 & 0,101098 & 1 \\
\hline Grupo de Tratamento & $\mathrm{BA}$ & Ituberá & 0,100663089 & 0,109046 & 0,923125 \\
\hline Grupo de Tratamento & $\mathrm{BA}$ & Coaraci & 0,100361374 & 0,117282 & 0,855727 \\
\hline Grupo de Tratamento & BA & Queimadas & 0,100258152 & 0,125905 & 0,7963 \\
\hline Grupo de Tratamento & MG & Pompéu & 0,100039985 & 0,10565 & 0,9469 \\
\hline Grupo de Tratamento & BA & São José do Jacuípe & 0,099803586 & 0,112737 & 0,885278 \\
\hline Grupo de Tratamento & MG & São Geraldo da Piedade & 0,09938 & 0,09938 & 1 \\
\hline Grupo de Tratamento & MG & Jequitinhonha & 0,099213 & 0,099213 & 1 \\
\hline Grupo de Tratamento & MG & Santo Hipólito & 0,098963 & 0,098963 & 1 \\
\hline Grupo de Tratamento & $\mathrm{BA}$ & Belmonte & 0,098892 & 0,098892 & 1 \\
\hline Grupo de Tratamento & BA & Itororó & 0,098769469 & 0,106238 & 0,9297 \\
\hline Grupo de Tratamento & PI & Rio Grande do Piauí & 0,09867 & 0,09867 & 1 \\
\hline Grupo de Tratamento & MG & Bonito de Minas & 0,098258 & 0,098258 & 1 \\
\hline Grupo de Tratamento & MG & Ibiaí & 0,0982 & 0,0982 & 1 \\
\hline Grupo de Tratamento & BA & Senhor do Bonfim & 0,098002023 & 0,133776 & 0,732583 \\
\hline Grupo de Tratamento & BA & Ibotirama & 0,097849 & 0,097849 & 1 \\
\hline Grupo de Tratamento & MS & Jaraguari & 0,097841 & 0,097841 & 1 \\
\hline Grupo de Tratamento & $\mathrm{BA}$ & Itanagra & 0,097783 & 0,097783 & 1 \\
\hline Grupo de Tratamento & $\mathrm{BA}$ & Santanópolis & 0,097458 & 0,097458 & 1 \\
\hline Grupo de Tratamento & MG & São João do Paraíso & 0,097282 & 0,097282 & 1 \\
\hline Grupo de Tratamento & $\mathrm{BA}$ & Macajuba & 0,097006205 & 0,098907 & 0,980782 \\
\hline Grupo de Tratamento & MG & Manga & 0,097005 & 0,097005 & 1 \\
\hline
\end{tabular}




\begin{tabular}{|c|c|c|c|c|c|}
\hline Grupo de Tratamento & MG & Cássia & 0,096716978 & 0,110617 & 0,874341 \\
\hline Grupo de Tratamento & BA & Ituaçu & 0,096556096 & 0,098176 & 0,9835 \\
\hline Grupo de Tratamento & $\mathrm{BA}$ & Santo Estêvão & 0,096514241 & 0,115076 & 0,8387 \\
\hline Grupo de Tratamento & MG & Inhapim & 0,09649364 & 0,115797 & 0,8333 \\
\hline Grupo de Tratamento & $\mathrm{BA}$ & Medeiros Neto & 0,09627 & 0,09627 & 1 \\
\hline Grupo de Tratamento & $A L$ & Rio Largo & 0,096017811 & 0,114171 & 0,841 \\
\hline Grupo de Tratamento & MG & Taiobeiras & 0,095507 & 0,095507 & 1 \\
\hline Grupo de Tratamento & MG & Pequi & 0,095436 & 0,095436 & 1 \\
\hline Grupo de Tratamento & BA & Maragogipe & 0,095348778 & 0,104366 & 0,9136 \\
\hline Grupo de Tratamento & MG & Bom Jesus do Amparo & 0,095187 & 0,095187 & 1 \\
\hline Grupo de Tratamento & MG & Águas Formosas & 0,095134482 & 0,098178 & 0,969 \\
\hline Grupo de Tratamento & PI & Arraial & 0,095117 & 0,095117 & 1 \\
\hline Grupo de Tratamento & MG & Paraopeba & 0,094885645 & 0,102413 & 0,9265 \\
\hline Grupo de Tratamento & MG & Peçanha & 0,094562864 & 0,100773 & 0,938375 \\
\hline Grupo de Tratamento & MG & Franciscópolis & 0,093314 & 0,093314 & 1 \\
\hline Grupo de Tratamento & MG & Taquaraçu de Minas & 0,093019 & 0,093019 & 1 \\
\hline Grupo de Tratamento & BA & Catolândia & 0,092985 & 0,092985 & 1 \\
\hline Grupo de Tratamento & MG & Santo Antônio do Rio Abaixo & 0,092769 & 0,092769 & 1 \\
\hline Grupo de Tratamento & PI & Canto do Buriti & 0,092622 & 0,092622 & 1 \\
\hline Grupo de Tratamento & BA & Caetanos & 0,092599315 & 0,111552 & 0,8301 \\
\hline Grupo de Tratamento & MG & Rio Pardo de Minas & 0,092566 & 0,092566 & 1 \\
\hline Grupo de Tratamento & MG & José Gonçalves de Minas & 0,092446 & 0,092446 & 1 \\
\hline Grupo de Tratamento & $\mathrm{BA}$ & Correntina & 0,092348076 & 0,109597 & 0,842615 \\
\hline Grupo de Tratamento & PB & Juazeirinho & 0,09206 & 0,09206 & 1 \\
\hline Grupo de Tratamento & MG & Quartel Geral & 0,091817 & 0,091817 & 1 \\
\hline Grupo de Tratamento & PB & Caturité & 0,091764 & 0,091764 & 1 \\
\hline Grupo de Tratamento & RJ & São João de Meriti & 0,09158745 & 0,166285 & 0,550786 \\
\hline Grupo de Tratamento & MG & Vargem Bonita & 0,091306 & 0,091306 & 1 \\
\hline Grupo de Tratamento & MG & Divino das Laranjeiras & 0,091278 & 0,091278 & 1 \\
\hline Grupo de Tratamento & MG & Bocaiúva & 0,091014941 & 0,098352 & 0,9254 \\
\hline Grupo de Tratamento & $\mathrm{BA}$ & Ubatã & 0,090792761 & 0,131493 & 0,690476 \\
\hline Grupo de Tratamento & RJ & Maricá & 0,09034144 & 0,131253 & 0,6883 \\
\hline Grupo de Tratamento & $\mathrm{BA}$ & Presidente Dutra & 0,090341 & 0,090341 & 1 \\
\hline Grupo de Tratamento & MG & Funilândia & 0,090296 & 0,090296 & 1 \\
\hline Grupo de Tratamento & MS & Bela Vista & 0,089817448 & 0,09688 & 0,9271 \\
\hline Grupo de Tratamento & $A L$ & Lagoa da Canoa & 0,089757903 & 0,106147 & 0,8456 \\
\hline Grupo de Tratamento & $A L$ & Jaramataia & 0,089693 & 0,089693 & 1 \\
\hline Grupo de Tratamento & BA & Una & 0,08961165 & 0,09714 & 0,9225 \\
\hline Grupo de Tratamento & BA & Lafaiete Coutinho & 0,089322 & 0,089322 & 1 \\
\hline Grupo de Tratamento & PE & Ipojuca & 0,088728401 & 0,130268 & 0,681122 \\
\hline Grupo de Tratamento & $\mathrm{BA}$ & Aurelino Leal & 0,088392634 & 0,090967 & 0,9717 \\
\hline Grupo de Tratamento & BA & Elísio Medrado & 0,088353 & 0,088353 & 1 \\
\hline Grupo de Tratamento & MS & Maracaju & 0,088107 & 0,088107 & 1 \\
\hline Grupo de Tratamento & MG & Divisa Alegre & 0,08796 & 0,08796 & 1 \\
\hline Grupo de Tratamento & MG & Ataléia & 0,087822635 & 0,100003 & 0,8782 \\
\hline
\end{tabular}




\begin{tabular}{|c|c|c|c|c|c|}
\hline Grupo de Tratamento & BA & Mansidão & 0,087729084 & 0,102104 & 0,859213 \\
\hline Grupo de Tratamento & MG & Juramento & 0,087685 & 0,087685 & 1 \\
\hline Grupo de Tratamento & BA & Nova Redenção & 0,087684 & 0,087684 & 1 \\
\hline Grupo de Tratamento & $\mathrm{BA}$ & Tapiramutá & 0,087592 & 0,087592 & 1 \\
\hline Grupo de Tratamento & PI & São José do Peixe & 0,0875 & 0,0875 & 1 \\
\hline Grupo de Tratamento & BA & Presidente Tancredo Neves & 0,087468631 & 0,089354 & 0,9789 \\
\hline Grupo de Tratamento & BA & Valente & 0,087157319 & 0,118215 & 0,737278 \\
\hline Grupo de Tratamento & $\mathrm{BA}$ & Uruçuca & 0,087154305 & 0,101354 & 0,8599 \\
\hline Grupo de Tratamento & BA & Boquira & 0,086815001 & 0,103302 & 0,8404 \\
\hline Grupo de Tratamento & MG & São Sebastião do Rio Preto & 0,086721 & 0,086721 & 1 \\
\hline Grupo de Tratamento & MG & Pedras de Maria da Cruz & 0,086713 & 0,086713 & 1 \\
\hline Grupo de Tratamento & BA & Ruy Barbosa & 0,086652806 & 0,096313 & 0,8997 \\
\hline Grupo de Tratamento & MG & Ferros & 0,086552 & 0,086552 & 1 \\
\hline Grupo de Tratamento & SP & Itupeva & 0,086496995 & 0,091774 & 0,9425 \\
\hline Grupo de Tratamento & MG & Visconde do Rio Branco & 0,086436305 & 0,104492 & 0,827205 \\
\hline Grupo de Tratamento & BA & Wagner & 0,086195 & 0,086195 & 1 \\
\hline Grupo de Tratamento & MS & Sidrolândia & 0,085539 & 0,085539 & 1 \\
\hline Grupo de Tratamento & BA & Iuiú & 0,085411624 & 0,091922 & 0,929175 \\
\hline Grupo de Tratamento & SP & Santa Cruz das Palmeiras & 0,085314644 & 0,097776 & 0,872552 \\
\hline Grupo de Tratamento & $\mathrm{BA}$ & Brumado & 0,085238131 & 0,109042 & 0,7817 \\
\hline Grupo de Tratamento & BA & Piatã & 0,085194 & 0,085194 & 1 \\
\hline Grupo de Tratamento & MG & Cachoeira da Prata & 0,084951 & 0,084951 & 1 \\
\hline Grupo de Tratamento & MS & Figueirão & 0,084756 & 0,084756 & 1 \\
\hline Grupo de Tratamento & $\mathrm{BA}$ & Barrocas & 0,084594 & 0,084594 & 1 \\
\hline Grupo de Tratamento & MG & Montezuma & 0,084276 & 0,084276 & 1 \\
\hline Grupo de Tratamento & PA & Pau D'Arco & 0,084164 & 0,084164 & 1 \\
\hline Grupo de Tratamento & MG & Nova Lima & 0,083983 & 0,083983 & 1 \\
\hline Grupo de Tratamento & MG & Ubaí & 0,083804 & 0,083804 & 1 \\
\hline Grupo de Tratamento & MS & Coxim & 0,083306 & 0,083306 & 1 \\
\hline Grupo de Tratamento & MG & Sardoá & 0,083176 & 0,083176 & 1 \\
\hline Grupo de Tratamento & MG & Couto de Magalhães de Minas & 0,083123 & 0,083123 & 1 \\
\hline Grupo de Tratamento & MS & Fátima do Sul & 0,083089798 & 0,085952 & 0,9667 \\
\hline Grupo de Tratamento & BA & Jaborandi & 0,083013 & 0,083013 & 1 \\
\hline Grupo de Tratamento & PR & Cambé & 0,08295 & 0,08295 & 1 \\
\hline Grupo de Tratamento & BA & Cotegipe & 0,082872 & 0,082872 & 1 \\
\hline Grupo de Tratamento & MG & Ibiracatu & 0,082456 & 0,082456 & 1 \\
\hline Grupo de Tratamento & BA & Aratuípe & 0,081293 & 0,081293 & 1 \\
\hline Grupo de Tratamento & PB & Areial & 0,08122 & 0,08122 & 1 \\
\hline Grupo de Tratamento & RN & Santa Cruz & 0,081158708 & 0,082236 & 0,9869 \\
\hline Grupo de Tratamento & PB & Massaranduba & 0,081138 & 0,081138 & 1 \\
\hline Grupo de Tratamento & MG & Guarani & 0,080799 & 0,080799 & 1 \\
\hline Grupo de Tratamento & MG & Caraí & 0,080546 & 0,080546 & 1 \\
\hline Grupo de Tratamento & BA & Riachão das Neves & 0,080191 & 0,080191 & 1 \\
\hline Grupo de Tratamento & MG & Presidente Kubitschek & 0,080149 & 0,080149 & 1 \\
\hline Grupo de Tratamento & MG & Brumadinho & 0,07992 & 0,07992 & 1 \\
\hline
\end{tabular}




\begin{tabular}{|c|c|c|c|c|c|}
\hline Grupo de Tratamento & MG & Jordânia & 0,079891 & 0,079891 & 1 \\
\hline Grupo de Tratamento & $\mathrm{BA}$ & Carinhanha & 0,07980917 & 0,084536 & 0,944085 \\
\hline Grupo de Tratamento & MG & São José da Barra & 0,079731 & 0,079731 & 1 \\
\hline Grupo de Tratamento & MG & Morada Nova de Minas & 0,079455 & 0,079455 & 1 \\
\hline Grupo de Tratamento & BA & Nazaré & 0,079281902 & 0,080612 & 0,9835 \\
\hline Grupo de Tratamento & MG & Dom Joaquim & 0,079096 & 0,079096 & 1 \\
\hline Grupo de Tratamento & RN & Lucrécia & 0,07909 & 0,07909 & 1 \\
\hline Grupo de Tratamento & $\mathrm{BA}$ & Quijingue & 0,079067 & 0,079067 & 1 \\
\hline Grupo de Tratamento & PB & Alagoa Nova & 0,079054 & 0,079054 & 1 \\
\hline Grupo de Tratamento & MG & Japonvar & 0,078917 & 0,078917 & 1 \\
\hline Grupo de Tratamento & MG & Perdizes & 0,078899 & 0,078899 & 1 \\
\hline Grupo de Tratamento & PA & Marituba & 0,077765941 & 0,123301 & 0,6307 \\
\hline Grupo de Tratamento & BA & Barra do Rocha & 0,07769 & 0,07769 & 1 \\
\hline Grupo de Tratamento & BA & Jequié & 0,077668061 & 0,119655 & 0,6491 \\
\hline Grupo de Tratamento & BA & Dom Macedo Costa & 0,077401 & 0,077401 & 1 \\
\hline Grupo de Tratamento & PE & Ilha de Itamaracá & 0,077275 & 0,077275 & 1 \\
\hline Grupo de Tratamento & BA & Simões Filho & 0,077179783 & 0,108915 & 0,708624 \\
\hline Grupo de Tratamento & MG & Tarumirim & 0,077097 & 0,077097 & 1 \\
\hline Grupo de Tratamento & $\mathrm{BA}$ & Jaguarari & 0,076643576 & 0,080788 & 0,9487 \\
\hline Grupo de Tratamento & RN & Lajes & 0,076517 & 0,076517 & 1 \\
\hline Grupo de Tratamento & BA & Santana & 0,076511254 & 0,0985 & 0,776764 \\
\hline Grupo de Tratamento & BA & Ubaíra & 0,076328615 & 0,087835 & 0,869 \\
\hline Grupo de Tratamento & MG & Francisco Badaró & 0,076215 & 0,076215 & 1 \\
\hline Grupo de Tratamento & RN & José da Penha & 0,075606 & 0,075606 & 1 \\
\hline Grupo de Tratamento & BA & Rafael Jambeiro & 0,075451 & 0,075451 & 1 \\
\hline Grupo de Tratamento & MG & Lassance & 0,075336 & 0,075336 & 1 \\
\hline Grupo de Tratamento & MG & Buritizeiro & 0,075082503 & 0,087662 & 0,8565 \\
\hline Grupo de Tratamento & BA & Jussiape & 0,07468 & 0,07468 & 1 \\
\hline Grupo de Tratamento & SP & Hortolândia & 0,074482739 & 0,095601 & 0,7791 \\
\hline Grupo de Tratamento & MG & São João Batista do Glória & 0,074349819 & 0,08123 & 0,9153 \\
\hline Grupo de Tratamento & MG & Timóteo & 0,07426712 & 0,09013 & 0,824 \\
\hline Grupo de Tratamento & BA & Paulo Afonso & 0,073506528 & 0,11097 & 0,6624 \\
\hline Grupo de Tratamento & BA & Paratinga & 0,073405442 & 0,082729 & 0,8873 \\
\hline Grupo de Tratamento & RN & Umarizal & 0,073276 & 0,073276 & 1 \\
\hline Grupo de Tratamento & MG & Miraí & 0,073194 & 0,073194 & 1 \\
\hline Grupo de Tratamento & MG & Francisco Dumont & 0,072988 & 0,072988 & 1 \\
\hline Grupo de Tratamento & BA & Ribeira do Pombal & 0,072966134 & 0,098422 & 0,74136 \\
\hline Grupo de Tratamento & MG & Machacalis & 0,07289 & 0,07289 & 1 \\
\hline Grupo de Tratamento & BA & Aramari & 0,072872 & 0,072872 & 1 \\
\hline Grupo de Tratamento & BA & Caraíbas & 0,072755 & 0,072755 & 1 \\
\hline Grupo de Tratamento & MS & Sonora & 0,072169 & 0,072169 & 1 \\
\hline Grupo de Tratamento & MG & Dionísio & 0,071866 & 0,071866 & 1 \\
\hline Grupo de Tratamento & SP & Sales Oliveira & 0,071676 & 0,071676 & 1 \\
\hline Grupo de Tratamento & MG & Engenheiro Navarro & 0,071065 & 0,071065 & 1 \\
\hline Grupo de Tratamento & $\mathrm{BA}$ & São Miguel das Matas & 0,070955 & 0,070955 & 1 \\
\hline
\end{tabular}




\begin{tabular}{|c|c|c|c|c|c|}
\hline Grupo de Tratamento & $\mathrm{BA}$ & Ibititá & 0,070950152 & 0,083946 & 0,845188 \\
\hline Grupo de Tratamento & SP & Artur Nogueira & 0,070910436 & 0,085527 & 0,8291 \\
\hline Grupo de Tratamento & BA & Iraquara & 0,070821869 & 0,072877 & 0,9718 \\
\hline Grupo de Tratamento & $\mathrm{BA}$ & Itambé & 0,070443 & 0,070443 & 1 \\
\hline Grupo de Tratamento & MG & Ipanema & 0,070423 & 0,070423 & 1 \\
\hline Grupo de Tratamento & MS & Caracol & 0,070421 & 0,070421 & 1 \\
\hline Grupo de Tratamento & BA & Iguaí & 0,06956598 & 0,072525 & 0,9592 \\
\hline Grupo de Tratamento & PB & Sousa & 0,06937 & 0,06937 & 1 \\
\hline Grupo de Tratamento & $\mathrm{BA}$ & Baianópolis & 0,069341 & 0,069341 & 1 \\
\hline Grupo de Tratamento & BA & Rio do Pires & 0,069173 & 0,069173 & 1 \\
\hline Grupo de Tratamento & $\mathrm{BA}$ & Angical & 0,069125149 & 0,080132 & 0,862641 \\
\hline Grupo de Tratamento & BA & Caetité & 0,069117127 & 0,086819 & 0,796106 \\
\hline Grupo de Tratamento & MG & Alvorada de Minas & 0,069095 & 0,069095 & 1 \\
\hline Grupo de Tratamento & MG & Felisburgo & 0,068926 & 0,068926 & 1 \\
\hline Grupo de Tratamento & MG & Guanhães & 0,068817864 & 0,07864 & 0,8751 \\
\hline Grupo de Tratamento & MG & Verdelândia & 0,06842 & 0,06842 & 1 \\
\hline Grupo de Tratamento & MG & Nova Era & 0,06840101 & 0,078985 & 0,866 \\
\hline Grupo de Tratamento & BA & Ibirapitanga & 0,068077 & 0,068077 & 1 \\
\hline Grupo de Tratamento & MG & Mesquita & 0,068044 & 0,068044 & 1 \\
\hline Grupo de Tratamento & MG & Salto da Divisa & 0,067929322 & 0,075168 & 0,9037 \\
\hline Grupo de Tratamento & PB & $\begin{array}{l}\text { São Sebastião de Lagoa de } \\
\text { Roça }\end{array}$ & 0,067816 & 0,067816 & 1 \\
\hline Grupo de Tratamento & PI & Canavieira & 0,067732 & 0,067732 & 1 \\
\hline Grupo de Tratamento & $A L$ & Coité do Nóia & 0,067388 & 0,067388 & 1 \\
\hline Grupo de Tratamento & MS & Bataguassu & 0,067369 & 0,067369 & 1 \\
\hline Grupo de Tratamento & $A L$ & Feira Grande & 0,067313472 & 0,068408 & 0,984 \\
\hline Grupo de Tratamento & BA & Barra da Estiva & 0,066904 & 0,066904 & 1 \\
\hline Grupo de Tratamento & BA & Ibitiara & 0,066853 & 0,066853 & 1 \\
\hline Grupo de Tratamento & SP & Tambaú & 0,066750142 & 0,084942 & 0,785832 \\
\hline Grupo de Tratamento & MG & Periquito & 0,066436 & 0,066436 & 1 \\
\hline Grupo de Tratamento & BA & Palmas de Monte Alto & 0,066359336 & 0,073293 & 0,905398 \\
\hline Grupo de Tratamento & BA & Lençóis & 0,066014 & 0,066014 & 1 \\
\hline Grupo de Tratamento & $\mathrm{BA}$ & Itapetinga & 0,065876655 & 0,09859 & 0,668188 \\
\hline Grupo de Tratamento & SP & Bragança Paulista & 0,065875501 & 0,086104 & 0,765069 \\
\hline Grupo de Tratamento & BA & Caculé & 0,065737244 & 0,069387 & 0,9474 \\
\hline Grupo de Tratamento & BA & Malhada & 0,065639041 & 0,069711 & 0,941588 \\
\hline Grupo de Tratamento & BA & Firmino Alves & 0,065244 & 0,065244 & 1 \\
\hline Grupo de Tratamento & MG & Itaipé & 0,065219 & 0,065219 & 1 \\
\hline Grupo de Tratamento & $\mathrm{BA}$ & Paramirim & 0,065128 & 0,065128 & 1 \\
\hline Grupo de Tratamento & MG & Santa Maria do Salto & 0,065025 & 0,065025 & 1 \\
\hline Grupo de Tratamento & BA & Mucuri & 0,06484 & 0,06484 & 1 \\
\hline Grupo de Tratamento & $\mathrm{BA}$ & Santa Inês & 0,064493 & 0,064493 & 1 \\
\hline Grupo de Tratamento & GO & São Luís de Montes Belos & 0,064376508 & 0,074839 & 0,8602 \\
\hline Grupo de Tratamento & BA & Vereda & 0,064221 & 0,064221 & 1 \\
\hline Grupo de Tratamento & MG & Rubim & 0,064139 & 0,064139 & 1 \\
\hline
\end{tabular}




\begin{tabular}{|c|c|c|c|c|c|}
\hline Grupo de Tratamento & MS & Paranhos & 0,064096745 & 0,066951 & 0,957368 \\
\hline Grupo de Tratamento & $\mathrm{BA}$ & Barro Preto & 0,063861 & 0,063861 & 1 \\
\hline Grupo de Tratamento & $\mathrm{SP}$ & Americana & 0,06366369 & 0,076396 & 0,833338 \\
\hline Grupo de Tratamento & PB & Dona Inês & 0,063643 & 0,063643 & 1 \\
\hline Grupo de Tratamento & BA & Rio de Contas & 0,063474 & 0,063474 & 1 \\
\hline Grupo de Tratamento & MG & Carmésia & 0,063421 & 0,063421 & 1 \\
\hline Grupo de Tratamento & MG & Virgolândia & 0,063194 & 0,063194 & 1 \\
\hline Grupo de Tratamento & MS & Ribas do Rio Pardo & 0,063189 & 0,063189 & 1 \\
\hline Grupo de Tratamento & $\mathrm{BA}$ & Potiraguá & 0,062986 & 0,062986 & 1 \\
\hline Grupo de Tratamento & BA & Ibicuí & 0,062674 & 0,062674 & 1 \\
\hline Grupo de Tratamento & MG & Joaíma & 0,06209758 & 0,076975 & 0,806724 \\
\hline Grupo de Tratamento & MG & Ponto dos Volantes & 0,061978 & 0,061978 & 1 \\
\hline Grupo de Tratamento & BA & Sapeaçu & 0,06168 & 0,06168 & 1 \\
\hline Grupo de Tratamento & MG & São Geraldo & 0,061608 & 0,061608 & 1 \\
\hline Grupo de Tratamento & $\mathrm{BA}$ & Piripá & 0,061565 & 0,061565 & 1 \\
\hline Grupo de Tratamento & BA & Nova Ibiá & 0,061386 & 0,061386 & 1 \\
\hline Grupo de Tratamento & MG & Santo Antônio do Itambé & 0,06093 & 0,06093 & 1 \\
\hline Grupo de Tratamento & MG & Senhora do Porto & 0,060373 & 0,060373 & 1 \\
\hline Grupo de Tratamento & $\mathrm{BA}$ & Érico Cardoso & 0,060367 & 0,060367 & 1 \\
\hline Grupo de Tratamento & $\mathrm{BA}$ & Aracatu & 0,060315 & 0,060315 & 1 \\
\hline Grupo de Tratamento & MG & Jequitaí & 0,060247 & 0,060247 & 1 \\
\hline Grupo de Tratamento & MG & São João Evangelista & 0,060188765 & 0,066324 & 0,907496 \\
\hline Grupo de Tratamento & BA & Bom Jesus da Lapa & 0,0599583 & 0,063114 & 0,95 \\
\hline Grupo de Tratamento & MG & Confins & 0,059807 & 0,059807 & 1 \\
\hline Grupo de Tratamento & $A L$ & Marechal Deodoro & 0,059631 & 0,059631 & 1 \\
\hline Grupo de Tratamento & PB & Lagoa Seca & 0,059545 & 0,059545 & 1 \\
\hline Grupo de Tratamento & PI & Guadalupe & 0,059492 & 0,059492 & 1 \\
\hline Grupo de Tratamento & MG & Coronel Pacheco & 0,059417 & 0,059417 & 1 \\
\hline Grupo de Tratamento & MS & Inocência & 0,05906 & 0,05906 & 1 \\
\hline Grupo de Tratamento & MG & Santa Efigênia de Minas & 0,059049 & 0,059049 & 1 \\
\hline Grupo de Tratamento & MG & Naque & 0,058983 & 0,058983 & 1 \\
\hline Grupo de Tratamento & BA & Oliveira dos Brejinhos & 0,058965043 & 0,066315 & 0,889166 \\
\hline Grupo de Tratamento & BA & Antas & 0,058933193 & 0,062595 & 0,9415 \\
\hline Grupo de Tratamento & PI & Landri Sales & 0,058875 & 0,058875 & 1 \\
\hline Grupo de Tratamento & MG & Rubelita & 0,058652 & 0,058652 & 1 \\
\hline Grupo de Tratamento & RN & Doutor Severiano & 0,058188 & 0,058188 & 1 \\
\hline Grupo de Tratamento & SP & Sumaré & 0,057732483 & 0,078369 & 0,736675 \\
\hline Grupo de Tratamento & MG & Iapu & 0,057518 & 0,057518 & 1 \\
\hline Grupo de Tratamento & MG & Guaraciama & 0,057422 & 0,057422 & 1 \\
\hline Grupo de Tratamento & MG & Presidente Juscelino & 0,057283 & 0,057283 & 1 \\
\hline Grupo de Tratamento & MS & Camapuã & 0,057117 & 0,057117 & 1 \\
\hline Grupo de Tratamento & BA & Itamari & 0,05704 & 0,05704 & 1 \\
\hline Grupo de Tratamento & PI & Jerumenha & 0,057024 & 0,057024 & 1 \\
\hline Grupo de Tratamento & BA & São Gabriel & 0,057013783 & 0,066919 & 0,851982 \\
\hline Grupo de Tratamento & MG & Monjolos & 0,056762 & 0,056762 & 1 \\
\hline
\end{tabular}




\begin{tabular}{|c|c|c|c|c|c|}
\hline Grupo de Tratamento & MG & Bandeira & 0,056754 & 0,056754 & 1 \\
\hline Grupo de Tratamento & $\mathrm{BA}$ & Seabra & 0,056627733 & 0,071794 & 0,788753 \\
\hline Grupo de Tratamento & $\mathrm{BA}$ & Jacaraci & 0,055862 & 0,055862 & 1 \\
\hline Grupo de Tratamento & BA & Igaporã & 0,055469 & 0,055469 & 1 \\
\hline Grupo de Tratamento & BA & Irajuba & 0,055298 & 0,055298 & 1 \\
\hline Grupo de Tratamento & MS & Laguna Carapã & 0,054953 & 0,054953 & 1 \\
\hline Grupo de Tratamento & BA & Mulungu do Morro & 0,054605953 & 0,055297 & 0,987503 \\
\hline Grupo de Tratamento & MG & Crucilândia & 0,054431 & 0,054431 & 1 \\
\hline Grupo de Tratamento & MG & Maravilhas & 0,054296 & 0,054296 & 1 \\
\hline Grupo de Tratamento & MG & Coluna & 0,053796283 & 0,064451 & 0,834685 \\
\hline Grupo de Tratamento & MG & Passa-Vinte & 0,053642 & 0,053642 & 1 \\
\hline Grupo de Tratamento & SP & Monte Mor & 0,053436194 & 0,055403 & 0,9645 \\
\hline Grupo de Tratamento & MG & Itueta & 0,053161 & 0,053161 & 1 \\
\hline Grupo de Tratamento & BA & Muritiba & 0,053104463 & 0,056118 & 0,9463 \\
\hline Grupo de Tratamento & MG & Rio Vermelho & 0,052968 & 0,052968 & 1 \\
\hline Grupo de Tratamento & BA & Ibiassucê & 0,052436 & 0,052436 & 1 \\
\hline Grupo de Tratamento & RS & Erechim & 0,052362667 & 0,064592 & 0,810668 \\
\hline Grupo de Tratamento & MS & Naviraí & 0,052211196 & 0,063057 & 0,828 \\
\hline Grupo de Tratamento & BA & Barreiras & 0,052198958 & 0,073654 & 0,708705 \\
\hline Grupo de Tratamento & MG & Olhos-d'Água & 0,052113 & 0,052113 & 1 \\
\hline Grupo de Tratamento & BA & Itagimirim & 0,051869 & 0,051869 & 1 \\
\hline Grupo de Tratamento & MS & Costa Rica & 0,05179817 & 0,052048 & 0,9952 \\
\hline Grupo de Tratamento & MG & Capitão Andrade & 0,051603 & 0,051603 & 1 \\
\hline Grupo de Tratamento & $A L$ & Pilar & 0,051409 & 0,051409 & 1 \\
\hline Grupo de Tratamento & SP & Pedreira & 0,051396358 & 0,066335 & 0,7748 \\
\hline Grupo de Tratamento & MG & Glaucilândia & 0,051199 & 0,051199 & 1 \\
\hline Grupo de Tratamento & MS & Angélica & 0,050513 & 0,050513 & 1 \\
\hline Grupo de Tratamento & $\mathrm{BA}$ & Santa Rita de Cássia & 0,050226645 & 0,051467 & 0,9759 \\
\hline Grupo de Tratamento & $\mathrm{BA}$ & Luís Eduardo Magalhães & 0,049485534 & 0,070002 & 0,706916 \\
\hline Grupo de Tratamento & PI & Itaueira & 0,04934 & 0,04934 & 1 \\
\hline Grupo de Tratamento & PI & Marcos Parente & 0,049041 & 0,049041 & 1 \\
\hline Grupo de Tratamento & MG & Antônio Dias & 0,04902 & 0,04902 & 1 \\
\hline Grupo de Tratamento & MG & Caetanópolis & 0,048995 & 0,048995 & 1 \\
\hline Grupo de Tratamento & RJ & Japeri & 0,048887068 & 0,081223 & 0,601887 \\
\hline Grupo de Tratamento & MG & Itanhomi & 0,048847 & 0,048847 & 1 \\
\hline Grupo de Tratamento & MG & Cedro do Abaeté & 0,048689 & 0,048689 & 1 \\
\hline Grupo de Tratamento & RN & Januário Cicco & 0,048504 & 0,048504 & 1 \\
\hline Grupo de Tratamento & $\mathrm{BA}$ & Ipiaú & 0,048482542 & 0,09263 & 0,5234 \\
\hline Grupo de Tratamento & MG & São Domingos do Prata & 0,048312 & 0,048312 & 1 \\
\hline Grupo de Tratamento & PI & Brejo do Piauí & 0,048276 & 0,048276 & 1 \\
\hline Grupo de Tratamento & BA & Pindaí & 0,048166799 & 0,048273 & 0,9978 \\
\hline Grupo de Tratamento & MG & Novo Cruzeiro & 0,048108569 & 0,063689 & 0,755367 \\
\hline Grupo de Tratamento & BA & Campo Alegre de Lourdes & 0,047204069 & 0,064958 & 0,726686 \\
\hline Grupo de Tratamento & MG & Morro da Garça & 0,047132 & 0,047132 & 1 \\
\hline Grupo de Tratamento & MG & Serranópolis de Minas & 0,047022 & 0,047022 & 1 \\
\hline
\end{tabular}




\begin{tabular}{|c|c|c|c|c|c|}
\hline Grupo de Tratamento & MG & Entre Folhas & 0,04701 & 0,04701 & 1 \\
\hline Grupo de Tratamento & MG & Morro do Pilar & 0,046853 & 0,046853 & 1 \\
\hline Grupo de Tratamento & PI & São Francisco do Piauí & 0,046841 & 0,046841 & 1 \\
\hline Grupo de Tratamento & BA & Pilão Arcado & 0,046829693 & 0,0792 & 0,591284 \\
\hline Grupo de Tratamento & BA & Ilhéus & 0,046777052 & 0,076287 & 0,613172 \\
\hline Grupo de Tratamento & MG & Alto Jequitibá & 0,046767 & 0,046767 & 1 \\
\hline Grupo de Tratamento & MG & Buenópolis & 0,046051 & 0,046051 & 1 \\
\hline Grupo de Tratamento & BA & Novo Horizonte & 0,045793 & 0,045793 & 1 \\
\hline Grupo de Tratamento & RS & Nova Candelária & 0,045623 & 0,045623 & 1 \\
\hline Grupo de Tratamento & MG & Piedade dos Gerais & 0,045479 & 0,045479 & 1 \\
\hline Grupo de Tratamento & $\mathrm{BA}$ & Abaré & 0,045308 & 0,045308 & 1 \\
\hline Grupo de Tratamento & BA & São José da Vitória & 0,045247 & 0,045247 & 1 \\
\hline Grupo de Tratamento & MG & Itambé do Mato Dentro & 0,045166 & 0,045166 & 1 \\
\hline Grupo de Tratamento & $\mathrm{BA}$ & Riacho de Santana & 0,044723412 & 0,049577 & 0,9021 \\
\hline Grupo de Tratamento & MG & Belo Vale & 0,044571 & 0,044571 & 1 \\
\hline Grupo de Tratamento & PB & Serra da Raiz & 0,044468 & 0,044468 & 1 \\
\hline Grupo de Tratamento & BA & Candiba & 0,043884734 & 0,048184 & 0,910774 \\
\hline Grupo de Tratamento & RN & Tenente Laurentino Cruz & 0,043655 & 0,043655 & 1 \\
\hline Grupo de Tratamento & BA & Caém & 0,043116754 & 0,046422 & 0,9288 \\
\hline Grupo de Tratamento & SP & Holambra & 0,042704 & 0,042704 & 1 \\
\hline Grupo de Tratamento & MG & São Félix de Minas & 0,041472 & 0,041472 & 1 \\
\hline Grupo de Tratamento & MS & Dois Irmãos do Buriti & 0,041013 & 0,041013 & 1 \\
\hline Grupo de Tratamento & MG & Nova Belém & 0,04089 & 0,04089 & 1 \\
\hline Grupo de Tratamento & $\mathrm{BA}$ & Botuporã & 0,039976 & 0,039976 & 1 \\
\hline Grupo de Tratamento & MG & Inhaúma & 0,039495 & 0,039495 & 1 \\
\hline Grupo de Tratamento & SP & Mogi Guaçu & 0,039415558 & 0,050468 & 0,781001 \\
\hline Grupo de Tratamento & MG & São João da Lagoa & 0,038844 & 0,038844 & 1 \\
\hline Grupo de Tratamento & MS & Caarapó & 0,038490698 & 0,050377 & 0,764053 \\
\hline Grupo de Tratamento & SP & Lindóia & 0,037619 & 0,037619 & 1 \\
\hline Grupo de Tratamento & PB & Montadas & 0,037425 & 0,037425 & 1 \\
\hline Grupo de Tratamento & MS & Chapadão do Sul & 0,037066 & 0,037066 & 1 \\
\hline Grupo de Tratamento & MG & Papagaios & 0,036408 & 0,036408 & 1 \\
\hline Grupo de Tratamento & MG & Coimbra & 0,036344003 & 0,041555 & 0,8746 \\
\hline Grupo de Tratamento & $\mathrm{BA}$ & Formosa do Rio Preto & 0,036294836 & 0,041784 & 0,86863 \\
\hline Grupo de Tratamento & SP & Monte Alegre do Sul & 0,034657 & 0,034657 & 1 \\
\hline Grupo de Tratamento & $\mathrm{BA}$ & Souto Soares & 0,034211114 & 0,040924 & 0,835967 \\
\hline Grupo de Tratamento & MS & Eldorado & 0,033884946 & 0,044137 & 0,767722 \\
\hline Grupo de Tratamento & $\mathrm{BA}$ & Ibipitanga & 0,033151 & 0,033151 & 1 \\
\hline Grupo de Tratamento & MG & Antônio Prado de Minas & 0,032963 & 0,032963 & 1 \\
\hline Grupo de Tratamento & SP & Santo Antônio de Posse & 0,032601515 & 0,038643 & 0,843659 \\
\hline Grupo de Tratamento & BA & Lajedinho & 0,031973 & 0,031973 & 1 \\
\hline Grupo de Tratamento & BA & Bom Jesus da Serra & 0,031816 & 0,031816 & 1 \\
\hline Grupo de Tratamento & SP & Águas de Lindóia & 0,031033841 & 0,039438 & 0,786902 \\
\hline Grupo de Tratamento & SP & Cosmópolis & 0,030847282 & 0,039384 & 0,783244 \\
\hline Grupo de Tratamento & MG & Capim Branco & 0,030708 & 0,030708 & 1 \\
\hline
\end{tabular}




\begin{tabular}{|c|c|c|c|c|c|}
\hline Grupo de Tratamento & MG & Santa Maria do Suaçuí & 0,030701513 & 0,041719 & 0,735912 \\
\hline Grupo de Tratamento & MS & Juti & 0,030227238 & 0,030425 & 0,9935 \\
\hline Grupo de Tratamento & MG & Passabém & 0,029611 & 0,029611 & 1 \\
\hline Grupo de Tratamento & MG & Catas Altas & 0,027576631 & 0,03044 & 0,905934 \\
\hline Grupo de Tratamento & MG & Fortuna de Minas & 0,026928 & 0,026928 & 1 \\
\hline Grupo de Tratamento & SP & Estiva Gerbi & 0,026675803 & 0,027718 & 0,9624 \\
\hline Grupo de Tratamento & MG & Fernandes Tourinho & 0,026587 & 0,026587 & 1 \\
\hline Grupo de Tratamento & MS & Água Clara & 0,025877963 & 0,038406 & 0,6738 \\
\hline Grupo de Tratamento & MG & Resplendor & 0,025850998 & 0,027657 & 0,9347 \\
\hline Grupo de Tratamento & MG & São Gonçalo do Rio Abaixo & 0,023721 & 0,023721 & 1 \\
\hline Grupo de Tratamento & PI & Francisco Ayres & 0,023627 & 0,023627 & 1 \\
\hline Grupo de Tratamento & RN & Barcelona & 0,02092925 & 0,026818 & 0,780418 \\
\hline Grupo de Tratamento & SP & Casa Branca & 0,017883074 & 0,021363 & 0,837105 \\
\hline Grupo de Tratamento & PB & Duas Estradas & 0,007884 & 0,007884 & 1 \\
\hline Grupo de Controle & MA & Água Doce do Maranhão & 0,401243 & 0,401243 & 1 \\
\hline Grupo de Controle & MT & Tangará da Serra & 0,303003566 & 0,406171 & 0,746 \\
\hline Grupo de Controle & RS & Cruzaltense & 0,216941 & 0,216941 & 1 \\
\hline Grupo de Controle & RJ & Trajano de Moraes & 0,20648647 & 0,222124 & 0,9296 \\
\hline Grupo de Controle & MG & Santa Cruz de Minas & 0,140115 & 0,140115 & 1 \\
\hline Grupo de Controle & MG & Nazareno & 0,120931 & 0,120931 & 1 \\
\hline Grupo de Controle & MT & Porto Estrela & 0,120138 & 0,120138 & 1 \\
\hline Grupo de Controle & RN & Baía Formosa & 0,113284 & 0,113284 & 1 \\
\hline Grupo de Controle & MT & Brasnorte & 0,112793698 & 0,121768 & 0,9263 \\
\hline Grupo de Controle & RJ & Cambuci & 0,110468 & 0,110468 & 1 \\
\hline Grupo de Controle & RS & Itaara & 0,1096 & 0,1096 & 1 \\
\hline Grupo de Controle & RS & Formigueiro & 0,102479 & 0,102479 & 1 \\
\hline Grupo de Controle & RS & São Paulo das Missões & 0,084519696 & 0,087904 & 0,9615 \\
\hline Grupo de Controle & MG & Congonhal & 0,078257 & 0,078257 & 1 \\
\hline Grupo de Controle & RS & São Valentim do Sul & 0,071713 & 0,071713 & 1 \\
\hline Grupo de Controle & MG & Descoberto & 0,068849 & 0,068849 & 1 \\
\hline Grupo de Controle & MT & Diamantino & 0,065191 & 0,065191 & 1 \\
\hline Grupo de Controle & RS & Herveiras & 0,061575 & 0,061575 & 1 \\
\hline Grupo de Controle & MG & Oliveira Fortes & 0,060549 & 0,060549 & 1 \\
\hline Grupo de Controle & RS & Canudos do Vale & 0,056535 & 0,056535 & 1 \\
\hline Grupo de Controle & SP & Pilar do Sul & 0,056181217 & 0,073526 & 0,7641 \\
\hline Grupo de Controle & MG & Piedade do Rio Grande & 0,05416 & 0,05416 & 1 \\
\hline Grupo de Controle & MT & Serra Nova Dourada & 0,054063 & 0,054063 & 1 \\
\hline Grupo de Controle & SP & Tapiraí & 0,053703 & 0,053703 & 1 \\
\hline Grupo de Controle & RS & Alto Feliz & 0,053533 & 0,053533 & 1 \\
\hline Grupo de Controle & RS & Dilermando de Aguiar & 0,053101 & 0,053101 & 1 \\
\hline Grupo de Controle & RS & Carlos Barbosa & 0,05248063 & 0,054063 & 0,970731 \\
\hline Grupo de Controle & GO & Santa Rita do Novo Destino & 0,051961 & 0,051961 & 1 \\
\hline Grupo de Controle & RS & Braga & 0,051178 & 0,051178 & 1 \\
\hline Grupo de Controle & MT & Comodoro & 0,048525228 & 0,05028 & 0,9651 \\
\hline Grupo de Controle & MG & Sem-Peixe & 0,048164 & 0,048164 & 1 \\
\hline
\end{tabular}




\begin{tabular}{l|l|l|l|l|l}
\hline Grupo de Controle & RS & Jari & 0,048128 & 0,048128 & 1 \\
\hline Grupo de Controle & RS & Barra do Rio Azul & 0,045899 & 0,045899 & 1 \\
\hline Grupo de Controle & GO & Cezarina & 0,043697477 & 0,055738 & 0,78398 \\
\hline Grupo de Controle & RS & Nova Araçá & 0,04336 & 0,04336 & 1 \\
\hline Grupo de Controle & MT & Feliz Natal & 0,042821521 & 0,051717 & 0,827997 \\
\hline Grupo de Controle & RS & Arroio do Meio & 0,042810487 & 0,047467 & 0,9019 \\
\hline Grupo de Controle & GO & Estrela do Norte & 0,039711 & 0,039711 & 1 \\
\hline Grupo de Controle & RS & Santana da Boa Vista & 0,039691975 & 0,053595 & 0,740591 \\
\hline Grupo de Controle & MT & Nova Guarita & 0,038709 & 0,038709 & 1 \\
\hline Grupo de Controle & RS & Gentil & 0,038147 & 0,038147 & 1 \\
\hline Grupo de Controle & RS & Toropi & 0,038015 & 0,038015 & 1 \\
\hline Grupo de Controle & MG & Rochedo de Minas & 0,034868 & 0,034868 & 1 \\
\hline Grupo de Controle & MG & Conceição da Barra de Minas & 0,02477 & 0,02477 & 1 \\
\hline Grupo de Controle & RS & Muitos Capões & 0,022968 & 0,022968 & 1 \\
\hline Grupo de Controle & MT & Vera & 0,021381716 & 0,023785 & 0,898958 \\
\hline Grupo de Controle & MT & Itaúba & 0,020638638 & 0,025182 & 0,819579 \\
\hline Grupo de Controle & GO & Santa Cruz de Goiás & 0,020476529 & 0,021112 & 0,9699 \\
\hline Fonte: Elaboração própria & & & &
\end{tabular}

Fonte: Elaboração própria

Tabela 2. A - Correlação entre variáveis de participação e índice de Malmquist

\begin{tabular}{|l|l|c|}
\hline \multirow{2}{*}{ íNDICEDEMALMQUIST } & Correlation Coefficient & ÍNDICE DE MALMQUIST \\
\cline { 2 - 3 } & Sig. (2-tailed) & 1,000 \\
\cline { 2 - 3 } Munic_auditoriaestrut._2008 & Correlation Coefficient & 918 \\
\cline { 2 - 3 } & Sig. (2-tailed) &, 011 \\
\cline { 2 - 3 } & $\mathrm{N}$ &, 685 \\
\hline \multirow{3}{*}{ Munic_auditoriaestrut._2009 } & Correlation Coefficient & 918 \\
\cline { 2 - 3 } & Sig. (2-tailed) &, 011 \\
\cline { 2 - 3 } & $\mathrm{N}$ &, 685 \\
\hline \multirow{3}{*}{ Munic_auditoriaestrut._2010 } & Correlation Coefficient & 918 \\
\cline { 2 - 3 } & Sig. (2-tailed) &, 011 \\
\cline { 2 - 3 } & $\mathrm{N}$ & 685 \\
\hline \multirow{3}{*}{ Munic_auditoriaestrut._2011 } & Correlation Coefficient & 918 \\
\cline { 2 - 3 } & Sig. (2-tailed) &, 011 \\
\cline { 2 - 3 } & $\mathrm{N}$ &, 685 \\
\hline \multirow{3}{*}{ Munic_auditoriaestrut._2012 } & Correlation Coefficient & 918 \\
\cline { 2 - 3 } & Sig. (2-tailed) &, 011 \\
\cline { 2 - 3 } & $\mathrm{N}$ &, 685 \\
\hline \multirow{3}{*}{ Munic_auditoriaestrut._2013 } & Correlation Coefficient & 918 \\
\cline { 2 - 3 } & Sig. (2-tailed) &, 011 \\
\cline { 2 - 3 } & $\mathrm{N}$ &, 685 \\
\hline \multirow{3}{*}{ Munic_auditoriaestrut._2014 } & Correlation Coefficient & 918 \\
\cline { 2 - 3 } & Sig. (2-tailed) &, 011 \\
\cline { 2 - 3 } & $\mathrm{N}$ &, 685 \\
\hline \multirow{3}{*}{ Munic_auditoriaestrut._2015 } & Correlation Coefficient & 918 \\
\cline { 2 - 3 } & Sig. (2-tailed) &, 011 \\
\cline { 2 - 3 } & $\mathrm{N}$ & 685 \\
\hline \multirow{3}{*}{ Munic_ouvidoriaimplant._2008 } & Correlation Coefficient & 918 \\
\cline { 2 - 3 } & Sig. (2-tailed) &, 005 \\
\cline { 2 - 3 } & $\mathrm{N}$ &, 842 \\
\hline Munic_ouvidoriaimplant._2009 & Correlation Coefficient & 918 \\
\hline & &, 067 \\
\hline
\end{tabular}




\begin{tabular}{|l|l|c|} 
& Sig. (2-tailed) &, 014 \\
\cline { 2 - 3 } & $\mathrm{N}$ & 918 \\
\hline \multirow{3}{*}{ Munic_ouvidoriaimplant._2010 } & Correlation Coefficient &, $069^{*}$ \\
\cline { 2 - 3 } & Sig. (2-tailed) &, 011 \\
\cline { 2 - 3 } & $\mathrm{N}$ & 918 \\
\hline \multirow{3}{*}{ Munic_ouvidoriaimplant._2011 } & Correlation Coefficient &, $074^{* *}$ \\
\cline { 2 - 3 } & Sig. (2-tailed) &, 007 \\
\cline { 2 - 3 } & $\mathrm{N}$ & 918 \\
\hline \multirow{3}{*}{ Munic_ouvidoriaimplant._2013 } & Correlation Coefficient &, $096^{* *}$ \\
\cline { 2 - 3 } & Sig. (2-tailed) &, 000 \\
\cline { 2 - 3 } & $\mathrm{N}$ & 918 \\
\hline \multirow{3}{*}{ Munic_ouvidoriaimplant._2014 } & Correlation Coefficient &, $093^{* *}$ \\
\cline { 2 - 3 } & Sig. (2-tailed) &, 001 \\
\cline { 2 - 3 } & $\mathrm{N}$ & 918 \\
\hline \multirow{3}{*}{ Munic_ouvidoriaimplant._2015 } & Correlation Coefficient &, $114^{* *}$ \\
\cline { 2 - 3 } & Sig. (2-tailed) &, 000 \\
\cline { 2 - 3 } & $\mathrm{N}$ & 918 \\
\hline \multirow{3}{*}{ Município_CMScadastrado_2012 } & Correlation Coefficient &, $114^{* *}$ \\
\cline { 2 - 3 } & Sig. (2-tailed) &, 000 \\
\cline { 2 - 3 } & $\mathrm{N}$ & 918 \\
\hline \multirow{3}{*}{ Município_CMScadastrado_2013 } & Correlation Coefficient &, 047 \\
\cline { 2 - 3 } & Sig. (2-tailed) &, 101 \\
\cline { 2 - 3 } & $\mathrm{N}$ & 841 \\
\hline & Correlation Coefficient &, 034 \\
\cline { 2 - 3 } & Sig. (2-tailed) &, 204 \\
\cline { 2 - 3 } & $\mathrm{N}$ & 918 \\
\cline { 2 - 3 } & Sig. (2-tailed) &, 482 \\
\hline & & \\
\hline
\end{tabular}

